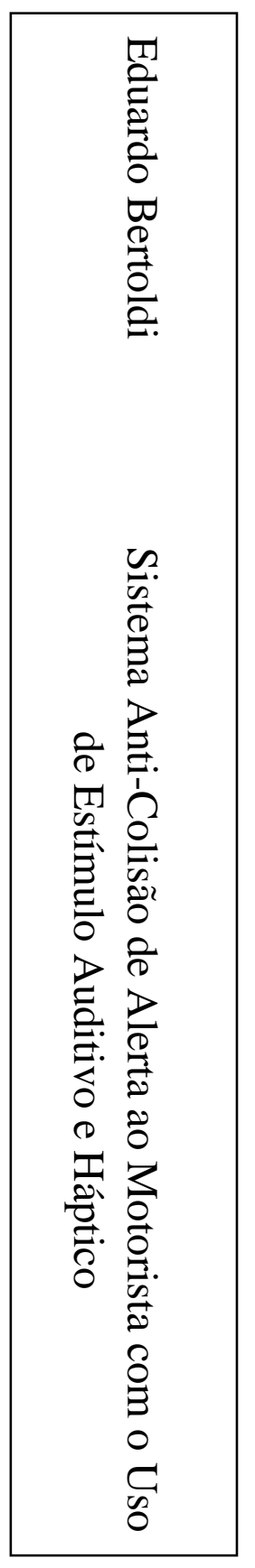


Universidade de São Paulo

EDUARDO BERTOLDI

SISTEMA ANTI-COLISÃO DE ALERTA AO MOTORISTA COM O USO DE ESTÍMULO AUDITIVO E HÁPTICO

São Paulo

2011 
EDUARDO BERTOLDI

SISTEMA ANTI-COLISÃO DE ALERTA AO MOTORISTA COM O USO DE ESTÍMULO AUDITIVO E HÁPTICO

Dissertação apresentada à Escola Politécnica da Universidade de São Paulo, para obtenção do título de mestre em Engenharia Elétrica.

São Paulo

2011 
EDUARDO BERTOLDI

\section{SISTEMA ANTI-COLISÃO DE ALERTA AO MOTORISTA COM O USO DE ESTÍMULO AUDITIVO E HÁPTICO}

Dissertação apresentada à Escola Politécnica da Universidade de São Paulo, para obtenção do título de mestre em Engenharia Elétrica.

Área de concentração: Sistemas Digitais

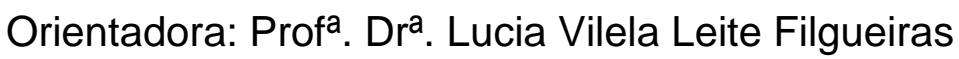

São Paulo

2011 
Este exemplar foi revisado e alterado em relação à versão original, sob responsabilidade única do autor e com a anuência de seu orientador.

São Paulo, de julho de 2011.

Assinatura do autor

Assinatura do orientador

FICHA CATALOGRÁFICA

Bertoldi, Eduardo

Sistema anti-colisão de alerta ao motorista com o uso de estímulo auditivo e háptico / E. Bertoldi. - ed. rev. -- São Paulo, 2011.

$134 \mathrm{p}$.

Dissertação (Mestrado) - Escola Politécnica da Universidade de São Paulo. Departamento de Engenharia de Computação e Sistemas Digitais.

1. Interface homem-computador 2. Engenharia (Fatores hu manos) 3. Segurança veicular 4. Interação homem-máquina I. Universidade de São Paulo. Escola Politécnica. Departamento de Engenharia de Computação e Sistemas Digitais II. t. 


\section{AGRADECIMENTOS}

Aos colegas da Siemens VDO / Continental, que incentivaram e apoiaram o desenvolvimento desse trabalho.

À orientadora Prof ${ }^{a}$. Dr ${ }^{\mathrm{a}}$ Lucia Vilela Leite Filgueiras, por ter acreditado no trabalho e pelo esforço desmedido para orientar sua execução.

Aos colegas do grupo de interação humano-computador do PCS-LTS da Poli/USP pelo grande suporte durante os experimentos.

Aos participantes dos experimentos, que deprenderam seu valioso tempo em prol da ciência.

À minha família, pela formação que me deram. À minha maravilhosa esposa Roberta, pela paciência e pelo apoio.

A Deus, que me concedeu energia e sabedoria. 
RESUMO

Neste trabalho, é desenvolvido um estudo sobre o uso de alertas auditivos e hápticos dentro do ambiente veicular. É proposto um sistema de assistência ao motorista para alertá-lo de que uma colisão lateral com outros veículos pode ser iminente, quando a observação do espelho retrovisor é insuficiente ou o motorista está desatento. O sistema é composto por um módulo de ativação e um módulo de alerta. O módulo de ativação detecta a condição de perigo por sensores posicionados ao redor do veículo e na tendência de abandono de faixa. Esse trabalho enfoca o módulo de alerta, para o qual se propõe o uso de som tridimensional juntamente com estímulo de vibração. Um ambiente de simulação é proposto para se reproduzir em laboratório o ambiente em que o motorista atua. Nesse ambiente, o sujeito deve utilizar um jogo de corrida projetado na parede à sua frente usando um volante e pedais para acelerar e frear. O motorista se mantém ocupado na tarefa de conduzir o veículo pela trajetória do jogo enquanto é submetido a situações em que um outro veículo se aproxima pela região lateraltraseira velozmente. O assento utilizado é equipado com os elementos geradores dos estímulos vibratórios e auditivos. No primeiro experimento, estuda-se o comportamento de 12 partipantes na situação crítica sem o uso do sistema de alerta e conclui-se que a reação preferencial em tal situação é o esterçamento do volante. No segundo experimento, 23 participantes são submetidos ao mesmo cenário adicionando-se o sistema de alertas auditivo e háptico. São coletados os dados de tempo de reação, esterçamento do volante, pressionamento dos pedais e distância entre os carros. Também são registradas as percepções dos participantes sobre o sistema de alerta utilizado. A análise dos dados indica que o sistema de alerta é elegível para uso e pode auxiliar em termos de tempo de reação, devendo-se, entretanto, revisar as características dos alertas utilizados, especialmente o auditivo, para se reduzir o desconforto e evitar prejuízo significativo no controle do veículo.

\section{Palavras Chave:}

Multimodalidade; projeto de alertas; interfaces automotivas; interação motoristaveículo; sistema de assistência ao motorista; interação homem-computador; fatores humanos; segurança veicular. 


\section{ABSTRACT}

In this work, we develop a study about the usage of auditive and haptic alerts in the vehicular environment. It is proposed a driver assistance system to warn the driver that a lateral collision with other vehicle may be imminent, when the rear mirror observation is insufficient or the driver is distracted. The system is composed by an activation module and a warning module. The activation module detects the dangerous condition using sensors placed around the vehicle and on the identification of a lane departure tendency. This work focuses on the warning module, which proposes the usage of tridimensional sound together with vibration stimulus. A simulation environment is proposed to reproduce in laboratory the environment where the driver actuates. In this environment, the subject is requested to play a driving game projected in the frontal wall using a steering wheel and pedals to accelerate and brake. While the driver conducts the vehicle over the game route, he/she is submitted to the situation where another vehicle approaches very fastly from behind. The seat is equipped with the vibration and auditory stimuli generator elements. In the first experiment, it is assessed the behavior of 12 subjects in the critical situation without the usage of the warning system and it is concluded that the major reaction in such situation is the steering of the wheel. In the second experiment, 23 subjects are submitted to the same cenario adding the auditory and haptic warning system. The following data are collected: reaction time, wheel steering, pedal pressing and distance between the vehicles. The perception of the participants about the used warning system is registered. The analysis of all data indicates that the system is eligible to be used and is able to help regarding reaction times. Nevertheless, it is still necessary to review the characteristics of the used warnings, specially the auditory, to reduce discomfort and avoid loss of control during driving.

Keywords:

Multimodality; warning design; automotive interfaces; driver-vehicle interaction; driver assistance system; human factors; vehicular safety 


\section{Lista de figuras}

Figura 1 - Interior do Toyota Prius no Salão do Automóvel de Frankfurt 2009. 18

Figura 2 - Uso do HUD no interior do Peugeot 5008 no Salão do Automóvel de Frankfurt 2009......... 28

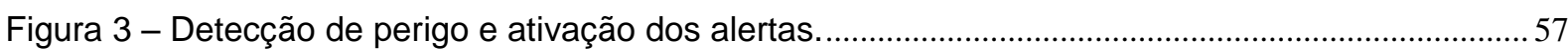

Figura 4 - Elementos vibratórios e sonoros no assento do motorista. .....................................................59

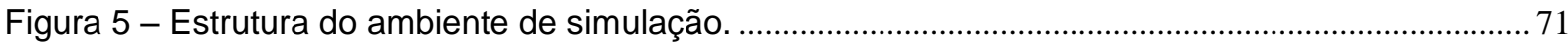

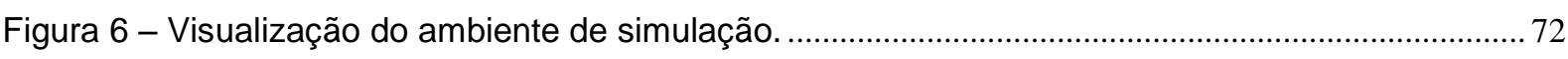

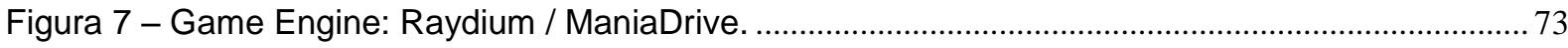

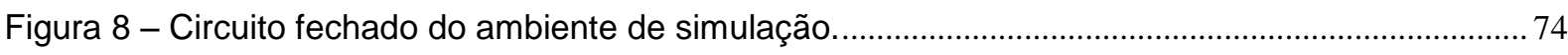

Figura 9 - Espelhos retrovisores no ManiaDrive ................................................................................... 75

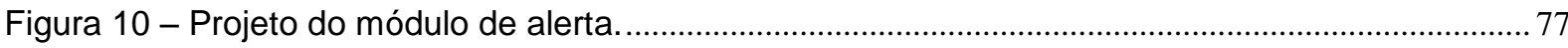

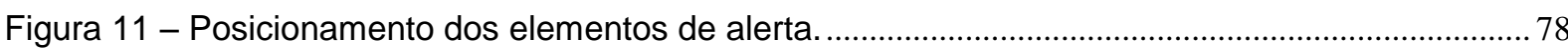




\section{Lista de tabelas}

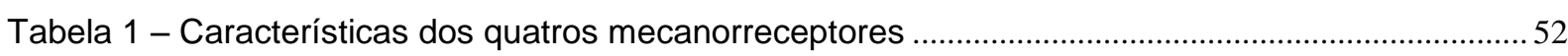

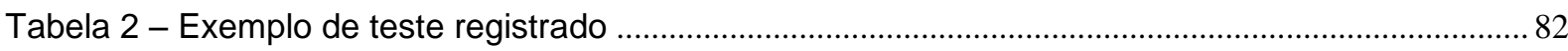

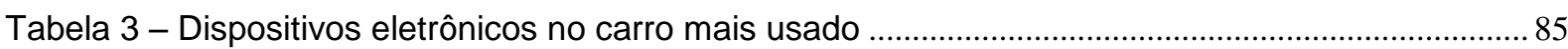

Tabela 4 - Percepção do carro azul no primeiro experimento ................................................................ 91

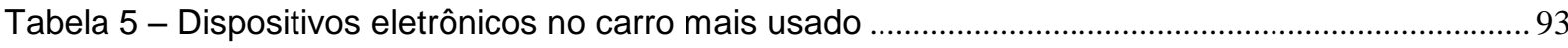

Tabela 7 - Intervalo de confiança da diferença das médias comparado a "sem alertas" (99\%).......... 112

Tabela 8 - Intervalo de confiança da diferença das médias comparado a "sem alertas" (95\%).......... 112

Tabela 9 - Intervalo de confiança da diferença da média para o alerta conjugado (95\%) . .................. 113

Tabela 10 - Proporção de ausência de reação e intervalo de confiança (95\%) ...................................... 116

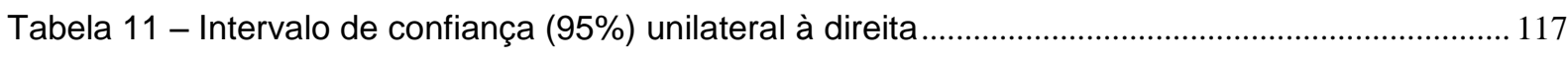

Tabela 12 - Intervalo de confiança (95\%) unilateral à esquerda ........................................................117 


\section{Lista de gráficos}

Gráfico 1 - Resultados obtidos em pesquisa sobre alertas multimodais. ....................................... 56

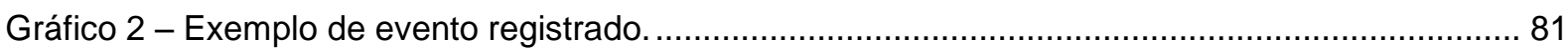

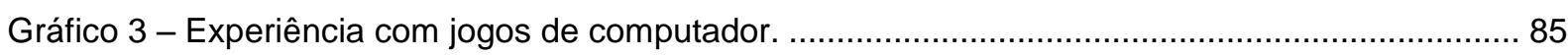

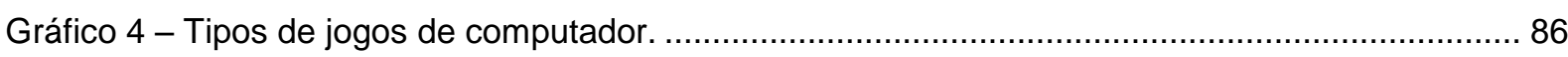

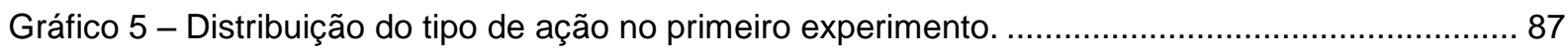

Gráfico 6 - Ação preferencial medida no primeiro experimento..................................................... 88

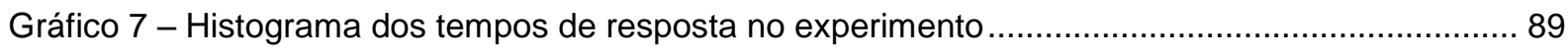

Gráfico 8 - Registro de ações exageradas nos pedais e nos volantes. .............................................. 89

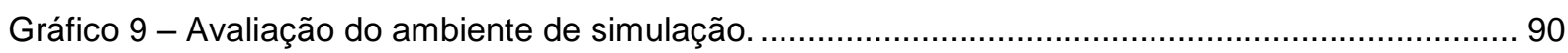

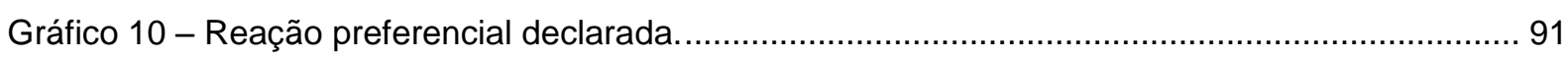

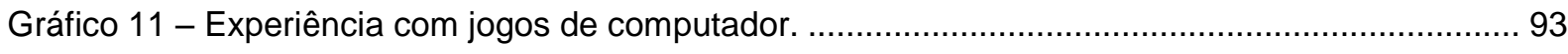

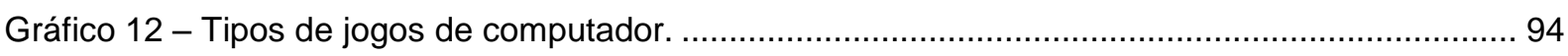

Gráfico 13 - Distribuição dos tipos de reação com algum alerta presente. ......................................... 95

Gráfico 14 - Reação preferencial com algum alerta presente...................................................... 96

Gráfico 15 - Distribuição dos tipos de reação com ambos os alertas presentes. ............................... 96

Gráfico 16 - Reação preferencial com ambos os alertas presentes. ................................................ 97

Gráfico 17 - Distribuição dos tipos de reação com alerta háptico presente....................................... 98

Gráfico 18 - Reação preferencial com alerta háptico presente........................................................ 98

Gráfico 19 - Distribuição dos tipos de reação com alerta auditivo presente..................................... 99

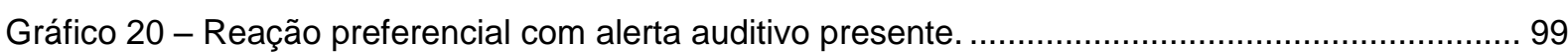

Gráfico 21 - Tempo médio de resposta com alertas presentes. ................................................... 100

Gráfico 22 - Histograma dos tempos de resposta com algum alerta presente .................................. 101

Gráfico 23 - Histograma dos tempos de resposta ambos os alertas presentes ............................... 101

Gráfico 24 - Histograma dos tempos de resposta com o alerta háptico presente .............................. 102

Gráfico 25 - Histograma dos tempos de resposta com o alerta auditivo presente ............................. 102

Gráfico 26 - Registro de ações exageradas com algum alerta presente........................................... 103

Gráfico 27 - Registro de ações exageradas com ambos os alertas presentes. ............................... 103

Gráfico 28 - Registro de ações exageradas com o alerta háptico presente. ....................................... 104

Gráfico 29 - Registro de ações exageradas com o alerta auditivo presente. .................................... 104

Gráfico 30 - Distribuição da percepção de utilidade do alerta auditivo. .............................................. 105

Gráfico 31 - Distribuição da percepção de utilidade do alerta háptico............................................ 105

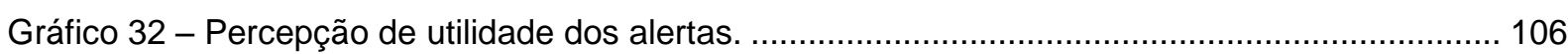

Gráfico 33 - Distribuição da percepção de incômodo do alerta auditivo............................................ 106

Gráfico 34 - Distribuição da percepção de incômodo do alerta háptico........................................... 107

Gráfico 35 - Percepção de incômodo dos alertas. …................................................................ 107

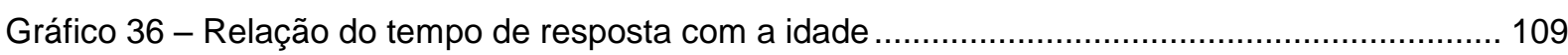

Gráfico 37 - Relação do tempo de resposta com a experiência ........................................................ 109

Gráfico 38 - Relação do tempo de resposta com o uso de jogos ................................................... 110

Gráfico 39 - Relação dos tempos de resposta com e sem alertas. ................................................ 111 


\section{Lista de abreviaturas e siglas}

ACAS

Contran

DC

Denatran

DVD

HRTF

HUD

HVI

ICAD

IEEE

IHC

$L C D$

LED

PDA

USP
Airbone collision Avoidance Systema

Conselho Nacional de Trânsito

Direct Current

Departamento Nacional de Trânsito

Digital Video Disc

Head Related Transfer Function

Head-up display

Human Vehicle Interface

International Conference on Auditory Display

Institute of Electrical and Electronics Engineers

Interação Humano Computador

Liquid Crystal Display

Light-Emitting Diode

Personal Digital Assistants

Universidade de São Paulo 


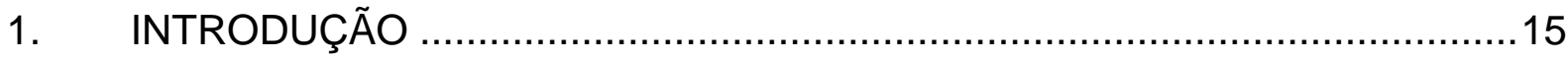

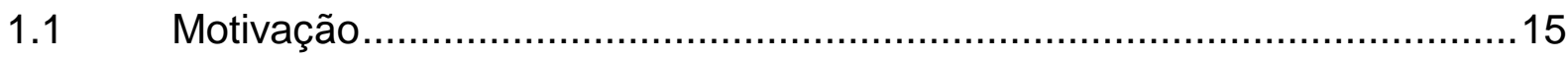

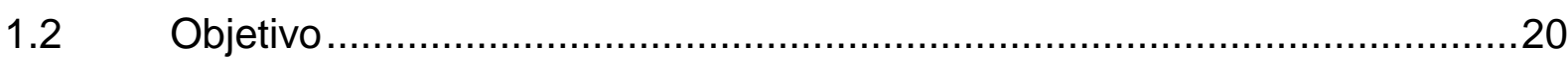

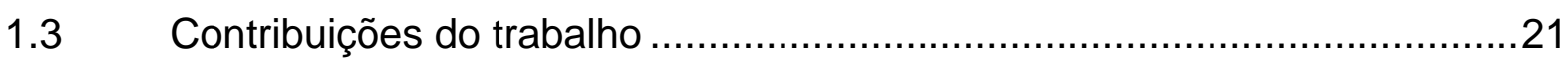

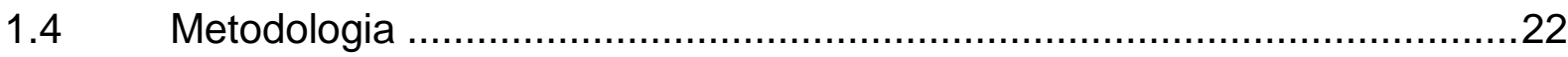

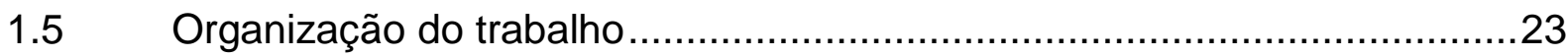

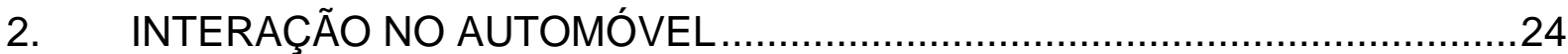

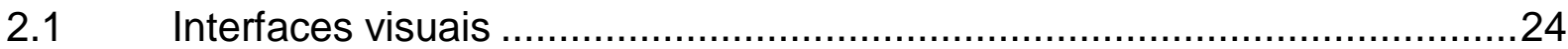

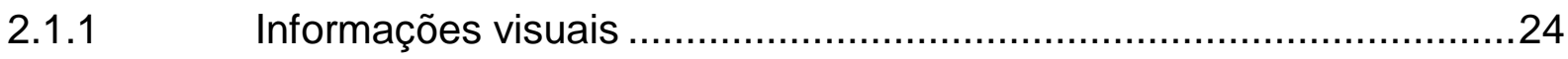

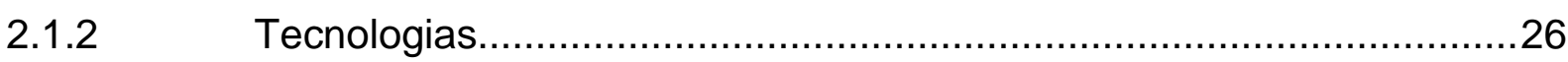

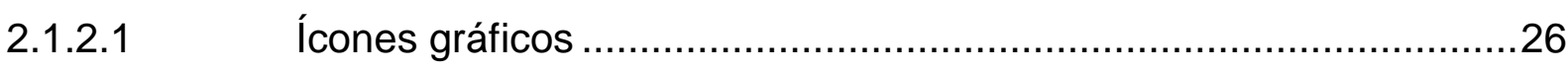

2.1.2.2 Display de Cristal Líquido de Segmentos......................................26

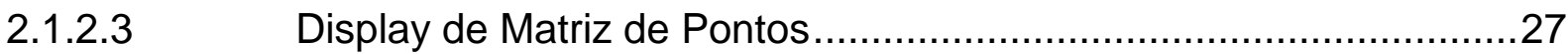

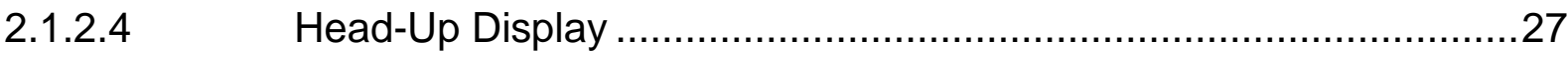

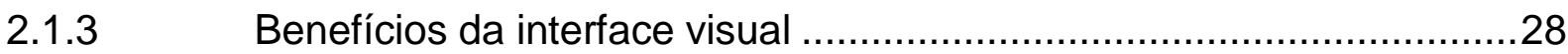

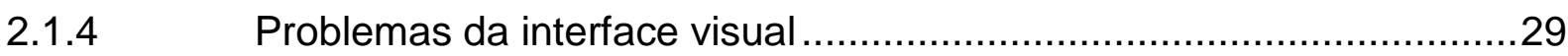

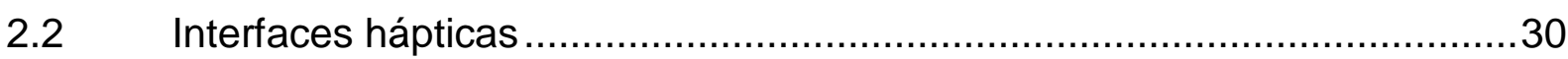

2.2.1 Informação hápticas................................................................

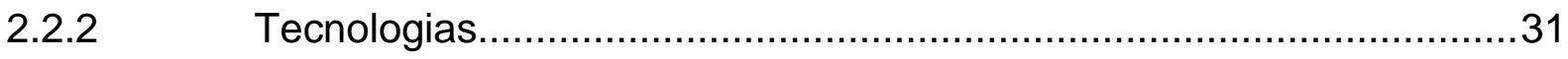

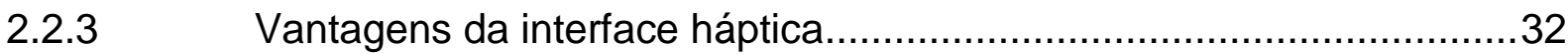

2.2.4 Desvantagens da interface háptica ...............................................

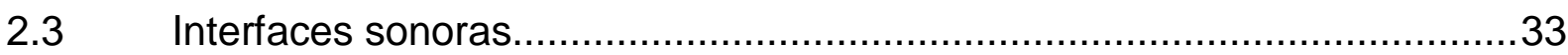

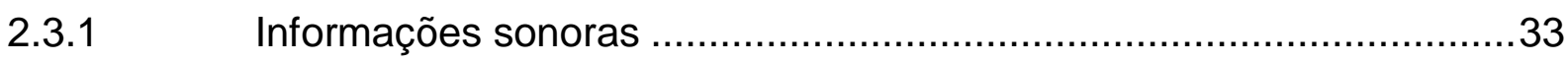

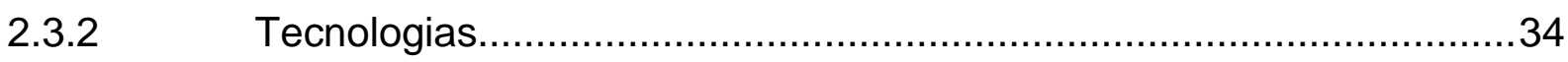

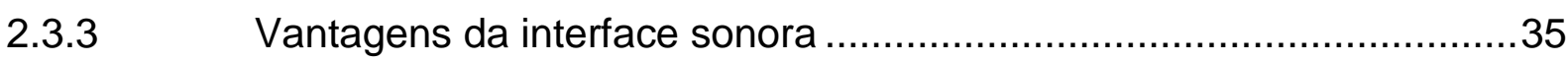

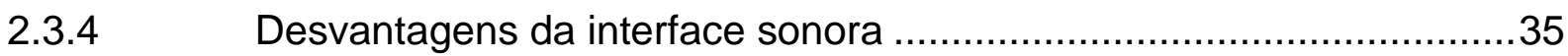

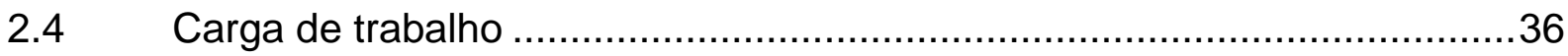

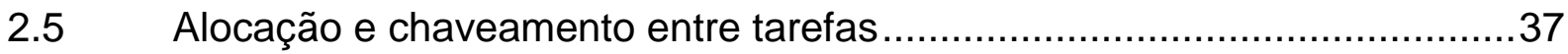

$2.6 \quad$ Usabilidade no automóvel .................................................................... 40

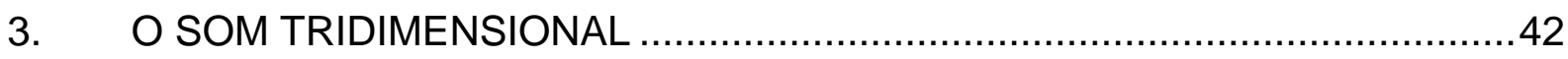




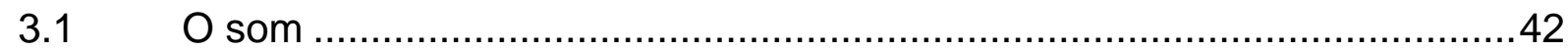

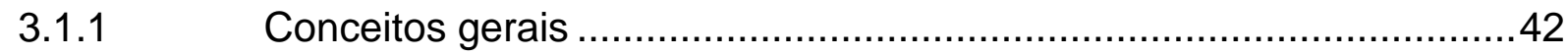

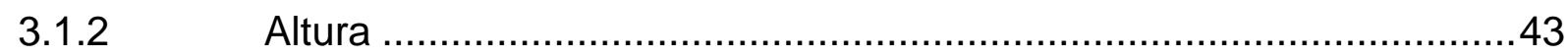

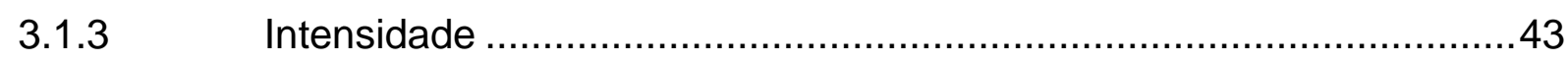

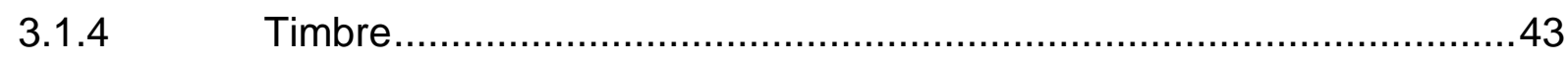

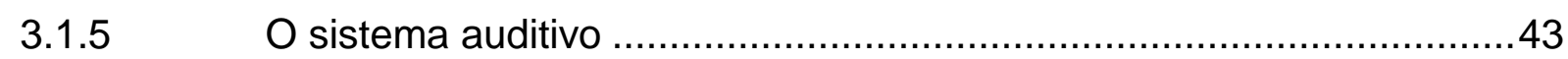

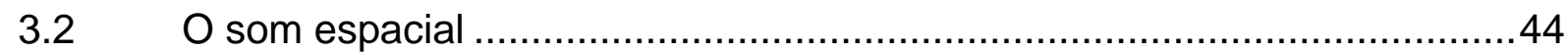

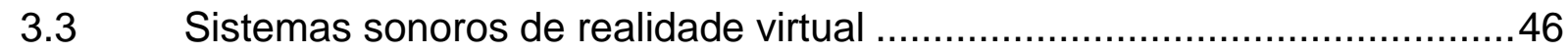

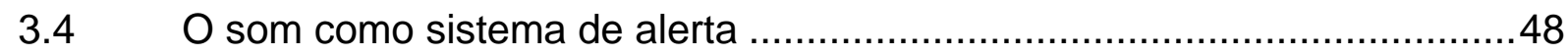

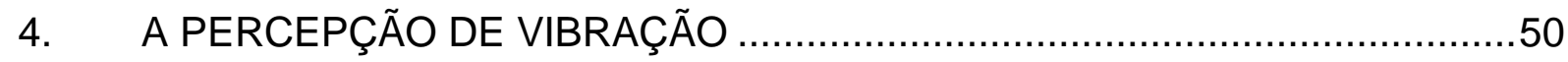

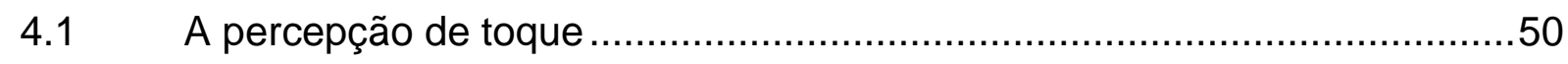

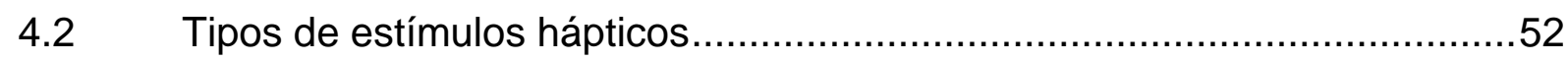

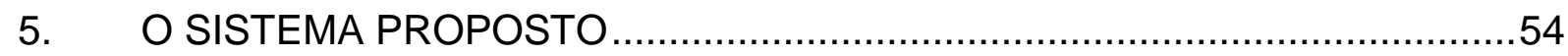

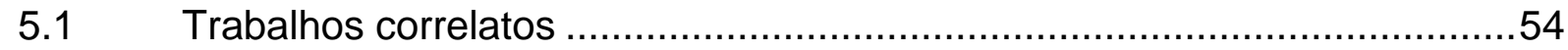

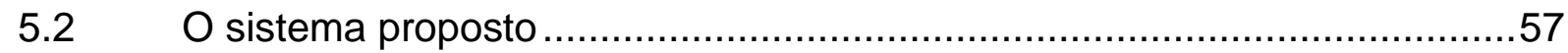

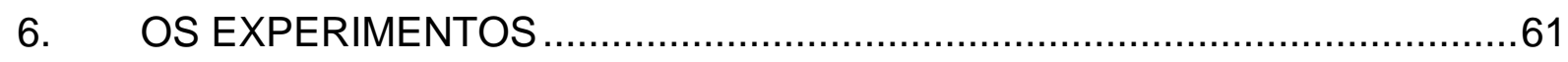

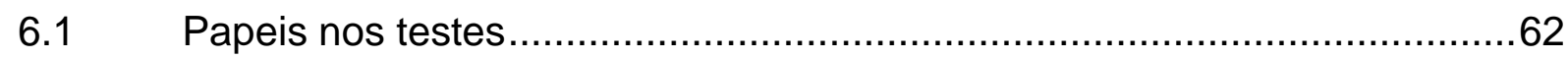

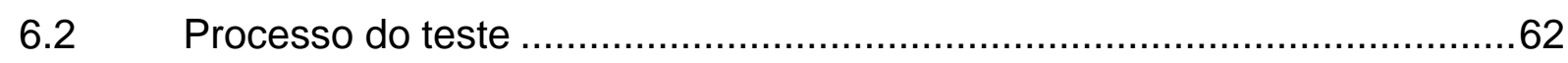

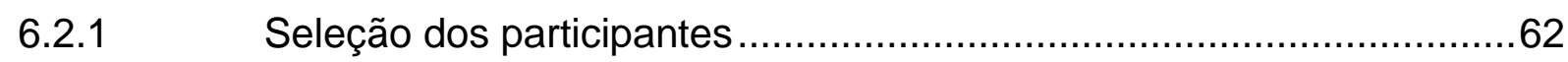

6.2.2 Esclarecimento aos participantes e consentimento ..........................63

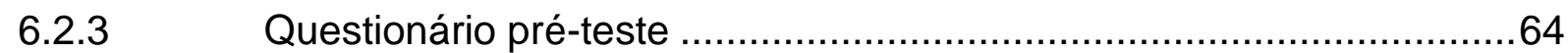

6.2.4 Treinamento nos dispositivos utilizados no teste ..............................66

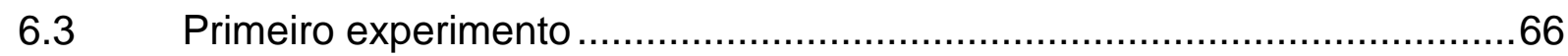

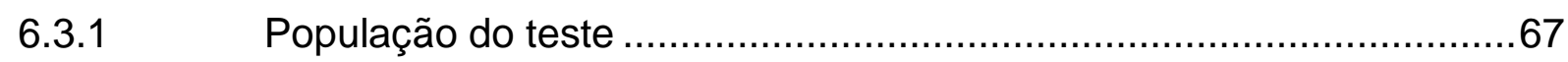

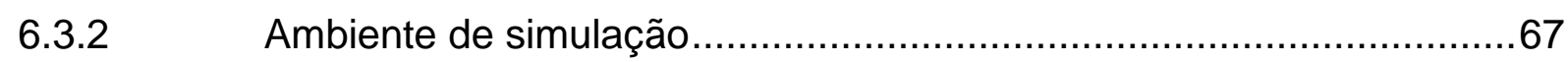

6.3.3 Questionário pós-teste primeiro experimento …..................................67

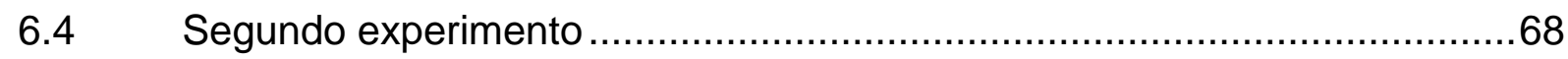

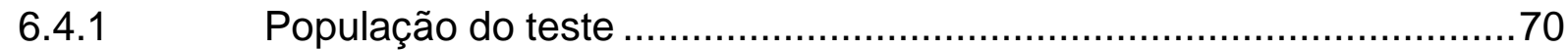

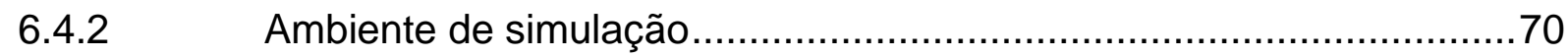

6.4.3 Questionário pós-teste segundo experimento …………..................72

6.5 Montagem do ambiente de simulação ………........................................73

6.5.1 Adaptações realizadas no ManiaDrive.............................................73

6.5.2 Desenvolvimento do módulo de alerta ...............................................

6.6 Método de avaliação ............................................................................. 


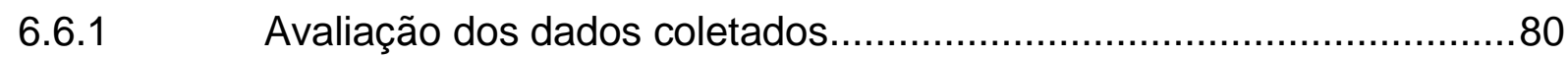

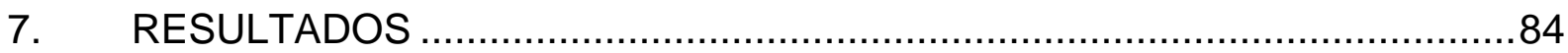

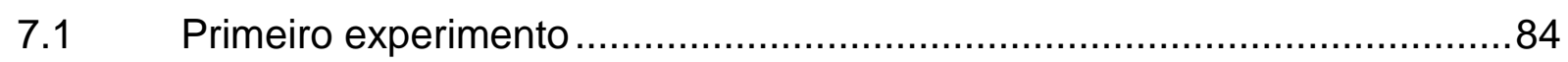

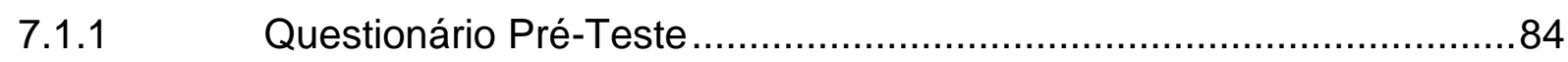

7.1.1.1 Experiência de direção ......................................................... 84

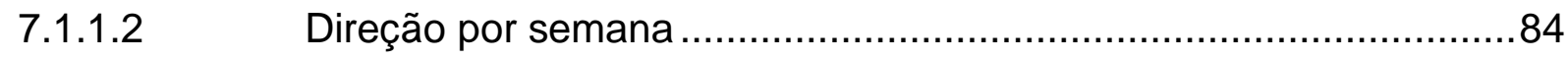

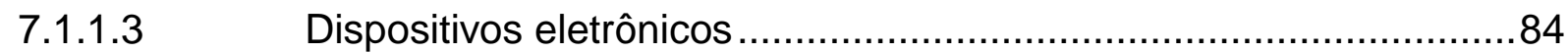

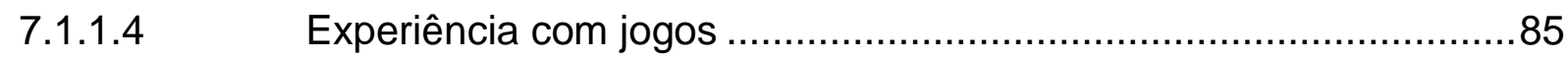

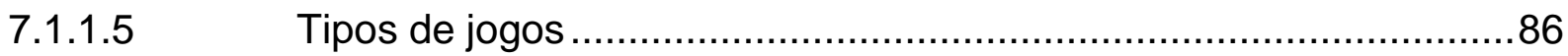

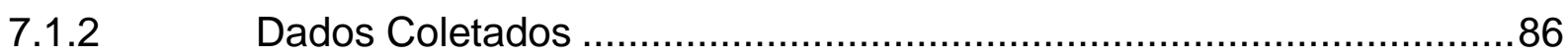

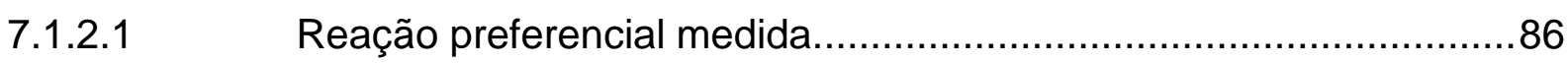

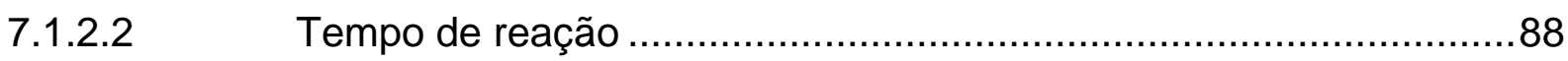

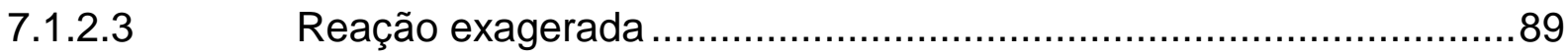

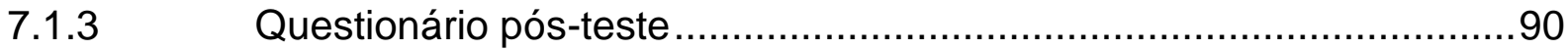

7.1.3.1 Avaliação do ambiente de simulação ............................................90

7.1.3.2 Atenção destinada ao carro azul ..................................................90

7.1.3.3 Percepção do carro azul ...........................................................

7.1.3.4 Reação preferencial declarada...................................................

7.1.3.5 Reações adversas................................................................

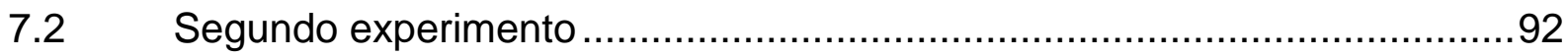

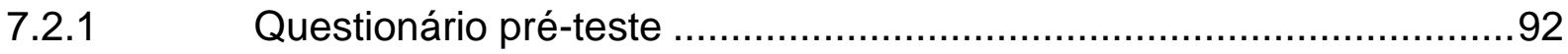

7.2.1.1 Experiência de direção ............................................................

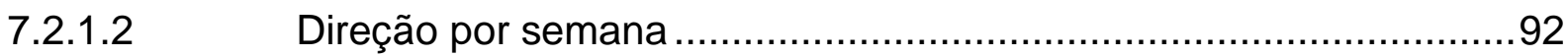

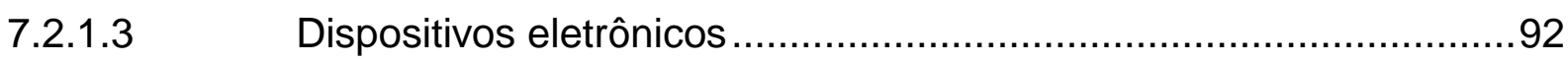

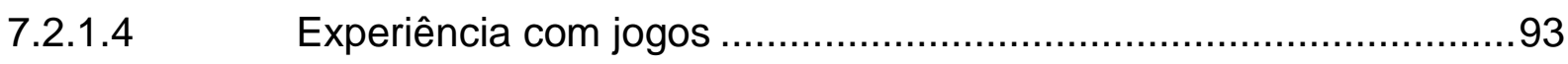

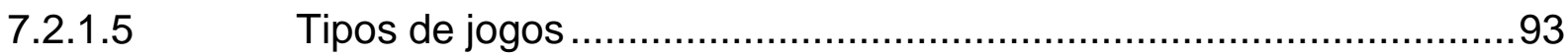

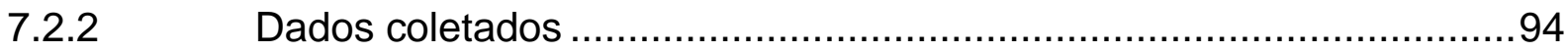

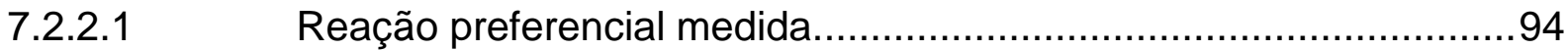

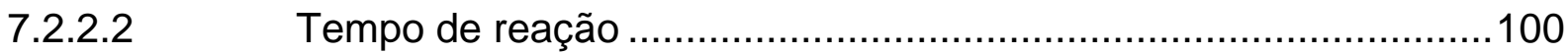

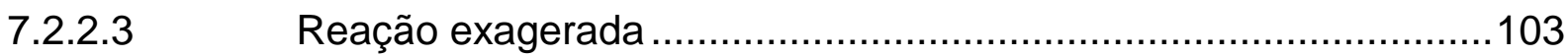

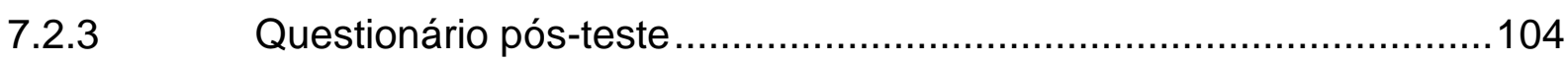

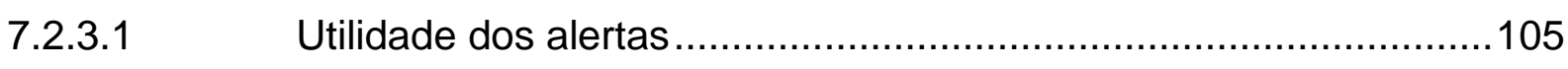

7.2.3.2 Incômodo dos alertas ............................................................106

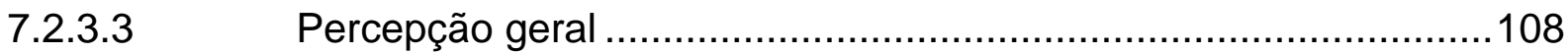




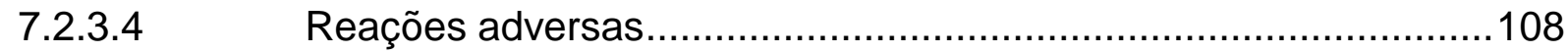

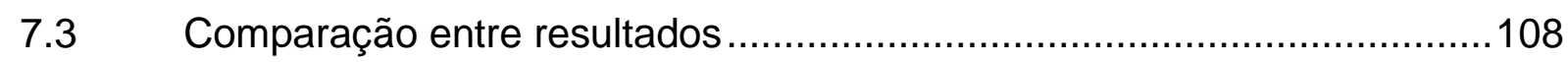

7.3.1 Relação da idade com o tempo de resposta...................................108

7.3.2 Relação da experiência com o tempo de resposta ............................109

7.3.3 Relação do uso de jogos com o tempo de resposta ..........................110

7.3.4 Relação dos tempos de resposta com e sem alertas ........................111

7.3.5 Relação dos tempos de resposta de cada alerta .............................113

7.3.6 Relação da reação preferencial ..................................................114

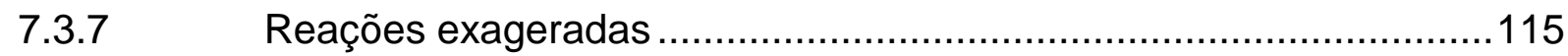

7.3.8 Relação entre a ausência de reação com e sem alertas ....................116

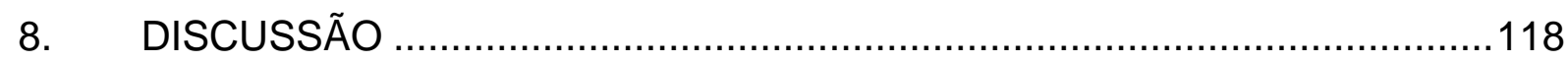

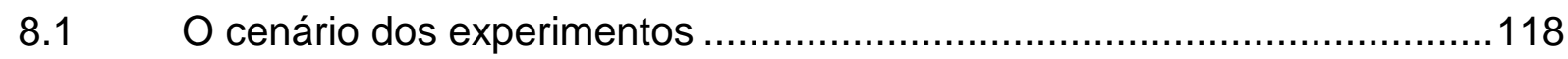

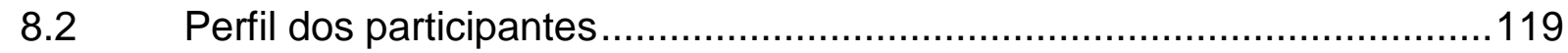

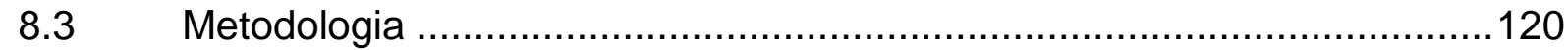

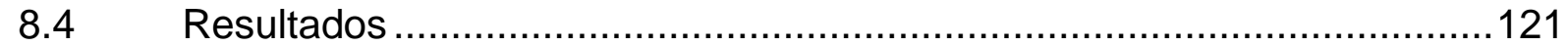

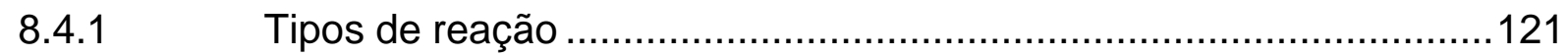

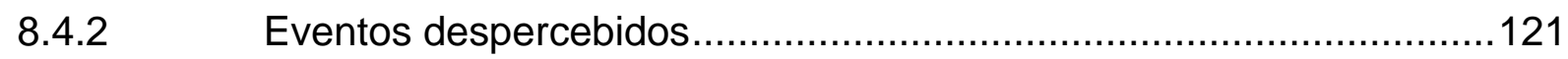

8.4.3 Tempos de reação ...............................................................122

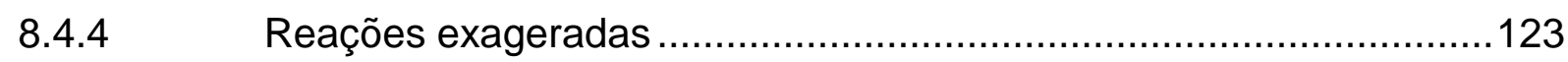

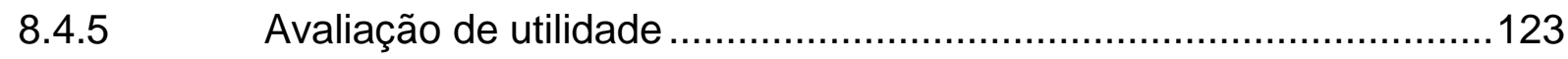

8.4.6 Avaliação de incômodo …………………................................123

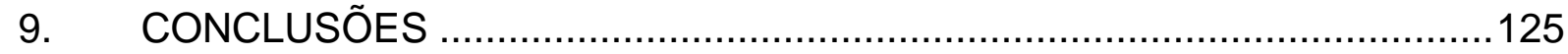

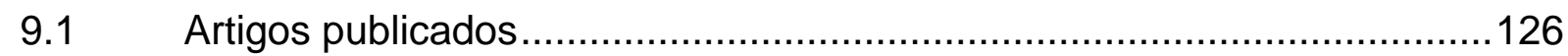

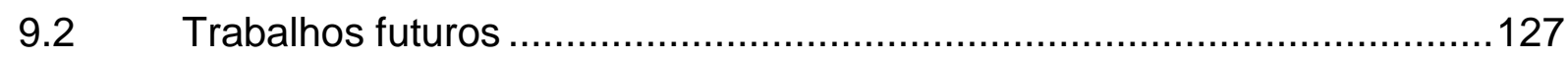

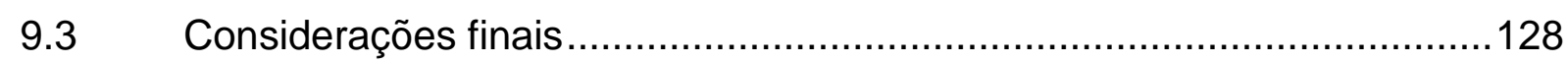

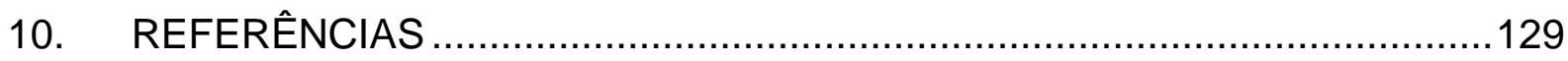




\section{INTRODUÇÃO}

Este trabalho versa sobre o uso do som tridimensional em conjunto com estímulos vibratórios em um sistema veicular para assistência ao motorista na tomada de decisão quando uma possível colisão lateral é iminente.

Nesta introdução, são discutidos dados e fatores que motivam a pesquisa nessa área. Na sequência, são apresentados os objetivos e as contribuições do trabalho. Seguem também uma descrição da metodologia utilizada na pesquisa e um breve resumo da forma como o trabalho foi organizado.

\subsection{Motivação}

Segundo o relatório de acidentes veiculares do U.S. Department of Transportation (2006, 2007), estima-se que nos Estados Unidos, cerca de 40 mil pessoas por ano morrem por razões diretamente ligadas ao trânsito. No Brasil, os dados do Anuário Estatístico do Departamento Nacional de Trânsito (Denatran) de 2006 falam de cerca de 20 mil vítimas fatais decorrentes de acidentes de trânsito, mas somente levam em conta as mortes ocorridas no local do acidente, sendo que a prática internacional é considerar os falecimentos até 30 dias depois do acidente. Esse número equivale às fatalidades de um acidente com um avião comercial de porte médio a cada dois dias, o que representa uma quantidade muita alta de vítimas fatais se comparado ao número de ocorrências com mortes na aviação civil norteamericana.

Apesar de o risco aparente do automóvel para a sociedade ser pequeno comparado com o risco aparente do avião, os números acima mostram que o trânsito de carros causa muito mais acidentes fatais do que o meio de transporte aéreo. Credita-se esse acontecimento ao fato de que, devido à alta exigência que a sociedade impõe à confiabilidade do sistema aéreo, os critérios de qualidade para a validação de componentes aeronáuticos são muito mais restritivos do que os critérios utilizados na validação de itens automotivos. $O$ acesso da sociedade ao carro é muito mais comum do que o acesso ao avião e, no carro, não são providos dispositivos de 
auxílio à tomada de decisão similares aos que são encontrados em um avião. Além disso, é preciso se dizer que a tarefa de pilotar uma aeronave civil é executada em um contexto de atividade profissional, para a qual o piloto tem o devido treinamento e uma supervisão constante, enquanto a tarefa de dirigir um veículo é comumente realizada de maneira informal e descontraída, fatores que contribuem para o desvio da atenção.

Em vista desses fatos, a indústria automotiva tem trabalhado em soluções que auxiliem o motorista na tomada de decisão. Novas tecnologias têm surgido e várias técnicas vêm sendo estudadas (ZHENG et al., 2004; SIMONDS, 2003; WU; CHEN; YANG, 2005). O advento de novas técnicas, entretanto, incorre em uma necessidade de avaliação de seus possíveis impactos negativos na confiabilidade do sistema (BAINBRIDGE, 1983). A inclusão de novas tecnologias no carro propicia, portanto, o surgimento de novos modos de falha.

É muito importante analisarem-se os componentes relacionados à segurança em um carro, especialmente quando se considera o alto nível de ruídos elétricos a qual os componentes eletrônicos estão submetidos. As instabilidades do ambiente veicular evocam um alto potencial de falha em seus componentes e, por esse motivo, há uma grande preocupação com a confiabilidade dos componentes eletrônicos usados no carro. Assim como a análise da confiabilidade dos componentes eletrônicos é fundamental para a segurança do automóvel, é importante que a confiabilidade seja também observada do ponto de vista do operador. A aplicação de tecnologias inovadoras para assistência ao motorista criou novos paradigmas de interação do veículo com o motorista e, consequentemente, ampliou a possibilidade de ocorrer uma influência negativa dos equipamentos eletrônicos na atenção do motorista, ao aumentar seu esforço cognitivo e sua carga mental de trabalho.

Confiabilidade e Human Vehicle Interface (HVI) são temas essenciais na discussão atual sobre o futuro da área automotiva. A crescente demanda por soluções automotivas de baixo custo é um desafio para a indústria e para os engenheiros bem como é uma grande ameaça à qualidade e à confiabilidade. Cada vez mais, são requisitados cronogramas curtos para desenvolvimento dos produtos, entrega da solução e começo da produção. Em tal cenário, é comum se negligenciarem 
algumas fases do processo padrão e se ignorarem algumas das mais básicas boas práticas de desenvolvimento eletrônico.

O desenvolvimento de interfaces seguras, que auxiliem o motorista em situações em que uma ação é requisitada com urgência ou mesmo em controles secundários, como acionamento do rádio, configuração do navegador e leitura de dados no painel de instrumentos é um compromisso e um grande desafio das empresas montadoras de carros. Com o objetivo de reduzir o número de controles individuais no interior do veículo, projetistas elaboram interfaces baseadas em menu, nas quais é disponibilizada ao motorista uma tela sensível ao toque, um sistema de controle central ou uma interface de reconhecimento de voz para buscar a redução do tempo em que o motorista dispensa ao controle, com os olhos fora da pista ou com as mãos fora do volante (DRIVER, 2005).

Há diversas pesquisas sendo realizadas para prover à indústria automotiva tecnologias de suporte ao motorista. Estudos sobre a identificação automática de placas e sua leitura para o motorista (WU; CHEN; YANG, 2005), o desenvolvimento de componentes de interação para um sistema de assistência no controle de distância e de velocidade (ADELL et al., 2007) e a execução de experimentos simulados e reais sobre a utilização dessas tecnologias (RIENER; FERSCHA, 2008) são alguns exemplos do que se têm trabalhado nessa área. A 1st International Conference on Automotive User Interfaces and Interactive Vehicular Applications, realizada na cidade de Essen, na Alemanha em 2009 apresentou diversos trabalhos sobre o impacto da adição de novas formas de interação no desempenho do motorista.

A proliferação de componentes eletrônicos no interior de carros de passeio coloca em questão até que ponto tais equipamentos auxiliam o motorista a conduzir em segurança o veículo ou o distraem, podendo causar um acidente. Muitas vezes os produtos encontrados dentro do veículo não são avaliados do ponto de vista da usabilidade, e comumente, são adotadas soluções que tipicamente se aplicam com sucesso nos demais produtos eletrônicos como celulares, tocadores de música e videogames, mas que, quando utilizadas no ambiente automotivo, fracassam por demandarem demasiada atenção do motorista no seu manuseio. 
De acordo com Norman (2007), a indústria automotiva sofre da mesma falta de conhecimento sobre fatores humanos que outras indústrias sofreram no passado. A grande quantidade de dispositivos eletrônicos em uso durante a direção e a integração de sistemas de alerta são muitas vezes inoportunos e irritantes.

As tecnologias que permitiram o uso dentro do carro de aparatos de entretenimento e de informação, como os Digital Video Discs (DVDs) portáteis, os navegadores e os computadores de bordo aliadas aos demais equipamentos pessoais que também são portados pelo motorista durante a direção, tais como, celular, Personal Digital Assistants (PDAs) e tocadores de música mudaram radicalmente o paradigma da interação do veículo com seu condutor. O que costumava se resumir a comandos mecânicos de acionamento de pedais, troca de marchas e manuseio do volante, hoje dá lugar a uma infinidade de botões, avisos sonoros e informações visuais disponíveis no painel de instrumentos, como mostrado na Figura 1 do interior do carro Toyota Prius exibido na versão 2009 do Salão do Automóvel de Frankfurt, uma das mais importantes exposições de carro do mundo.

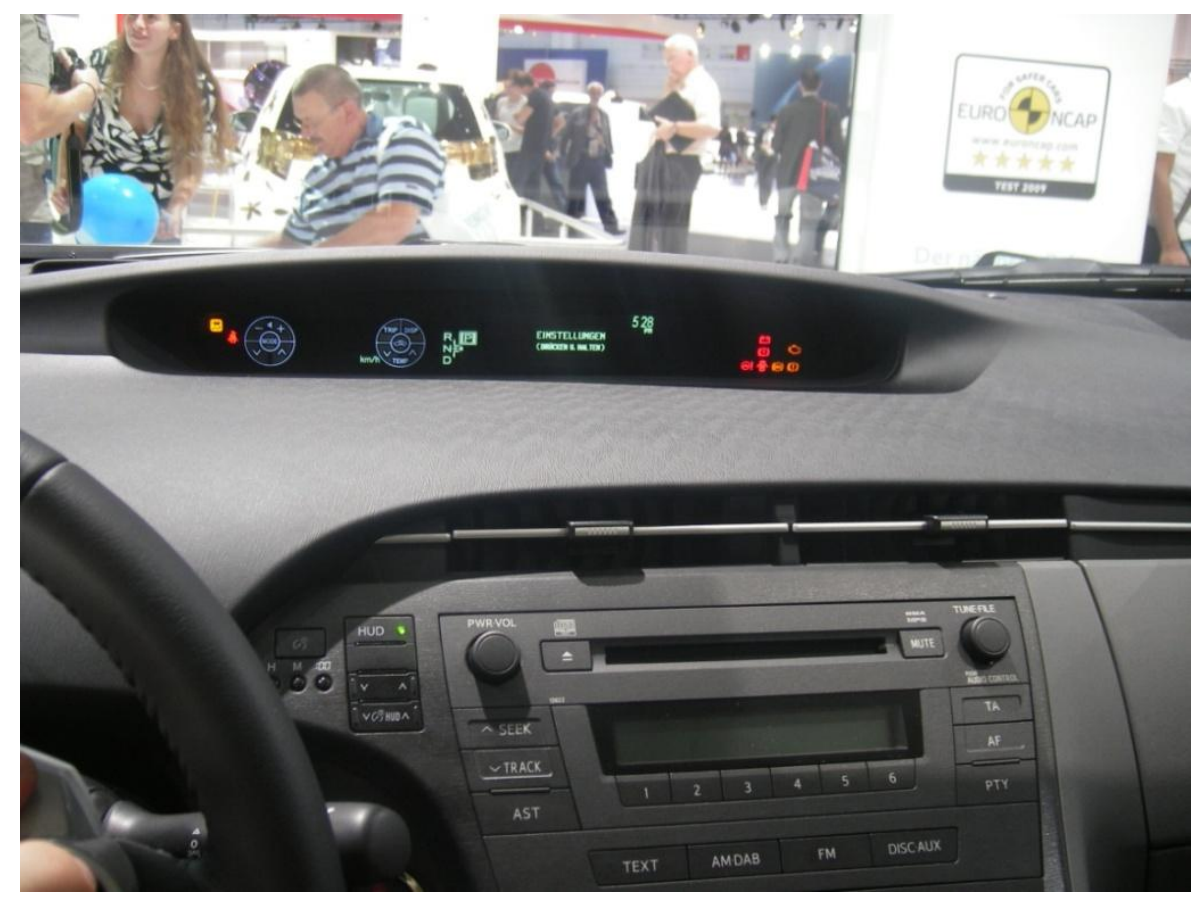

Figura 1 - Interior do Toyota Prius no Salão do Automóvel de Frankfurt 2009. Fonte: autor

Fletcher et al. (2003) delineiam alguns dos principais papéis dos sistemas de assistência ao motorista, dentre eles: detecção de cansaço ou de desatenção por 
parte do motorista, identificação de pontos-cego, validação da distância entre veículos, auxílio na manutenção da faixa, reconhecimento de placas de trânsito e expansão da visão com ajuda da inteligência computacional. Ainda segundo Fletcher et al. (2003), não se podem prever as circunstâncias em que um acidente ocorre, mas o uso de sistemas como os citados acima podem contribuir para evitá-los ou ao menos reduzir sua severidade.

Muitos dos sistemas de assistência ao motorista são baseados em dispositivos de alarme, os quais são ativados quando uma situação de risco é identificada pelo sistema. A conglomeração de diferentes dispositivos de alarme é um problema em qualquer sistema eletrônico em que a atenção do operador possa ser desviada pelo atendimento aos alarmes ativos, mas no veículo essa problemática é presente de forma intensificada, uma vez que o desvio da atenção do motorista por conta de um falso alarme ou de um fato de importância menor do que a condução estável do seu veículo pode ocasionar um acidente.

A carga cognitiva a que é submetido o motorista somada ao esforço desprendido na correta divisão de tarefas durante o ato da direção justificam também um estudo cuidadoso sobre a melhor forma de se projetar os sistemas com os quais o motorista interage. Os canais visual e motor, em especial, são submetidos a uma grande carga de trabalho e podem ser ainda mais demandados caso a interação elaborada não otimize a capacidade do motorista de processar as informações provenientes dos seus vários canais perceptuais.

Segundo Bellotti et al. (2002), os sistemas de detecção automática e os estudos sobre Interação Humano Computador (IHC) são campos de pesquisa correlatos que trabalham juntos no desenvolvimento de sistemas avançados de assistência ao motorista, objetivando a redução do tempo de reação e, consequentemente, impactando positivamente no controle lateral e longitudinal ao prover informações de forma simples e compreensiva.

Em Driver (2005), conclui-se que o desenvolvimento de interfaces humanocomputador seguras para comandos secundários sem o comprometimento das funções primárias tem se tornado um grande desafio para a indústria automotiva, 
uma vez que se acredita que a distração no volante contribui em cerca de $25 \%$ dos acidentes.

Por outro lado, o potencial de redução de acidentes existente nos dispositivos de assistência ao motorista é enorme. Os modernos sensores desenvolvidos pela indústria automotiva permitem a detecção de obstáculos laterais e longitudinais, bem como o reconhecimento, no ambiente que circunda o carro, de padrões indicativos de situações de risco.

Os números relativos à falta de atenção no trânsito e à quantidade de acidentes com danos materiais e pessoais mencionados nesta seção identificam a carência de interfaces apropriadas para a apresentação das informações obtidas pelos sensores ao condutor do veículo. Ou seja, a pesquisa técnica evoluiu muito no sentido de desenvolver sistemas que reconheçam as situações de perigo, mas pouco se avançou no desenvolvimento de interfaces que levem em conta os fatores humanos inerentes ao ato da direção.

\subsection{Objetivo}

Esse trabalho tem como objetivo avaliar, com base nos estudos já realizados sobre o tema e na teoria sobre desempenho humano e cognição, o uso de alertas auditivos e hápticos em um sistema de alerta intra-veicular de colisão lateral que tire proveito de uma divisão otimizada da carga de trabalho, ao utilizar os canais perceptuais menos demandados: a audição e a percepção háptica.

As questões de pesquisa são:

- Qual a influência do alerta auditivo na reação do motorista em caso de quase colisão?

- Qual a influência do alerta háptico na mesma situação?

- O uso conjunto dos alertas auditivo e háptico gera efeito diferenciado?

- Qual a influência negativa do uso de tais alertas?

Discute-se ainda o uso de uma interface de som tridimensional, uma ferramenta pouco explorada pelos sistemas de alerta, mas que se apresenta como muito 
poderosa uma vez que a aptidão do canal auditivo para percepção espacial é precisa, rápida e de pouco esforço cognitivo (SHERMAN; CRAIG, 2003).

A consideração de sistemas multimodais para assistência ao motorista é parte integrante desse estudo, uma vez que é discutível se o alerta sonoro de fato conduz a uma ação imediata ou meramente atrai a atenção do operador para uma direção cabendo a ele o processamento das informações e a tomada da decisão sobre que ação tomar (ROSSMEIER; GRABSCH; DÖRING, 2005).

Objetiva-se observar que o tempo de resposta do motorista aos eventos de perigo seja reduzido significativamente com o uso desse sistema e que, adicionalmente, o sistema não interfira significativamente no ato da direção.

\subsection{Contribuições do trabalho}

A contribuição principal desse trabalho é delinear os benefícios obtidos pela aplicação de um sistema de alerta multimodal com o uso de som tridimensional e estímulo háptico com base nas características de carga de trabalho, tempo de resposta e esforço cognitivo. Os resultados obtidos poderão naturalmente ser aplicados a estudos sobre interação além do contexto veicular.

Assim como as avançadas pesquisas sobre interação no computador pessoal e no ambiente aeronáutico, como Begault (2007), contribuem com arcabouços conceituais úteis na construção de conhecimento sobre usabilidade e fator humano nos automóveis, esse trabalho se propõe a contribuir para a compreensão da influência da multimodalidade nos sistemas de alerta.

Outra contribuição desse trabalho é, portanto, oferecer à comunidade científica e à indústria subsídios para o desenvolvimento de interfaces em sistemas de auxílio à tomada de decisão. As conclusões desta pesquisa servem de referência para o projeto de sistemas automotivos de alerta voltados à usabilidade, permitindo uma compreensão clara da localização da fonte de perigo e de sua criticidade. 


\subsection{Metodologia}

A primeira abordagem desse estudo recaiu na busca de referências sobre fator humano em sistemas críticos, com uma pesquisa bibliográfica sobre os principais conceitos utilizados na área e sobre as problemáticas mais comuns de serem tratadas com um foco nas modelagens relacionadas ao erro humano (REASON, 1990), nas discussões sobre cognição (SARTER; AMALBERTI, 2000) e no conhecimento de confiabilidade e segurança de sistemas computacionais.

Os conhecimentos de computação pervasiva, o conceito de que o computador está embarcado no ambiente de forma invisível para o usuário, e de realidade virtual (SHERMAN; CRAIG, 2003) auxiliaram na definição da interface para estudo, a qual apresenta características de realidade aumentada, uma vez que reproduz sons e estímulos hápticos em adição aos sons e estímulos do mundo real.

A pesquisa encontra nas referências sobre usabilidade (NORMAN, 1988) e desempenho humano (WICKENS; HOLLANDS, 2000) as bases que permitem a discussão da eficiência dos dispositivos que se propõem a ajudar o ser humano na execução de tarefas rotineiras e cotidianas, tais como engenharia cognitiva, projeto centrado no usuário, teoria sobre o erro humano, carga de trabalho, mecanismos de chaveamento, de tomada de decisão e de seleção da ação.

As informações sobre interfaces sonoras são baseadas nas normas HFDS - Human Factors Design Standard e no conhecimento disponível na literatura sobre o tema, especialmente nos anais da conferência International Conference on Auditory Display (ICAD). Os dados estatísticos referentes a acidentes de trânsito e suas causas foram extraídos de relatórios oficiais do U.S. Department of Transportation (2006, 2007). No levantamento de tecnologias inovadoras na área de interação automotiva, foram pesquisados trabalhos no Institute of Electrical and Electronics Engineers (IEEE), em especial no periódico Transactions on Intelligent Systems.

$\mathrm{Na}$ avaliação da solução são utilizadas tanto métricas quantitativas quanto qualitativas. Entende-se que além das medições de tempo de resposta, estimativas de tempo de frenagem ou de ação, é fundamental que sejam registradas a 
percepção e a compreensão do dispositivo por parte do operador, para o que são usadas escalas categóricas de avaliação. Para tanto, foi submetido um plano de testes com ususários ao Comitê de Ética em Pesquisa e, posteriormente, foram feitos testes com usuários em um simulador.

\subsection{Organização do trabalho}

Esse trabalho está organizado da seguinte maneira:

Seção 1 é a Introdução, onde se descrevem a motivação, o objetivo, as contribuições do trabalho e a metodologia utilizada na pesquisa.

Seção 2 é referente a aspectos de interação no automóvel. São pormenorizados dispositivos que usam canais específicos de percepção como a visão, o som e o tato. São discutidos aspectos gerais da interação no interior do automóvel, como carga de trabalho e esforço cognitivo.

Seção 3 oferece detalhes sobre o uso de interfaces sonoras e aborda questões sobre o som tridimensional. Uma visão geral dos recursos computacionais disponíveis para essa tecnologia e das aplicações correlatas de realidade virtual é apresentada.

Seção 4 discute a questão das interfaces táteis, explorando a vibração como meio de transmitir informações ao usuário.

Seção 5 apresenta trabalhos relacionados que justificam a inserção da técnica em estudo e apresenta o sistema proposto.

Seção 6 apresenta os experimentos realizados para avaliação do sistema proposto.

Seção 7 mostra os resultados obtidos nos experimentos.

Seção 8 discute os cenários dos experimentos, o perfil dos participantes, a metodologia utilizada e os resultados obtidos nos experimentos.

Seção 9 apresenta as conclusões do trabalho. 


\section{INTERAÇÃO NO AUTOMÓVEL}

A interação entre o motorista e seu veículo hoje é muito diferente da interação presente há alguns anos atrás. As inovações tecnológicas no veículo normalmente aparecem primeiramente nos países mais desenvolvidos e nos carros mais luxuosos, mas comumente, após alguns anos, essas tecnologias se popularizam e passam a fazer parte de carros mais simples em todas as partes do mundo.

Essa seção discorre sobre algumas tecnologias que, do ponto de vista da interação, se propõem a mudar a forma como o condutor se relaciona com seu veículo. As tecnologias são subdividas em três tipos: visuais, hápticas e sonoras. Adicionalmente, são discutidos os conceitos de carga de trabalho, de esforço cognitivo e de usabilidade no contexto automotivo.

\subsection{Interfaces visuais}

Esta seção descreve as principais informações apresentadas pelos dispositivos de interface visual disponíveis nos automóveis e quais as tecnologias utilizadas para a apresentação dessas informações. Discutem-se ainda os benefícios e os problemas do uso de tais dispositivos no interior do veículo.

\subsubsection{Informações visuais}

O motorista, durante 0 ato da direção, precisa processar uma diversidade de informações, sejam elas provenientes do ambiente externo ao veículo ou do interior. Em sua maioria, essas informações se apresentam no formato visual. O motorista deve estar sempre atento à movimentação dos veículos à sua volta, à passagem dos pedestres, às sinalizações de seta, semáforo, limites de velocidade e à condição da pista, bem como deve consultar as indicações que o próprio veículo o apresenta para conduzir com segurança. 
No carro, várias informações relacionadas ao estado do veículo precisam ser mostradas ao motorista. Tipicamente no painel de instrumentos são providos ícones visuais que podem ser divididos em três categorias (CONTRAN, 2007):

i) indicativos de mau funcionamento de algum subsistema, por exemplo, em caso de temperatura elevada do motor ou defeito no freio de estacionamento;

ii) alerta, como no caso de acionamento do desembaçador traseiro ou

iii) aviso de função acionada, por exemplo, o acionamento dos faróis.

O reconhecimento do significado de cada um dos ícones por parte do motorista é fundamental para garantir a eficácia do sistema de avisos. Para tanto, no Brasil, o Conselho Nacional de Trânsito (Contran) padroniza as ilustrações de cada aviso (CONTRAN, 2007), bem como das cores, sendo vermelha cor usada nos avisos de mau funcionamento, âmbar nos casos de alerta e verde ou azul no caso de indicação de acionamento.

A velocidade instantânea do veículo, a quantidade de combustível no tanque e a quilometragem total já percorrida pelo carro são algumas das informações fundamentais para que o motorista possa atingir seu destino em segurança respeitando as regras de trânsito e tendo controle sobre o seu veículo.

Outras informações visuais podem ser providas no interior de carros de passeio para fins de conforto e assistência ao motorista. Dados como consumo médio, consumo instantâneo, autonomia estimada, tempo de viagem, velocidade de rotação do motor, temperatura do motor, mapas para navegação e demais alertas visuais não são itens obrigatórios nos veículos brasileiros, mas vêm sendo utilizados cada vez mais por conta da demanda dos próprios motoristas, aos quais interessa saber os dados que os permitem identificar o desempenho do seu carro.

Adicionalmente o motorista está submetido a informações visuais provenientes de dispositivos acessórios presentes no carro, como o abridor de portas, o levantador de janelas, o rádio, o controle de ar condicionado entre outros. Segundo Pettitt (2008), as fontes de distração visual podem ser categorizadas como internas ou externas ao veículo, bem como iniciadas pelo motorista, como fazer uma ligação do 
celular ou não-iniciadas pelo motorista, como um comportamento inadequado dos passageiros, que atraia a atenção do motorista.

\subsubsection{Tecnologias}

Para a apresentação das informações visuais, várias tecnologias podem ser usadas. Nesta seção, procuram-se descrever as características de algumas tecnologias utilizadas para tal fim em ordem de potencial para exibição de informação de cada tecnologia. Grande parte das informações apresentadas nesta seção provêm de observações profissionais do autor por meio da sua experiência na indústria automobilística na área de instrumentação. Além das tecnologias aqui apresentadas, naturalmente, a observação dos diversos elementos mecânicos disponíveis ao motorista consiste em importante fonte de informações.

\subsubsection{I ĺcones gráficos}

Os ícones são ilustrações características grafadas no mostrador do painel de instrumentos que se tornam visíveis quando a sua iluminação é acionada e não podem ser visualizadas caso a iluminação, comumente implementada com um ou mais Light-Emitting Diodes (LEDs), esteja apagada. Permitem a apresentação de informações binárias ou em alguns casos podem ser iluminadas por duas cores, que indicam estados diferentes de uma mesma funcionalidade, por exemplo, o acionamento das luzes externas.

\subsubsection{Display de Cristal Líquido de Segmentos}

As telas de Liquid Crystal Display (LCD) são constituídas de um líquido polarizador da luz, comprimido em celas entre duas lâminas transparentes que, quando controladas eletricamente, permitem ou bloqueiam a passagem de luz. No caso dos LCDs de segmentos, cada segmento pode ser controlado individualmente, permitindo a visualização de números, letras e símbolos.

Sua utilização se restringe à apresentação de informações curtas e com simplicidade de processamento, como hora, quilometragem, mensagens de texto curtas e 
símbolos específicos previsto no projeto do display. Sua limitação se deve ao fato de que tudo o que o display pode mostrar deve ser contemplado no seu projeto, ou seja, não há liberdade para se desenhar quaisquer figuras ou se escrever livremente um texto.

\subsubsection{Display de Matriz de Pontos}

O display de matriz de pontos é constituído de um arranjo de indicadores luminosos retangulares, que, posicionados sequencialmente, empreendem um aspecto contínuo ao conjunto de pontos. Assim como na seção 2.1.2.2, a tecnologia dos display de matriz de pontos pode ser LCD, mas, neste caso, a ativação de cada indicador pode ser feita de forma independente e é administrada por um controlador que processa as instruções do processador.

Sua resolução e seu tamanho variam, mas, em geral, é possível se desenhar figuras e textos de até seis palavras, o que dá muito mais liberdade no projeto da interface com o usuário do que no caso do uso do display de segmentos, uma vez, que com um mesmo display, pode-se investigar a melhor maneira de se apresentar determinada informação ao operador.

\subsubsection{Head-Up Display}

A tecnologia Head-Up Display (HUD), inicialmente aplicada para fins de aviação militar, consiste de um display transparente que tenha a capacidade de mostrar informações sem obstruir a visão do usuário. O conceito do HUD para uso automotivo foi proposto no fim da década de 80 e diversos dispostivos teste foram desenvolvidos e instalados em carros para avaliação. Esses sistemas tinham sérias limitações devido à qualidade dos displays disponíveis no momento.

Nos últimos anos, uma grande quantidade de sistemas veiculares para informação e navegação tem sido colocada no mercado utilizando HUD. Alguns sistemas provêem informações sobre tráfego, mapas e rotas alternativas sendo necessária uma interface gráfica para apresentação de símbolos ilustrativos. Na maioria deles, a 
interface visual é um display localizado no painel de instrumentos ou no console central (FUKANO et al., 1994).

Segundo Charissis e Naef (2007), o uso do HUD se justifica, pois as requisições correntes de navegação, informação e entretenimento têm tornado o tradicional painel de instrumentos, usado para a apresentação da velocidade, da quantidade de combustível e de outros dados, em um complexo dispositivo capaz de distrair o motorista.

Na indústria automotiva, várias são as aplicações para o HUD: desde a projeção de informações comumente disponibilizadas no painel de instrumentos, como velocidade, rotação do motor, temperatura do motor e quantidade de combustível, até avisos que se propõem a chamar a atenção do motorista para fenômenos específicos. Na Figura 2, o HUD é usado para apresentar informação de velocidade no Peugeot 5008, durante o Salão do Automóvel de Frankfurt 2009.

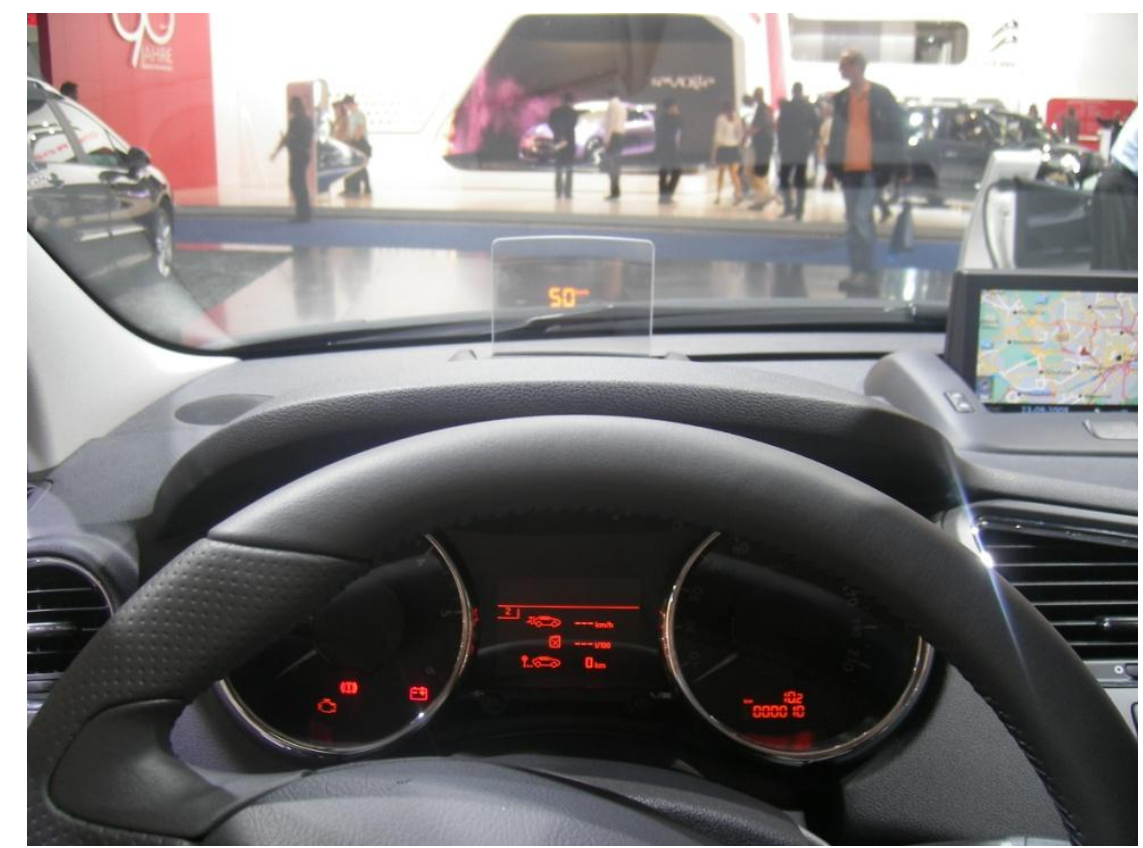

Figura 2 - Uso do HUD no interior do Peugeot 5008 no Salão do Automóvel de Frankfurt 2009. Fonte: autor

\subsubsection{Benefícios da interface visual}

A interface visual é a forma pela qual o ser humano capta a maior quantidade de informações do mundo exterior e, portanto, é uma forma rápida de apresentar 
informações ao motorista. Uma vantagem clara da interface visual no interior do veículo é o fato de que muitas informações devem estar disponíveis constantemente: quilometragem, velocidade, nível de combustível e outras. O motorista deve conseguir acessá-las sem necessidade de fazer uma requisição específica e, nesse caso, a interface visual é naturalmente a mais apropriada, pois os dados podem estar sempre presentes sem perturbar a atenção do motorista, que, caso deseje, pode consultá-las redirecionando seu campo visual.

Ao se utilizar a interface visual para a apresentação de informações deve-se ter o cuidado de apresentá-las de forma apropriada. Por exemplo, as informações representadas pelos mostradores do painel de instrumentos relativas a fenômenos dinâmicos, como rotação e temperatura do motor e velocidade do carro, utilizam comumente uma representação gráfica por meio dos ponteiros, que, conforme 0 princípio da compatibilidade de movimento, citado por Wickens e Hollands (2000), é fundamental para a produção de um modelo mental apropriado da situação.

Devido ao volume de informações que a interface visual é capaz de transmitir em um curto espaço de tempo, é possível utilizá-la para dados mais complexos, como a funcionalidade de navegação, na qual é apresentado ao motorista um mapa com instruções e comandos. Neste caso, ao mesmo tempo em que o motorista conduz o veículo, ele deve capturar as informações do dispositivo de navegação.

\subsubsection{Problemas da interface visual}

Para as informações que precisam ser utilizadas no momento em que são disponibilizadas, como é o caso dos alarmes de perigo, o uso da interface visual é discutível, pois o motorista pode não estar atento ao gráfico que indica o perigo. Isto pode fazê-lo não atuar na mitigação do problema.

Outra desvantagem do uso de interfaces visuais no ambiente automotivo é a grande demanda que o motorista tem de sua percepção visual, uma vez que muitas das suas ações são baseadas na sua percepção espacial e na confirmação visual de que os comandos foram eficazes. Ainda segundo Wickens e Hollands (2000), as diversas possibilidades de confusão no momento da interpretação das informações 
gráficas, como a solução de ambiguidade e o viés, são também fatores que exigem um cuidado especial no projeto da interface gráfica.

Quando mais complexos os dados a serem apresentados, maior é a demanda por atenção no momento da interpretação, o que pode ser problemático no já conturbado ambiente em que o motorista se encontra.

\subsection{Interfaces hápticas}

As interfaces hápticas estão atreladas à percepção táctil do ser humano. Sempre que um dispositivo interage com o homem utilizando como interface um elemento mecânico projetado para responder com força, pressão ou vibração, pode-se dizer que este usa uma interface háptica.

São apresentadas nesta seção as interfaces hápticas que já são utilizados no interior do veículo e também as pesquisas que têm sido feitas para propiciar uma exploração mais elaborada dos fatores vantajosos no uso dessas interfaces.

\subsubsection{Informação hápticas}

As interfaces hápticas estão presentes em muitos dos dispositivos automotivos, mesmo sem que o motorista perceba este fato. Alguns botões apresentam uma textura característica que auxilia o motorista a identificá-los. A resposta motora dos pedais de acelerador, freio e embreagem também é um exemplo de interface por meio da qual o motorista percebe o estado do carro, uma vez que a pressão necessária para seu acionamento reflete uma condição do veículo.

Nos botões giratórios (knobs) para navegação em menus ou controle de volume, o motorista pode perceber passos mecânicos ao girar o botão, e assim perceber que seu comando foi bem sucedido.

As informações hápticas descritas acima são alguns exemplos do que já existe em uso no interior dos veículos e refletem o enorme potencial das interfaces hápticas para a geração de uma experiência de uso diferenciada. Há, entretanto, uma grande 
quantidade de técnicas em estudo - Suzuki e Jansson (2003), Adell et al. (2007), Riener e Ferscha (2008) - visando utilizar a interface háptica como uma ferramenta de alerta ao motorista para assistência à tomada de decisão. O conteúdo dos trabalhos acima é discutido na seção em que a proposta deste trabalho é apresentada.

Para tanto, são explorados métodos de atrair a atenção do motorista atuando nos dispositivos com os quais o motorista tem contato constante: o volante, o banco e os pedais. Por exemplo, espera-se que ao se aplicar uma tensão direcionada no volante, o motorista entenda que o carro está lhe sugerindo uma determinada manobra (NAVARRO, et al., 2007). Em caso de detecção de um desvio da faixa, o volante ou o banco podem vibrar para despertar o motorista de um possível estado de sonolência. Ou ainda, ao identificar uma violação do limite de velocidade, o pedal do acelerador, poderia vibrar suavemente, ao que o motorista tenderia a responder controlando de forma mais cuidadosa a velocidade do veículo (ADELL et al., 2007).

\subsubsection{Tecnologias}

A interface háptica tem sido usada em diversas áreas da ciência. Na medicina, o uso dos chamados phantoms permitiu a execução de cirurgia à distância uma vez que os operadores, ao movimentar as ferramentas simuladas ligadas ao aparato eletrônico, recebem um retorno mecânico sempre que a ferramenta real entra em contato físico com a superfície de um objeto (WAGNER; HOWE; STYLOPOULOS, 2002).

Para aplicações em que uma percepção fina de tato e textura é necessária, há equipamentos disponíveis no mercado que fazem uso de um complexo arranjo de motores para proporcionar uma suave percepção do objeto simulado, como o dispositivo Phantom Omni, que torna possível tocar e manipular objetos virtuais. Para as aplicações em que não há necessidade de um retorno tão minucioso, as técnicas utilizadas são mais simples. Em simuladores de direção, a percepção de rigidez do volante é resultado de uma aplicação de campo magnético à barra de direção metálica numa intensidade tal que o movimento desta gera uma força no sentido contrário. 
No caso dos alertas vibratórios, uma das soluções é usar um pequeno motor Direct Current (DC) com rotor ligeiramente desbalanceado. Ao se requisitar um movimento do dispositivo, o sistema vibra numa intensidade proporcional à velocidade de giro do rotor. Essa técnica é a mais comumente usada para implementar a função vibratória dos celulares.

\subsubsection{Vantagens da interface háptica}

De acordo com o estudo de Navarro et al. (2007), o uso de interfaces hápticas para sistemas de alerta ao motorista, além de favorecer o diagnóstico da situação, contribui para a realização da ação desejada de forma ainda mais incisiva, ao guiar o motorista rapidamente para a tomada da ação.

Para a transmissão de informações do carro para o motorista a percepção háptica se apresenta como uma interface interessante ao aliviar o sobrecarregado recurso visual de mais entradas, para as quais não haveria capacidade de processamento. Segundo Wickens e Hollands (2000), é aparente que o ser humano consegue dividir sua atenção melhor entre canais de percepção desassociados, como é o caso da visão com o tato e também do tato com a audição.

\subsubsection{Desvantagens da interface háptica}

Em um ambiente carregado de estímulos mecânicos e motores - movimentação do volante, vibrações naturais do veículo, aceleração e frenagem - o uso de um dispositivo de vibração pode ser confundido com outras entradas hápticas às quais o motorista está submetido. Além disso, o acionamento desnecessário, o falso-alarme, pode gerar irritação e perda de confiança no sistema de alerta.

Uma vez que o acionamento de um estímulo mecânico constante seria por demais perturbador ao motorista, a única maneira de usá-lo é por meio de ativações temporárias. Neste caso, entretanto, corre-se o risco de o motorista não perceber o evento por, temporariamente, não estar em contato físico com a interface - volante ou pedal - ou percebê-lo equivocadamente uma vez que a percepção táctil em 
algumas regiões do corpo humano é menos sensível, por exemplo, nas costas, onde há contato com o banco, do que em outras (BEAR; CONNORS; PARADISO, 2001).

\subsection{Interfaces sonoras}

A interação do ser humano com os sons à sua volta é fundamental para sua locomoção e para a identificação de obstáculos e de ameaças que o circundam. Nesta seção, é descrito como as informações sonoras se relacionam com o ser humano no interior de um veículo. São apresentadas as informações que o motorista obtém por meio do canal sonoro, algumas tecnologias para geração e captação do som são descritas e são discutidas as vantagens e desvantagens do uso da interface sonora do carro.

\subsubsection{Informações sonoras}

Na direção do veículo, o motorista está em constante interação com os sons que são gerados ao seu redor, interna e externamente ao veículo. O condutor encontra na sua percepção auditiva dados que lhe permitem reconhecer a configuração espacial dos veículos nas regiões em que não há contato visual direto.

No interior do veículo, diversos dispositivos geram sons que interagem com 0 motorista. O mais tradicional deles é o rádio, que proporciona conforto durante o ato da direção ao entreter os passageiros e o motorista. Como é pormenorizado na seção sobre som, as informações que o rádio disponibiliza são tanto verbais quanto não verbais e podem interferir na interpretação que motorista tem do ambiente externo ao carro. A reprodução, no rádio, de sons que imitam ruídos típicos do trânsito como buzinas e alarmes pode gerar confusão e ocasionar acidentes.

Outra interação sonora fundamental que acontece no carro é a identificação por parte do motorista de estados específicos do seu carro. O barulho gerado pelo motor pode indicar a necessidade de uma troca de marchas e o ruído proveniente das pastilhas de freio quando essas estão desgastadas é proposital e sugere a necessidade de troca desse componente. 
Adicionalmente às formas de interação sonora descritas acima, novas interfaces sonoras no veículo têm se popularizado. O uso de celular no veículo é autorizado pelo Contran quando se utilizam os alto-falantes como interface de reprodução, o chamado viva-voz, e quando o microfone é afixado no veículo, não demandando do motorista manuseio do aparelho celular. Interfaces de reconhecimento de voz para entradas de comandos ao carro, como acionamento de funções e configurações específicas.

Em diversos carros em produção no Brasil, a interface sonora é utilizada também como sistema de alerta ao motorista. Em alguns modelos, sons característicos são acionados para avisar o acontecimento de situações reconhecidas como de risco, por exemplo, se o motorista abrir a porta enquanto a chave não foi retirada da ignição ou se o motorista está esquecendo-se de apagar as luzes externas do veículo. Para algumas variantes, é disponibilizado um alarme sonoro quando o veículo ultrapassa certa velocidade. Um dos acessórios veiculares que tiram proveito do som para alertar o motorista é o sensor de estacionamento, que produz um som diferenciado de acordo com a proximidade de um obstáculo traseiro, indicando ao motorista a necessidade de interromper a manobra.

\subsubsection{Tecnologias}

Para a reprodução dos alarmes sonoros no interior do veículo tipicamente são utilizados alto-falantes de baixa potência e frequência limitada. Alguns desses trabalham na frequência de ressonância de $2 \mathrm{KHz}$ ou $4 \mathrm{KHz}$, onde sua resposta em amplitude é otimizada. Para padrões sonoros simples são utilizados os buzzers, cuja limitação em amplitude e frequência é mais severa que nos alto-falantes, utilizados quando se deseja uma qualidade melhor no som.

São comumente encontrados nos veículos os alto-falantes utilizados para reprodução do som do rádio, os quais são, muitas vezes, aproveitados como interface para funções secundárias, como a reprodução de voz proveniente do celular. Muitos rádios disponibilizam uma interface para controle do volume na saída no caso se deseje sobrepor seu som com as informações vindas de outro dispositivo. 
Não é permitido pelo Denatran o uso de fones de ouvido pelo motorista durante a direção por acreditar que a possível obstrução dos sons à sua volta seja prejudicial à sua percepção do ambiente ao seu redor (DENATRAN, 1997).

Suied et al. (2005) revelam que diferentes padrões sonoros são interpretados pelo ser humano com diferentes percepções de urgência e, baseando-se em princípios de acústica e semiótica, propõem metodologias para projeto de interfaces sonoras automotivas.

\subsubsection{Vantagens da interface sonora}

A percepção sonora humana é um dos sentidos fundamentais para a proteção pessoal, pois, ao captar sons vindos de qualquer direção, não apresenta regiões de não cobertura, como a visão. A capacidade do ser humano de reagir em um pequeno espaço de tempo a entradas provenientes do canal auditivo se coloca como uma vantagem fundamental dessa forma de interação. Conforme Suied et al. (2005), o som é capaz de produzir uma alta percepção de urgência no usuário, contribuindo para casos em que é necessário chamá-lo à atenção rapidamente.

Segundo Sodnik et al. (2008), o uso de interfaces auditivas no carro se justifica pelas características de flexibilidade e escalabilidade, variando de simples earcons e ícones audíveis a complexas interfaces de fala. Isso a torna uma boa alternativa para seu uso predominante em domínios móveis.

A percepção espacial apurada que pode ser gerada com o processamento do som é um benefício da interface sonora pouco aproveitado nos dispositivos eletrônicos presentes nos veículos.

\subsubsection{Desvantagens da interface sonora}

Durante o ato da direção, a reprodução de sons no veículo pode levar o motorista a confundir se o som que ele escuta foi gerado pelo dispositivo eletrônico ou se foi produzido pelo ambiente externo. Por esse motivo, há que se ter um cuidado especial no projeto dos sons a serem reproduzidos no interior do veículo. 
Quando o som é usado como sistema de alarme, sua falsa ativação pode representar para o motorista um distúrbio capaz de provocar irritação e de interferir na qualidade da direção.

No ambiente consideravelmente ruidoso no veículo, é possível que um sinal sonoro temporário seja interpretado erroneamente por conta da interferência causada pelos ruídos espúrios do carro e do ambiente circundante.

\subsection{Carga de trabalho}

De acordo com Wickens e Hollands (2000), uma tarefa pode incorporar múltiplos estágios de processamento de informação e é definida por um objetivo específico. $O$ objetivo da tarefa dirigir é manter o carro centralizado na faixa em uma determinada velocidade sem colisão. Vários canais perceptuais podem ser usados para atingir tal objetivo, e os vários estágios de seleção e execução das respostas são críticos tanto quanto os estágios dos canais de percepção.

Segundo Wickens e Hollands (2000), um dos principais mecanismos de processamento humano quando se discute o desempenho em uma dada tarefa é a característica de demanda de recursos da tarefa. Diz-se que uma tarefa é mais simples ou mais automatizada quando um menor emprego de recursos é suficiente para obter um desempenho alto na tarefa. Quando é necessária uma utilização maior de recursos para o mesmo nível de desempenho, diz-se que a tarefa é difícil ou não automatizada.

Processos humanos automatizados são formados na base de mapeamentos consistentes entre estímulos e alguma categorização adicional, e eles são rápidos, acurados e relativamente sem consumo de recursos. É importante ressaltar que o fator automatização levado em conta na característica de demanda de recursos de uma tarefa é dinâmico, ou seja, uma tarefa pode demandar muitos recursos inicialmente, mas, com o aprendizado e a prática, passar a demandar poucos recursos do operador. 
Young e Stanon (1997) concluem em seu trabalho que a introdução de novas tecnologias que se propõem a absorver parte da carga de trabalho do motorista pode, na verdade, deteriorar seu desempenho em vez de melhorá-lo. Isso pode ocorrer, porque, no caso de ser necessário retomar o controle do veículo, o motorista sofre uma demanda instantânea tão acentuada que não é capaz atender, resultando em uma colisão.

Ao se lidar com o tema carga de trabalho, é importante que sejam feitos levantamentos qualitativos e quantitativos do esforço necessário para o cumprimento de certas tarefas, são as chamadas predições. Apesar de ser desejável a predição da carga de trabalho e do desempenho antes do projeto, é geralmente essencial se medir a carga de trabalho de sistemas já existentes em algum estágio do desenvolvimento da solução. Ao avaliar qualquer sistema ou operador, deve-se sempre examinar primeiro o desempenho no sistema de interesse, como a entrada de dados no computador, desvios de direção da faixa central ou compreensão do aprendizado a partir de certo método de instrução (WICKENS; HOLLANDS, 2000).

A imposição de uma tarefa secundária como medida dos recursos ou capacidades residuais não utilizados na tarefa primária é uma técnica muito utilizada na pesquisa sobre carga de trabalho. Supõe-se que o desempenho na tarefa secundária seja prejudicado conforme o aumento na demanda que a tarefa primária impõe. Sendo assim, medições do desempenho na tarefa secundária possibilitam uma compreensão da demanda que a tarefa primária requisita.

Métodos adicionais de avaliação das questões relacionadas à carga de trabalho e desempenho existem, tais como medidas fisiológicas: variabilidade da pulsação, diâmetro da pupila e acompanhamento visual; e medições subjetivas das mais variadas dimensões.

\subsection{Alocação e chaveamento entre tarefas}

Um sujeito pode dividir seu tempo entre uma tarefa automática e uma que demande recursos com uma eficiência muito alta se ele receber um treinamento para desviar seus recursos da tarefa automática (WICKENS; HOLLANDS, 2000). Há, entretanto, 
um custo para chavear entre tarefas uma consequente tendência de continuar executando uma tarefa de menor prioridade por mais tempo do que o ideal para evitar o chaveamento, caso surja uma tarefa de maior prioridade.

O estudo de Kuaja (2009) investigou a influência da estrutura do menu usado no software de um dispositivo móvel no desempenho do motorista, em termos de divisão do seu tempo. Conclui-se que uma apresentação de ícones estruturada em forma de grids distribuídos de forma não sistemática no display conduz a um chaveamento entre a tarefa da direção e da manipulação do dispositivo menos eficiente que no caso de uma apresentação dos ícones em lista.

Os processos envolvidos na atuação do motorista durante a direção podem ser divididos em três estágios: percepção, memória de trabalho e resposta. Segundo Wickens e Hollands (2000), os recursos utilizados para memória perceptual e de trabalho ou atividade cognitiva parecem ser os mesmos, e estes são funcionalmente separados daqueles responsáveis pela seleção e execução de respostas.

Nos estágios da percepção e da memória de trabalho, há evidências de que as modalidades de percepção auditiva e visual conseguem apresentar uma distribuição de divisão de recursos mais fácil do que em modalidades concorrentes que demandam o mesmo canal como fonte de informação. Além disso, diz-se que os códigos espacial e verbal, presentes no conteúdo das informações em processamento, também apresentam relativa independência quanto à necessidade de recursos. É aparente que o ser humano possa por vezes dividir atenção entre os olhos e o ouvido melhor que entre duas informações auditivas. Isto é, a divisão do tempo inter-modos é melhor que a divisão intra-modos (WICKENS; HOLLANDS, 2000).

Independência semelhante se observa na eficiência com que os controles manual e vocal podem ser conduzidos na resposta aos estímulos. Esse fator indica que a resposta manual tem normalmente uma natureza espacial enquanto a resposta vocal é essencialmente verbal. No veículo, esse fato pode ser facilmente constatado na facilidade com que um motorista experiente conversa com os passageiros e, ao mesmo tempo, utiliza os pés e as mãos para conduzir o automóvel. 
Em adição à distinção entre as modalidades visual e auditiva de processamento, há boas evidências, segundo Wickens e Hollands (2000), de que dois aspectos do processamento visual, referentes à visão focal e periférica, parecem provir de recursos separados no sentido de (a) suporte a gestão eficaz do tempo, (b) serem caracterizadas por estruturas cerebrais qualitativamente diferentes e (c) serem associadas a tipos qualitativamente diferentes de processamento de informação.

A relativa independência dos canais de percepção visual e auditivo justifica em grande parte o uso de interfaces sonoras no carro, uma vez que a maioria das informações de que o motorista precisa para conduzir são provenientes do seu canal visual, o que o sobrecarrega. Em especial, nas situações de perigo, onde há proximidade excessiva entre os carros ou quando o veículo se encontra em uma velocidade acima do permitido, o uso da interface visual para alerta ao motorista não devem ser a melhor opção, pois justamente nesses momentos, seus olhos estão atentos ao exterior do carro e não devem ser desviados para o interior por conta de um alarme.

O aumento da eficiência na gestão do tempo pelo aumento da similaridade resulta das circunstâncias em que uma propriedade comum no display, um arranjo mental, uma rotina de processamento ou um mecanismo de temporização podem ser cooperativamente divididos no serviço de duas tarefas que são executadas concorrentemente. O funcionamento dos pedais de aceleração e embreagem do carro é um exemplo de similaridade quanto à forma de atuação, o que facilita a ação do motorista concomitantemente nos dois atuadores.

A capacidade de gestão do tempo também é relacionada à experiência do usuário da tarefa. Wikman, Nieminen e Summala (1998) mostram que motoristas mais experientes conseguem controlar dispositivos como rádio e celular enquando dirigem de forma mais eficiente. Em comparação com os motoristas mais experientes, foram encontradas evidências de que os motoristas com menos experiência desviam o olhar da estrada por mais tempo. Os mais experientes também são mais capazes de ajustar melhor a divisão do seu tempo de acordo com as diferentes situações de tráfego. 
Os assuntos tratados nos últimos itens, carga de trabalho e alocação e chaveamento de tarefas fornecem subsídios para se discutir a usabilidade no contexto automotivo. Os conceitos apresentados anteriormente permitem a avaliação da usabilidade no automóvel, tema fundamental para a compreensão do impacto no comportamento do motorista no emprego de novas tecnologias no interior veicular.

\subsection{Usabilidade no automóvel}

A incorporação de itens de entretenimento e de comunicação no interior do carro coloca em questão a influência que tais aparatos têm sobre a qualidade da direção. Norman (2007) critica a adição, no interior do veículo, de equipamentos eletrônicos que possam distrair o motorista, uma vez que seu manuseio durante a direção, mesmo que não recomendável, passa a ser inevitável dada à presença de tais dispositivos.

Simonds (2003) discute como a implementação de soluções de comunicação difere da indústria automotiva para a indústria de computadores pessoais. De fato, a especificidade que as soluções automotivas devem ter para atrair a atenção dos consumidores e o ambiente em que são usadas cada uma dessas soluções são fatores fundamentais para se entender que a interação no carro deve ser analisada de forma cuidadosa, visando sempre à redução da carga de trabalho do motorista.

A relação do motorista com os controles que seu carro disponibiliza é diretamente ligada à maneira como ele resolve os problemas que aparecem dinamicamente à sua volta. A ocorrência de uma freada brusca do veículo à frente, enquanto o motorista ajusta a sintonia do seu rádio, por exemplo, pode resultar em um acidente, por conta do atraso na reação do motorista, devido à tarefa secundária. Há veículos, inclusive, em que os controles para configuração do rádio se encontram nos botões ao lado do volante ou até fazem parte deste, como um elemento para reduzir a desatenção do motorista e melhorar a ergonomia da tarefa da direção.

Pesquisas têm sido realizadas sobre a tendência dos sistemas de segurança de deixarem de ser passivos para se tornarem ativos e sobre as implicações que a excessiva automação tem nos controles automotivos. Krum et al. (2008) ressaltam a 
importância de se manter o ser humano no ciclo de controle do veículo, atento à sua carga cognitiva, impedindo-a de se tornar por demais leve, a ponto de ser difícil trazê-lo de volta à atenção no caso de uma emergência, e tampouco demasiadamente pesada, com informações irrelevantes ou excessivas.

Há estudos, inclusive, que buscam obter do motorista aspectos afetivos que permitam ao sistema eletrônico reconhecer a melhor maneira de interagir com o motorista. Jones e Jonsson (2005) propõem a análise de aspectos da fala do motorista para reconhecer o seu estado emocional e propiciar uma resposta adequada do veículo. 


\section{O SOM TRIDIMENSIONAL}

O som é uma importante forma de comunicação entre os seres humanos e entre o ser humano e as coisas que o circundam. O som tridimensional é, em especial, fonte de estudos que procuram tirar proveito de seu potencial de localização espacial. Nesta seção são apresentados os conceitos de som e de som espacial, bem como uma revisão da utilização do som em dispositivos de realidade virtual. Ao final, são discutidos os requisitos da utilização do som como um sistema de alerta e os recursos computacionais que podem ser usados como ferramenta para tratamento do som.

\subsection{O som}

Neste item são apresentados alguns conceitos básicos sobre o som de maneira geral como sua constituição, suas características e a forma como o ser humano o percebe.

\subsubsection{Conceitos gerais}

O som é um fenômeno físico caracterizado pela oscilação de pressão resultante da propagação de uma onda mecânica por um meio sólido, líquido ou gasoso. Como qualquer onda, pode ser caracterizada por seus atributos de frequência, velocidade, intensidade, amplitude, período, comprimento de onda e direção (BONJORNO, 1993).

A velocidade do som no ar a uma temperatura de $20^{\circ} \mathrm{C}$ ao nível do mar é de aproximadamente $340 \mathrm{Km} / \mathrm{h}$. Essa velocidade é fundamental a característica de alguns efeitos como o eco e a percepção auditiva espacial. Os demais atributos são os que de fato caracterizam a percepção humana do som. A seguir são detalhados os parâmetros altura, intensidade e timbre. 


\subsubsection{Altura}

A altura de um som é determinada pela sua frequência e também pode ser denominada de tom. $\mathrm{O}$ aspecto grave ou agudo de um som é identificado tendo por base a sua altura. Em tons mais graves a frequência é menor do que em tons mais agudos.

O ser humano percebe apenas a faixa de frequências sonoras que vai de até 20 a $20000 \mathrm{~Hz}$, segundo Cutnell e Johnson (1998).

\subsubsection{Intensidade}

A intensidade de um som é determinada pela pressão da onda sonora ou ainda pela energia concentrada em uma determinada área. O processo de percepção humano segue uma escala logarítmica, cuja medida é feita tipicamente em decibéis $(\mathrm{dB})$ ou Watts $/ \mathrm{m}^{2}$. É a intensidade do som que caracteriza se o usuário conseguirá compreender a mensagem sonora. A exposição contínua a sons de níveis altos ( $>85 \mathrm{~dB}$ ) ou a exposição mesmo que temporária a níveis altíssimos de intensidade (>160dB) causam danos permanentes à audição humana (CUTNELL; JOHNSON, 1998).

\subsubsection{Timbre}

O timbre de um som é a característica derivada dos diversos harmônicos que acompanham o tom principal. É o timbre que permite a diferenciação de sons com intensidade e altura semelhantes, mas provenientes de instrumentos musicais distintos. Quando os sons adicionais ao tom principal não têm uma coerência harmônica com este, ou seja, apresentam uma distorção, o som resultante é chamado de ruído e é desagradável ao ser humano (CUTNELL; JOHNSON, 1998).

\subsubsection{O sistema auditivo}

A audição é um elemento de grande importância para o ser humano na sua capacidade de aprendizado e de relacionamento com outras pessoas. O processo 
envolvido na captação e interpretação dos sons por parte do ser humano passa por conhecimentos de acústica, fisiologia e psicologia. A acústica foi tratada enquanto se discutiam os conceitos básicos do som. A psicologia do som é discutida ligeiramente ao apresentarmos o conceito de som espacial. Nesta seção, fala-se sobre a fisiologia do sistema auditivo humano.

A orelha humana é constituída por três partes: a orelha externa, a orelha média e a orelha interna. Cada uma dessas partes tem um propósito diferente na captação do som e na conversão dos estímulos mecânicos em sinais elétricos transmitidos ao cérebro (JUNIOR; SASSON, 1998).

A parte externa protege a orelha média, impedindo a ocorrência de danos ao tímpano e funciona como uma antena, ao direcionar as ondas sonoras ao canal auditivo, por meio do qual, o som atinge a orelha média movimentando o tímpano na mesma frequência do som. Nesse ponto, a energia mecânica da onda sonora é convertida em vibração do tímpano.

Da orelha média fazem parte o tímpano, os ossículos móveis - martelo, bigorna e estribo - e a tuba auditiva. O propósito dos ossículos é amplificar o som e, por meio da bigorna, transmitir as vibrações à orelha interna, provocando compressões no líquido aquoso que preenche a cóclea chamado endolinfa.

$\mathrm{Na}$ orelha interna, se encontram as células sensoriais auditivas, que quando estimuladas pela pressão que a endolinfa exerce sobre a membrana da cóclea, geram o impulso nervoso levado pelo nervo auditivo ao cérebro, o qual, por um processo complexo, interpreta os sinais construindo a imagem sonora (JUNIOR; SASSON, 1998).

\subsection{O som espacial}

Segundo Sherman e Craig (2003), o ser humano é capaz de perceber a tridimensionalidade dos sons por conta de uma variedade de características destes. A diferença de tempo que o som leva para atingir cada ouvido, a diferença de amplitude do sinal entre os ouvidos, o eco, a reverberação, a filtragem do som pelos 
materiais que este transpõe, a oclusão de certas frequências e a filtragem imposta pela própria orelha externa são algumas das características que o cérebro leva em conta para perceber a posição da fonte sonora.

Teoricamente, pode-se elaborar uma fórmula matemática que transforme um sinal sonoro mono em estéreo, reproduzindo em cada um dos seus dois canais, o sinal audível para cada uma das orelhas. Essa função é chamada Função de Transferência Relativa à Cabeça ou Head Related Transfer Function (HRTF) (SHERMAN; CRAIG, 2003). Pela complexidade de se levantar teoricamente essa função, o que se faz tipicamente é um estudo empírico utilizando-se um modelo de cabeça que represente da melhor forma possível a constituição craniana do ser humano e, com dois microfones independentes, é registrada a captação sonora de cada ouvido.

Essa função de transferência é única para cada indivíduo, uma vez que o formato das orelhas, a distância inter-auricular e os elementos constitutivos do crânio são diferente de pessoa para pessoa. De acordo com Belotti et al. (2002), o uso de HRTF não individualizadas implica em uma resolução de percepção direcional limitada a $30^{\circ}$, enquanto que a capacidade humana para distinguir a localização do som pode chegar a $2^{\circ}$ na posição frontal, $10^{\circ}$ na posição lateral e $6^{\circ}$ para sons vindos de trás.

Muitos estudos têm sido feitos na intenção de se entender a forma como o ser humano percebe os sons à sua volta, seja em ambientes reais ou virtuais (DOERR et al., 2007). Keyrouz F.; Diepold e Keyrouz S. (2007) dizem que, como o ser humano adquire $80 \%$ das informações de forma visual, a computação gráfica é, há muito tempo, atrativa para o projeto de ambientes imersivos. Komata (2003) cita que, como a manipulação sonora atraiu a atenção do público, o processamento tridimensional do som tende a ocupar um espaço importante quanto à imersão em vários jogos eletrônicos e aplicações computacionais em combinação com imagens. 


\subsection{Sistemas sonoros de realidade virtual}

A simulação de ambientes imersivos usados para treinamento nas áreas aeronáutica, automobilística e naval envolve tipicamente equipamentos extremamente complexos e caros com soluções específicas para o modelamento visual e motor (DOERR et al., 2007).

Tipicamente, alguns treinamentos essenciais para pilotos, como familiarização com o cockpit e tarefas de orientação custam às empresas muitas horas nos simuladores de vôo. Tais tarefas podem, entretanto, ser exercidas nos Sistemas de Treinamento Virtuais, que são semelhantes aos simuladores de vôo, mas com sistemas imersivos reconfiguráveis, que são projetados para proverem os requisitos tridimensionais que essas tarefas demandam (DOERR et al., 2007).

O uso de estímulos auditivos nos ambientes virtuais construídos para treinamentos de situações dinamicamente complexas é fundamental, pois fazem parte da percepção obtida pelo operador e o auxiliam de forma muito impactante na sua tomada de decisão.

Dispositivos de áudio de alta fidelidade são muito mais baratos que dispositivos de vídeo e isso pode ser explorado na criação de ambientes virtuais. De acordo com Sherman e Craig (2003), a adição de som de alta qualidade pode ajudar a criar uma experiência de imersão fidedigna mesmo quando a qualidade da apresentação visual deixa a desejar.

A grande preocupação das pesquisas atuais sobre a utilização do som tridimensional nas experiências de imersão é o gasto computacional necessário para se reproduzir fielmente os modelos mais completos atualmente existentes do sistema auditivo e da percepção auditiva humana.

O esforço computacional necessário para a criação e o processamento de sons tridimensionais é, ainda assim, muito menor do o utilizado para a recriação de cenário visual tridimensionais. Por outro lado, os ouvidos humanos são muito mais sensíveis a interrupções e inconsistências do que os olhos. É importante, portanto, 
que o som gerado seja computado rapidamente e em exato sincronismo com a informação visual (SHERMAN; CRAIG, 2003).

Em ambiente imersivos, esse tratamento do som deve ser feito em tempo real, mas para a avaliação da percepção auditiva e de algoritmos em teste, pode-se trabalhar com sinais calculados previamente e, nestes casos, a preocupação com o cálculo em tempo real perde o sentido.

A geração do som pode ser caracterizada em basicamente dois métodos: de referência absoluta ou de referência relativa à cabeça do usuário. Na geração de referência absoluta, o posicionamento da fonte de som não se altera com o movimento do usuário, permanece fixa. É o caso da utilização de alto-falantes espacialmente posicionados para a produção de um ambiente imersivo. A falta de necessidade de um rastreamento da posição relativa do usuário é uma vantagem desse método. Para grandes públicos, o uso alto-falantes é mais aplicável por não serem necessários numerosos aparatos individuais, como é o caso de salas de cinema. Por outro lado, não se tem controle sobre o que acontece com o som entre a sua geração, nos alto-falantes, e os ouvidos dos usuários.

Com o uso de fones de ouvido, o controle sobre os sons recebidos individualmente pelos ouvidos é muito maior do que com o uso de alto-falantes, permitindo uma correlação mais precisa entre a percepção espacial e o modelamento computacional. Por outro lado, há a necessidade de identificar a posição do usuário, pois, como a movimentação de sua cabeça é acompanhada pelo fone de ouvido, a percepção é de que a fonte de som também se move, o que geralmente não é desejável em um ambiente imersivo.

Há também pesquisas como as de Keyrouz F.; Diepold e Keyrouz S. (2007) e Valin; Michaud e Rouat (2006) que estudam como se determinar automaticamente o posicionamento da fonte de som a partir do som obtido por dois ou mais microfones distribuídos espacialmente, com o intuito de se reproduzir em robôs de vigilância a percepção auditiva humana, por se reconhecer que a audição é um sentido fundamental na proteção por permitir a identificação e localização de objetos fora da região de cobertura do sentido visual. 


\subsection{O som como sistema de alerta}

Muitos dos trabalhos voltados ao projeto de monitores auditivos, como Baldwin (2007) e Ulfvengren (2007), trabalharam com os parâmetros sonoros para identificar as características que tornavam um determinado som mais eficaz e natural na transmissão de informações urgentes.

Suied et al. (2005) apontam o uso de dois tipos de som não verbal como forma de alertar o usuário para algum fato relevante: os ícones audíveis e os earcons. Os ícones audíveis são sons que procuram imitar algum equivalente na vida cotidiana. Eles representam ações, processos ou objetos por similaridade. O segundo tipo de som é o earcon, introduzido para representar sons que não encontram um equivalente no cotidiano e são figurativos, se identificam com um objeto ou ação somente se o usuário for treinado para isso.

No estudo feito por Adell et al. (2007), fazendo uso de sons verbais e não-verbais para alertar ao motorista de uma distância muito pequena para o veículo da frente, conclui-se que os sons verbais como "Alerta, mantenha a distância" tiveram uma avaliação melhor do que os sons não-verbais, como o som de uma freada brusca.

Suied et al. (2005) concluem que muitos dos dispositivos de interface sonora utilizados no ambiente veicular não são satisfatórios por não conseguirem que o usuário diferencie alertas de perigo, alarmes de descuido e sons meramente informativos. É proposta uma abordagem voltada à acústica e à semiótica para projetar sons mais adequados.

A norma Human Factor Design Standard (2003) diz que sistemas de alerta sonoro devem:

a. Alertar o usuário para o fato de que um problema existe,

b. Informar o usuário da prioridade e da natureza do problema,

C. Guiar a resposta inicial do usuário, e

d. Confirmar prontamente se a resposta do usuário corrigiu o problema. 
Das abordagens adotadas pelos trabalhos acima descritos e pelas diretivas da norma citada, pode-se observar o quão complexo é o projeto de um alerta sonoro que seja eficaz na tarefa de chamar o usuário à atenção de um determinado fato. Os resultados dos experimentos já feitos (BALDWIN, 2007), (ULFVENGREN, 2007), (DOERR et al., 2007) podem, entretanto, auxiliar na definição de parâmetros sonoros adequados, como posição, tipo, frequência, timbre e volume do som. Além disso, o uso de monitores multimodais pode ajudar no atendimento das diretivas que a norma cita. 


\section{A PERCEPÇÃO DE VIBRAÇÃO}

O sistema sensorial somático é o responsável pelas sensações de toque, de calor, de frio e de dor e, para captar tais sentidos, faz uso de mecanorreceptores, de termorreceptores e de nociceptores, receptores especializados distribuídos ao longo da pele cada um com uma função no sistema sensorial somático. Nessa seção são detalhadas características dos mecanorreceptores, os responsáveis pela sensação de toque com ênfase na percepção de vibração.

Muitos trabalhos têm investigado como usar a percepção háptica no domínio automotivo como um sistema de assistência ao motorista (HAAS, 2007; RIENER; FERSCHA, 2008; SUZUKI; JANSSON, 2003; ADELL et al., 2007). Adell et al. (2007) consideram três alternativas de feedback háptico para avaliar qual é a melhor maneira de alertar o motorista por uma força no pedal do acelerador. Haas (2007) afirma algumas boas práticas para integrar áudio e tato em monitores multimodais, as quais são apresentadas ao final desta seção.

De acordo com Riener (2009), o estímulo vibro-tátil pode trazer o motorista a vários níveis de atenção, nos quais o motorista dedica uma quantidade maior ou menor de seus recursos a uma determinada tarefa. $O$ experimento mostrado em Riener e Ferscha (2008) demonstra que o posicionamento dos elementos vibro-táteis no assento do motorista é eficiente na comunicação entre veículo e motorista.

\subsection{A percepção de toque}

Segundo Bear; Connors e Paradiso (2001), a percepção de toque começa na pele, que é composta pela epiderme e pela derme e que é responsável pelo nosso mais direto contato com o mundo. $O$ tato é o sentido que nos permite identificar a posição, a textura, a agudez e a duração do toque.

Por meio do toque, o ser humano percebe acontecimentos à sua volta sem que seja necessária a ativação da sua visão. É, portanto, uma função de vital importância 
para as relações entre os seres humanos e entre o ser humano e as coisas à sua volta.

Os mecanorreceptores são as entidades capazes de responder eletricamente a deformações mecânicas. Eles possuem no seu interior ramos de axônios desmielinizados com canais iônicos mecanossensíveis. A abertura desses canais e a consequente transmissão elétrica pelos axônios é ativada pela extensão ou dobra do mecanorreceptor (BEAR; CONNORS; PARADISO, 2001).

Os mecanorreceptores da pele são quatro: os corpúsculos de Meissner, de tamanho aproximado $0,1 \mathrm{~mm}$, ficam na epiderme em regiões mais externas como nas impressões digitais dos dedos; os discos de Merkel, compostos por uma terminação neural e por uma célula não-neural epitelial, as terminações de Ruffini, que medem cerca de $1 \mathrm{~mm}$ e podem ser achados tanto em regiões com pelo quanto sem e, finalmente, os corpúsculos de Pacini, ligeiramente maiores que as terminações de Rufini e são localizados na derme, a camada mais interna da pele (BEAR; CONNORS; PARADISO, 2001).

A classificação dos mecanorreceptores se faz observando-se duas características de seu funcionamento. O primeiro é o tamanho de seu campo receptor, o que significa qual a região da pele que um mecanorreceptor isolado de um determinado tipo pode perceber. O segundo é o seu tipo de adaptação: lenta, quando o canal iônico continua ativado mais um tempo longo após a deformação ou rápida, quando a resposta ao estímulo mecânico ocorre rapidamente e cessa mesmo que o estímulo persista.

A Tabela 1 elenca essas características para os quatros mecanorreceptores discutidos aqui. Essas características são fundamentais na compreensão das funções específicas de cada mecanorreceptor apresentadas abaixo. 


\begin{tabular}{|c|c|c|c|}
\hline & & \multicolumn{2}{|c|}{ Tamanho do campo receptor } \\
\hline & & Pequeno & Grande \\
\hline \multirow{2}{*}{ Adaptação } & Rápida & $\begin{array}{c}\text { Corpúsculos de } \\
\text { Meissner }\end{array}$ & $\begin{array}{c}\text { Corpúsculo de } \\
\text { Pacini }\end{array}$ \\
\hline & Lenta & Discos de Merkel & $\begin{array}{c}\text { Terminações de } \\
\text { Ruffini }\end{array}$ \\
\hline
\end{tabular}

Tabela 1 - Características dos quatros mecanorreceptores (adaptado de Bear; Connors e Paradiso (2001))

Mecanorreceptores compõem a maior parte do sistema somático sensorial; dentre esses, os corpúsculos de Paccini são os mais estudados (BEAR; CONNORS; PARADISO, 2001). Sua ágil resposta a pressão e rápida adaptação, somadas ao grande campo receptor, fazem desses receptores os mais sensitivos à vibração.

No caso dos corpúsculos de Paccini, a conformação espacial, composta por gomos concêntricos como em uma cebola, funciona como seletora dos estímulos mecânicos, ou seja, o deslizamento dos gomos um com relação ao outro filtra movimentos muito rápidos e movimentos muito lentos, ativando os canais iônicos nas mudanças de pressão, respondendo especialmente bem na faixa de freqüência de vibração de $200 \mathrm{~Hz}$ a $300 \mathrm{~Hz}$

\subsection{Tipos de estímulos hápticos}

As características do sistema sensorial somático apontadas acima implicam em três maneiras de se tirar proveito desse canal de percepção humano, são elas: 0 estímulo elétrico, excitando diretamente as fibras nervosas, o estímulo térmico e o estímulo mecânico.

Riener (2009) apresenta três tipos de interface que possibilitam interferência mecânica: a pneumática, a piezo-elétrica e a vibro-tátil, dando ênfase a essa última interface como a maneira normalmente mais segura e prática de tirar proveito do sentido somático do usuário, no caso o motorista.

Adell et al. (2007) propuseram três tipos de resposta háptica no pedal do acelerador: baixa contra-força $(30 \mathrm{~N})$, alta contra-força $(46 \mathrm{~N})$ e uma pulsação vibratória de $3 \mathrm{~mm}$ e 
9N, para alertar ao motorista que a velocidade excedeu o limite ou que a distância para o carro adiante está muito pequena.

Suzuki e Jansson (2003) descobriram que a vibração transmitida pelo volante ao motorista, como alerta de que o veículo está saindo da faixa, resulta em maior eficiência na tomada de decisão, especialmente quando o motorista desconhece o significado dos alertas. Acredita-se, neste caso, que o modelo mental do motorista associa diretamente a vibração no volante com o desvio do carro. Navarro et al. (2007), inclusive, chegaram à conclusão de que a adição de um alerta sonoro à vibração do volante não resultou em melhor desempenho do motorista.

O estímulo vibratório é muito utilizado em aparelhos de celular e em outros dispositivos móveis, por chamarem à atenção o usuário sem gerar distúrbio ambiente em locais em que um sinal audível seria inadequado.

O estímulo háptico pode também atuar em conjunto com outros tipos de estímulos sensoriais, como no caso dos displays multimodais. Haas (2007) discute a necessidade de se integrar os sentidos áudio e tátil em sistemas a serem usados em ambientes desafiadores, com o argumento de que, se utilizados conjuntamente, os sinais táteis e audíveis podem se complementar um ao outro em situações em que o nível de ruído ou o alto grau de vibração mascaram um dos sentidos. 


\section{O SISTEMA PROPOSTO}

A inserção no veículo dos modernos dispositivos de entretenimento e as influências internas e externas sob as quais o motorista é submetido resultam em perda de atenção e em um atraso na reação do motorista, quando essa é requisitada. Nesses casos, acredita-se que o uso de sistemas de alerta multimodais resulta em tempos de reação mais curtos quando o motorista precisa ter o controle sobre o veículo.

Um dos mais frequentes casos de acidentes na estrada é a oclusão de ameaça do campo visual do motorista. Segundo o DNIT (2008), cerca de 9\% dos acidentes no Brasil ocorrem devido a fechadas laterais. Nesses casos, os espelhos retrovisores dão ao motorista o retorno visual de certa área na traseira, mas ainda fica uma zona cega, onde outro veículo pode não ser detectado.

Para dar suporte ao motorista nos casos em que os espelhos retrovisores não indicam a presença de outro veículo ou quando o motorista está desatento, propõese estudar a situação em que um sistema identifica que outro veículo está em rota de colisão com o carro em que o sistema está instalado e alerta o motorista por meio de estímulos hápticos e auditivos. Alto-falantes e elementos vibratórios no assento são acionados, indicando a direção do perigo e possibilitando uma resposta rápida do motorista.

\subsection{Trabalhos correlatos}

O uso de estímulo sonoro para ajudar motorista no controle do carro está sob estudo da sociedade acadêmica. Verbist (2009) comprovou que o retorno auditivo tridimensional é eficaz no auxílio ao motorista para manter o carro na faixa em condições de baixa visibilidade. Usando dois alto-falantes e controlando a frequência, a amplitude e a localização percebida do som, Verbist (2009) mediu o desvio lateral médio em um ambiente de simulação sem nenhum retorno visual e concluiu que monitores auditivos são capazes de auxiliar motorista em pistas curvas sem clareza nas informações visuais. 
Adicionalmente, pesquisas sobre o uso de som tridimensional no interior automotivo (BELLOTTI et al., 2002) descobriram que a exploração dos canais auditivos pode melhorar a dirigibilidade especialmente em condições de baixa visibilidade e que o som é capaz de prover informações sobre orientação espacial mesmo no interior veicular.

No caso de uma detecção de colisão iminente, o tempo de reação do motorista deve ser ainda menor do que no caso de uma saída inesperada da faixa. Estudos como Suzuki e Jansson (2003) e Rossmeier, Grabsch e Döring (2005) têm discutido se os alertas sonoros somente chamam o motorista à atenção, delegando ao sentido visual o reconhecimento da ação mais apropriada a ser tomada ou se a percepção auditiva, por si só, conduz a uma ação.

Riener (2009) sugere que o uso do canal sensorial háptico poderia representar uma grande melhoria na efetividade dos sistemas avançados de assistência ao motorista, uma vez que o retorno vibro-tátil pode ser altamente eficaz quando necessário atrair a atenção do motorista, consequentemente reduzindo os tempos de reação.

O trabalho de Fitch et al. (2007) utiliza estímulos auditivos tridimensionais e hápticos direcionais para ajudar o motorista a direcionar sua atenção para a direção de uma possível colisão e conclui que o uso adicional de alerta hápticos no assento reduz em até $257 \mathrm{~ms}$ o tempo de resposta e aumenta a porcentagem de identificações corretas de direção de $32 \%$ para $84 \%$ se comparado ao uso somente do alerta auditivo. 


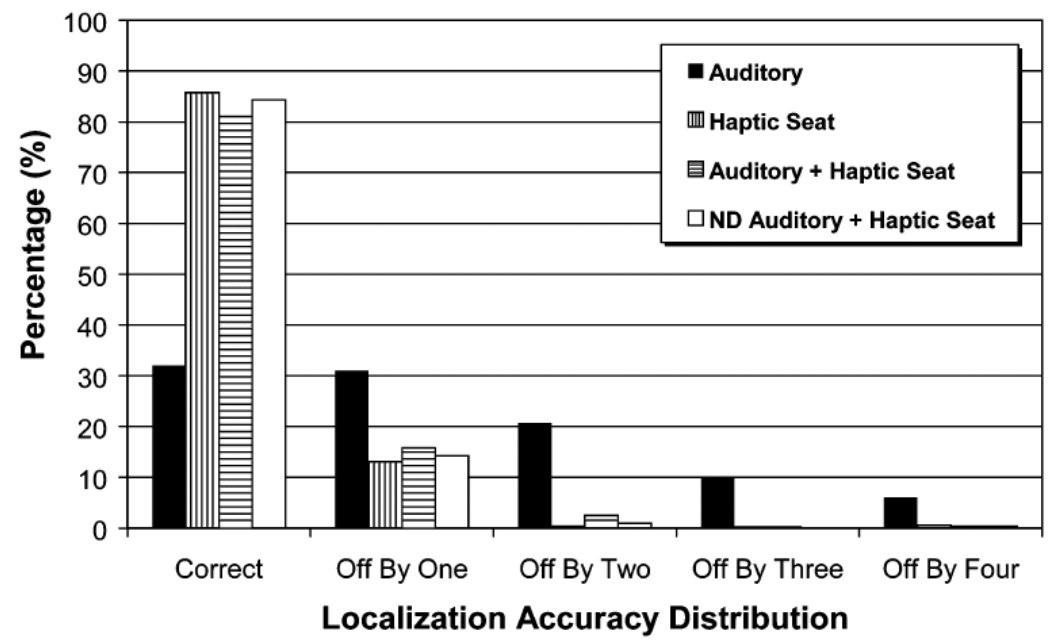

Gráfico 1 - Resultados obtidos em pesquisa sobre alertas multimodais. Fonte: Fitch et al. (2007)

O sistema proposto por Fitch et al. (2007) se assemelha ao sistema apresentado a seguir, mas a metodologia usada na avaliação de Fitch et al. apresenta fragilidades notórias, uma vez que o sujeito participante do teste é requisitado a responder verbalmente qual a direção do alerta (frontal, direita, traseira/direita, etc.) enquanto dirige um veículo. Neste caso, influenciam as medidas mecanismos diferentes daqueles envolvidos na tomada de decisão do motorista, como girar o volante e pisar no freio. Os tempos medidos não são, portanto, tempos de reação do motorista para tomar uma ação dado que um alerta ocorreu, mas sim tempos de reação verbal em resposta a estímulos auditivos e hápticos que poderiam ser tomados em qualquer outra situação. A direção do veículo tem somente o papel de manter o motorista ocupado e atento a uma tarefa enquanto os alertas são apresentados de forma descontextualizada.

Além disso, as medições dos tempos de reação são feitas por um moderador que pressiona teclas em um computador, e não de forma automática por um sistema de medição, o que pode levar a imprecisões consideráveis.

O uso conjugado dos canais auditivo e háptico é o conceito para o sistema de alerta de colisão proposto aqui. Nas próximas seções, é apresentada uma explicação do conceito, seguido por uma descrição da configuração experimental montada para avaliação do conceito e, finalmente, é discutida a metodologia usada na avaliação. 


\subsection{O sistema proposto}

O sistema proposto neste trabalho é um dispositivo de alerta constituído de dois altofalantes posicionados próximos à cabeça do motorista e de elementos vibratórios posicionados no assento. Baseado em informações capturadas por sensores ao redor do carro e na tendência de desvio da faixa, o sistema ativa os alertas, como indicado na Figura 3.

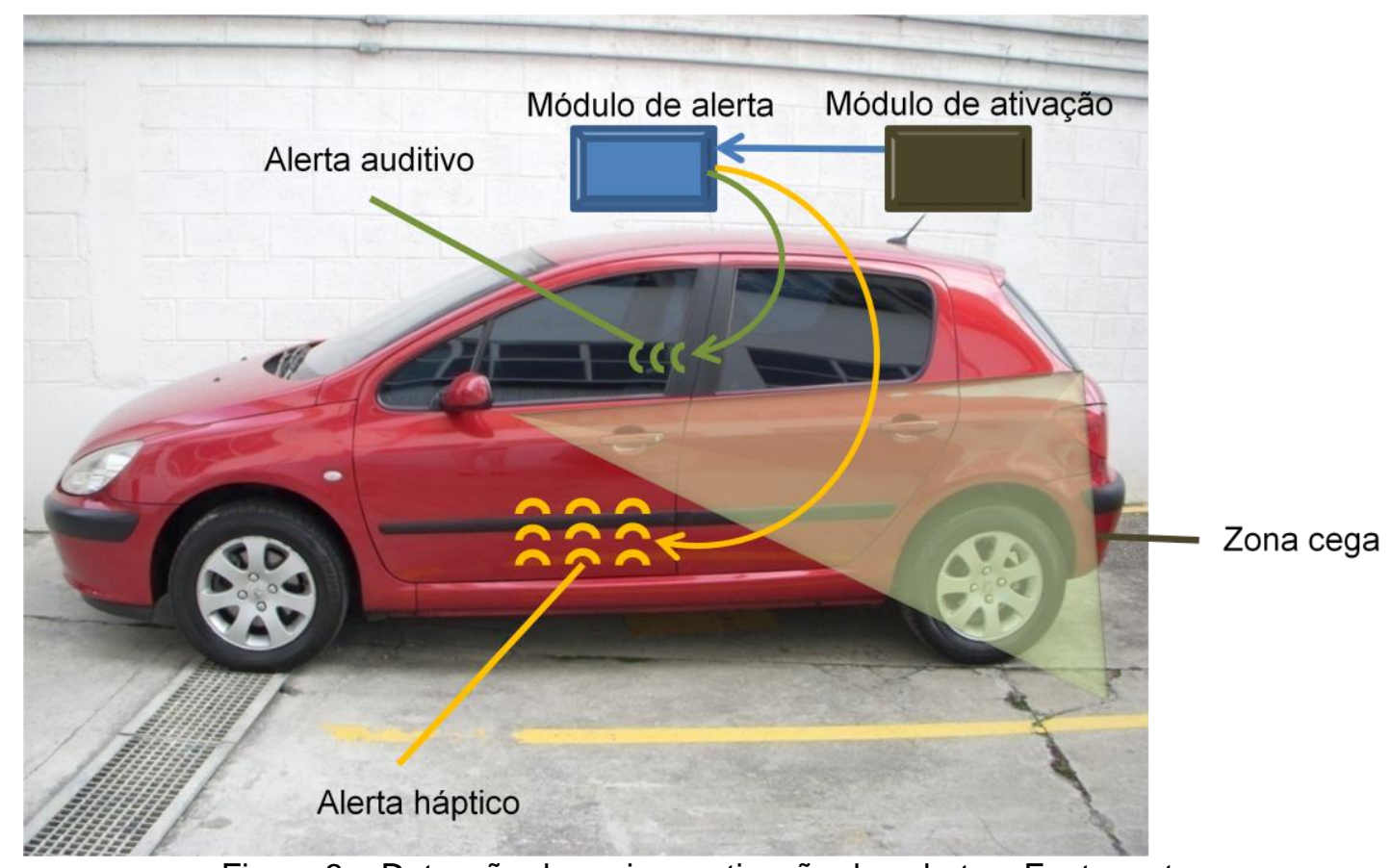

Figura 3 - Detecção de perigo e ativação dos alertas. Fonte: autor

O módulo de ativação é responsável por identificar a condição de perigo e informá-la ao módulo de alerta, responsável pela ativação dos estímulos. Se o carro está a ponto de colidir com outro carro identificado no seu lado esquerdo, os elementos vibratórios na esquerda do assento vibram e os alto-falantes produzem um sinal sonoro que representa um objeto em movimento vindo do lado esquerdo. Quando a ameaça vem do lado direito, a vibração é ativada no lado direito do assento e a orientação do som emula uma aproximação pela direita.

O alerta sonoro é gerado por alto-falantes posicionados em ambos os lados do assento do motorista. Como é proibido o uso de fones de ouvido durante a direção, opta-se por alto-falantes posicionados próximos ao motorista, por esses indicarem um claro posicionamento espacial, por conduzirem ao nível de atenção desejado e 
por serem adequados à percepção de urgência necessária. Os parâmetros de amplitude, timbre e altura devem ser tais que gerem um efeito tridimensional indicando a aproximação do outro veículo por meio das técnicas de realidade virtual apresentadas na seção 3.3 .

Uma vantagem dessa abordagem é que a geração do som não está atrelada à cabeça. Esse método é chamado de referência absoluta (SHERMAN; CRAIG, 2003) e, neste caso, não há necessidade de rastrear a cabeça do motorista, o que simplifica o algoritmo e agiliza a saída da estimulação audível. Segundo Sherman e Craig (2003), uma vez que os ouvidos humanos são altamente perceptivos a distúrbios, interrupções e inconsistências no som é muito importante que o som gerado seja processado rapidamente e em exato sincronismo com a informação visual.

Uma forma de onda pulsada é gerada na frequência de $1 \mathrm{KHz}$, pois, como especificado em Bellotti et al. (2002), o uso de um tom contínuo pode trazer problemas na identificação da espacialidade. Além disso, o som gerado sugere a aproximação de um objeto pela região lateral / traseira. A ativação dos elementos vibratórios é feita em sincronia com o estímulo sonoro, usando a frequência de $250 \mathrm{~Hz}$, na qual é obtida a melhor resposta táctil.

A Figura 4 mostra as características e o posicionamento dos elementos vibratórios e dos alto-falantes. A escolha do assento do motorista para posicionar os elementos é justificada pelo trabalho de Riener (2009), no qual foi utilizado feedback háptico no assento para transmitir ao motorista alertas de navegação e se concluiu que essa modalidade de interação é elegível para aliviar o motorista de distração. 


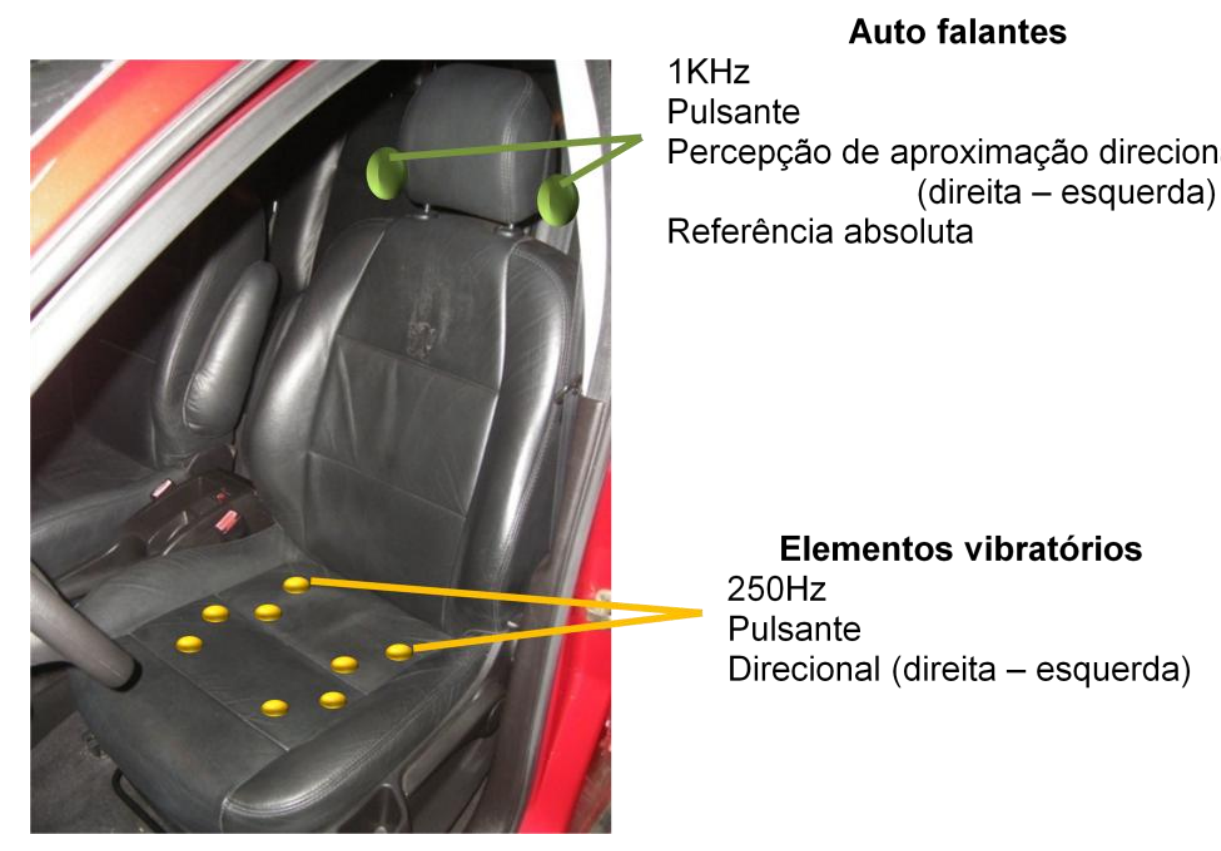

Figura 4 - Elementos vibratórios e sonoros no assento do motorista. Fonte: autor

Para avaliação do sistema proposto, um ambiente de simulação foi montado e dois experimentos foram conduzidos. O primeiro experimento tem por objetivo estudar os mecanismos envolvidos na tomada de decisão do motorista ao se deparar com uma situação em que sua intervenção é requisitada com urgência devido a uma possível colisão lateral com outro veículo. O segundo experimento tem por objetivo avaliar o uso de um dispositivo de alerta vibratório e auditivo para chamar a atenção do motorista para o fato de que uma colisão lateral é iminente.

Neste trabalho, não é desenvolvido o sistema de detecção do perigo, o qual deverá usar sensores ao redor do veículo e implementar um algoritmo para identificar quando o veículo está em rota de colisão com outro. Sabe-se que tal módulo é possível de ser implementado, uma vez que a indústria aeronáutica já faz uso de sistemas equivalentes ao apresentado aqui. Por exemplo, o Airbone collision avoidance system (ACAS) é um sistema aeronáutico que emite ondas e analisa as reflexões para identificar se há alguma outra aeronave em rota de colisão (WILLIAMS, 2004). O próprio sistema de auxílio a estacionamento, que usa sensores para identificar obstáculos, pode ser usado como referência para o módulo de detecção. Naturalmente que esses sistemas existentes teriam de ser profundamente estudados e adaptados para que o módulo de detecção implemente uma estratégia robusta e segura de identificação do perigo. 
O sistema de alerta como apresentado nesta seção não é de fato desenvolvido neste trabalho. É implementado um protótipo baseado nas especificações do sistema e é montado um ambiente de teste que permita a avaliação deste protótipo. Os experimentos realizados nesse ambiente e as características do protótipo desenvolvidos são apresentados na seção a seguir. 


\section{OS EXPERIMENTOS}

Os experimentos objetivam estudar como o ser humano reage ao ser submetido a alertas multimodais durante a direção de um veículo. O sistema em desenvolvimento visa alertar o motorista de que uma colisão lateral pode ser iminente, otimizando o tempo de reação ao tirar proveito dos canais perceptuais menos demandados durante a direção: o tato e a audição.

A necessidade de serem realizados dois experimentos é proveniente da percepção de que se deveria, antes de desenvolver o protótipo de teste, entender qual seria a reação típica dos participantes quando deparados com uma situação de quase colisão no simulador. Percebeu-se também que haveria a necessidade de estabelecer um grupo de controle, que participaria da avaliação sem fazer uso dos alertas auditivo e hápticos propostos. Isso permitiu uma comparação entre o desempenho dos participantes com e sem o sistema de alertas.

O primeiro experimento realizado objetiva fazer uma avaliação de natureza qualitativa do comportamento dos motoristas ao se depararem com a situação problema deste trabalho, na qual um obstáculo lateral traseiro é identificado e, consequentemente, uma ação é requisitada com urgência. É preciso saber se a primeira ação após a identificação do problema é frear ou girar o volante para desviar do perigo ou alguma outra ação. Precisa-se identificar também em que intensidade cada uma dessas ações é exercida. Os resultados desse experimento são usados também como parâmetro de comparação para os resultados do segundo experimento.

O segundo experimento objetiva avaliar se a adição dos alertas sonoro e háptico de fato melhoram e até que ponto influenciam o desempenho do motorista na presença e na ausência da informação visual. As contribuições individuais do alerta auditivo e do alerta háptico são avaliadas também.

Esses três estímulos são alternadamente apresentados ao motorista de forma aleatória, alternando de alerta na esquerda para alerta na direita. $O$ primeiro 
estímulo da sequência é alternado entre sujeitos e as sequências de estímulos aplicadas a cada sujeito são independentes.

Os dados de controle do volante e dos pedais, bem como a posição e a velocidade do veículo são armazenados para análise posterior. O parâmetro a ser medido e discutido é resultante do primeiro experimento, no qual é identificada a ação esperada. Os padrões de estímulo apresentados são gravados em sincronismo com o tempo medido para permitir uma avaliação do tempo de reação obtido em cada padrão.

\subsection{Papeis nos testes}

Além dos participantes dos testes, somente o moderador, papel exercido pelo autor, atuou no teste. Seu papel foi de informar e instruir os participantes, além de operar o software de coleta de dados e acompanhar o registro dos dados. Eventualmente, foi necessário dialogar com o participante ao longo do teste.

Após a instrução de como os testes deviam ser executados, não houve interferência direta do moderador sobre as ações do participante. Durante a execução das tarefas, o moderador pôde auxiliar o participante em algumas situações:

- O participante não compreendeu o objetivo da tarefa;

- O participante estava com dificuldades no manuseio básico dos equipamentos;

- O sistema aparentava estar com algum problema;

\subsection{Processo do teste}

\subsubsection{Seleção dos participantes}

Os participantes foram convidados através de lista de e-mail e convites pessoais para amigos, colegas e conhecidos. Aos convidados que aceitaram participar, foi solicitado que realizassem o agendamento da data e horário desejado. Em ambos os experimentos, no momento do agendamento foi feita uma triagem para selecionar os candidatos com mais de 2 anos de carteira de motorista, declarando o sujeito ter 
dirigido constantemente nos últimos 2 anos, ao menos 2 horas de direção por semana.

\subsubsection{Esclarecimento aos participantes e consentimento}

O Termo de Consentimento Livre e Esclarecido é o documento que expressa e memoriza que o participante foi informado plenamente e concordou livremente em participar da pesquisa. O TCLE documenta ainda o compromisso da equipe de pesquisa com a privacidade do participante e a confidencialidade dos dados coletados.

Esse documento foi feito em duas vias, sendo que uma fica com o participante e a outra, assinada pelo participante, é arquivada pelo pesquisador.

A aplicação do TCLE foi realizada de acordo com os seguintes passos:

- O esclarecimento ao indivíduo quanto à pesquisa foi realizado pelo moderador do teste;

- Todos os participantes da pesquisa receberam, no primeiro momento da pesquisa, informações completas e pormenorizadas sobre as razões da pesquisa e sobre as atividades das quais participariam. Os participantes foram informados dos benefícios ressultantes da pesquisa e do potencial incômodo que poderia resultar da participação, uma vez que não foram identificados riscos para o participante.

Em seguida, foram informados de que:

- Não precisavam responder a qualquer questão que não desejassem responder;

- Poderiam desistir a qualquer momento de participar da pesquisa, sem precisar declarar o motivo;

- Os dados de teste seriam tratados de forma a não revelar a identidade dos participantes;

- Os dados coletados poderiam ser veiculados apenas em relatórios técnicos, eventos didáticos e científicos, e nunca em mídias de massa;

- Não receberiam nenhuma remuneração pela participação, a menos de eventual ressarcimento de despesas. 
- Os pesquisadores poderiam ser contatados a qualquer momento nos endereços e telefones fornecidos, para questões relacionadas ao desenvolvimento da pesquisa.

Essas informações foram dadas verbalmente aos participantes pelo moderador do teste, que leu em voz alta a carta de apresentação e o TCLE, solicitando que o participante acompanhasse a leitura. Após a leitura:

- O moderador perguntou ao participante se entendeu cada item do termo e esclareceu melhor o participante caso ele não tenha entendido alguma parte.

- O moderador perguntou ao participante se ele concorda em participar da pesquisa e em assinar o TCLE.

- Se o participante não desejou participar da pesquisa, o moderador agradeceu e encerrou o protocolo.

- Se o participante declarou que concorda em participar da pesquisa, ofereceu-se o documento em duas vias, aguardou-se o tempo para a leitura, se necessário, e assinatura. O moderador entregou uma cópia para o participante e reteve a outra para arquivo.

\subsubsection{Questionário pré-teste}

Após a assinatura do TCLE, foi realizado o questionário a seguir com os sujeitos de forma a identificar a população participante dos testes. Procura-se com as questões desse questionário identificar qual a relação do desempenho do participante no simulador com sua experiência de direção, com sua experiência com jogos e com o uso de equipamentos eletrônicos no carro.

1) Há quanto tempo você dirige?

2) Quantas horas em média você dirige por semana?

- Menos de duas horas

- Entre duas e dez horas

- Mais de dez horas 
3) Quais os dispositivos eletrônicos existentes no veículo que você mais dirige?

- Rádio

- Ar condicionado

- Computador de bordo (consumo médio, autonomia,...)

- GPS - Navegador

- Câmbio automático

- Assistência sonora de estacionamento

- Head Up Display

- Outros

4) Você utiliza jogos de computador?
- Nunca
- Muito Raramente
- Todo mês
- Toda semana
- Todo dia

5) Que jogos?
- Jogos de corrida
- Jogos de luta
- Jogos de estratégia
- Jogos de dança
- Jogos musicais (Guitar Hero)
- Jogos de esportes
- Wii
- PS2
- PS3
○ Outros

As respostas às questões são anotadas e toda a conversa é gravada. 


\subsubsection{Treinamento nos dispositivos utilizados no teste}

Após o questionário pré-teste, o participante recebeu um rápido treinamento para se familiarizar com os dispositivos do teste. Por cerca de 5 minutos, o moderador explicou o funcionamento da simulação e dos dispositivos com os quais o participante interagiria. Após essa explicação, o participante teve 5 minutos para usar o equipamento no ambiente simulado sem que se começasse a coleta de dados. O participante recebeu os seguintes treinamentos:

- Manuseio do volante para fazer curva e para manter o veículo em uma reta

- Controle dos pedais de aceleração e de freio

- Significado das indicações visuais que apareceriam na tela de simulação

Para o segundo experimento, os participantes tiveram um treinamento adicional a respeito do significado dos estímulos vibratório e auditivo.

São descritos nas seções seguintes os testes realizados, bem como a população de participantes, os ambientes utilizados e os questionários feitos após o teste.

\subsection{Primeiro experimento}

No primeiro experimento, o participante teve de percorrer um circuito fechado de cerca de $10 \mathrm{Km}$ com curvas para a direita e para a esquerda, além de alguns aclives e declives. O carro pilotado pelo participante tem a cor vermelha. Ao passar por pontos pré-determinados do circuito, o simulador faz com que um carro de cor azul apareça atrás do carro vermelho distante cerca de $100 \mathrm{~m}$, e se aproxime velozmente às vezes pela direita, às vezes pela esquerda. Nos espelhos retrovisores emulados no simulador, o participante pode perceber a aproximação do carro azul, a menos quando o carro azul se encontra na zona cega do retrovisor.

O posicionamento da informação visual remete ao estímulo visual no espelho retrovisor que o motorista tem ao perceber um veículo na sua região lateral / traseira, simulando, assim, a situação em que o motorista deve tomar uma ação para evitar uma colisão lateral. 
O primeiro experimento se propôs a responder às seguintes questões:

Como reage o motorista na situação em que uma colisão lateral é iminente?

O motorista freia?

O motorista acelera?

O motorista esterça o volante?

Qual ação acontece primeiro?

Qual o tempo típico para cada reação?

\subsubsection{População do teste}

Para o primeiro experimento, foram feitos testes com 12 sujeitos, tendo por prérequisito, no mínimo, 2 anos de carteira de motorista, declarando o sujeito ter dirigido constantemente nos últimos 2 anos, ao menos 2 horas de direção por semana.

\subsubsection{Ambiente de simulação}

O ambiente de simulação para o primeiro experimento foi composto pelos seguintes equipamentos:

- 1 volante Leadership para jogo

- 1 conjunto de pedais (freio e acelerador) Leadership para jogo

- 1 projetor

- 1 computador

- 1 cadeira não-giratória para o participante

\subsubsection{Questionário pós-teste primeiro experimento}

Após a execução do primeiro experimento, foi realizado um questionário pós-teste, com as seguintes questões:

1) Como você avalia o ambiente de simulação?

- Péssimo

- Ruim

- Nem bom nem ruim

- Bom 
○ Excelente

- Não sei avaliar

2) O carro azul chamou-o à atenção?
- Absolutamente não
- Pouco
○ Muito
○ Não sei

3) Você acha que percebeu todas as vezes que o carro azul apareceu?
- Certamente sim, estava muito atento aos retrovisores
- Muito provavelmente sim
○ Muito provavelmente não
- Certamente não, estava distraído com outras tarefas.

4) Qual foi a sua reação quando o carro azul se aproxima?
- Girei o volante
- Desacelerei
- Acelerei
○ Freei
○ Não fiz nada

5) Qual a sua sugestão para melhorar o ambiente de simulação?

\subsection{Segundo experimento}

No segundo experimento, o participante percorreu a mesma pista, mas além dos estímulos visuais do primeiro experimento, recebeu também estímulos vibratórios e auditivos. Quando o carro azul se aproxima pela região traseira / esquerda, além do estímulo visual, ocorre uma vibração na parte esquerda do assento e um som é emitido no alto-falante à esquerda da cabeça do motorista. Quando o carro azul se 
aproxima pela região traseira / direita, ocorre uma vibração na parte direita do assento e um som é emitido no alto-falante à direita da cabeça do motorista. A aproximação do carro azul é feita de forma caótica, garantido-se sempre que ele tentará se chocar lateralmente ou fechar o outro veículo. Esse algoritmo de aproximação faz com que em algumas vezes, mas não em todas as vezes, o carro azul se aproxima por meio da zona cega. Esses dois casos não são diferenciados na coleta de dados.

O estímulo auditivo utilizado no experimento é direcional, podendo ser ativado pela direita ou pela esquerda. Esse alerta, entretanto, não possui todas as características tridimensionais especificadas para o sistema de alerta proposto, como a percepção de aproximação do som, pois a intenção com o experimento é fazer uma avaliação do conceito, e, nessa fase, o processamento do som tridimensional não está desenvolvido.

Os elementos vibratórios utilizados não vibram na freqüência ótima descrita na seção 4.1. São elementos retirados de aparelhos celulares, pois estes pareceram adequados à avaliação proposta nesses experimentos, em termos de intensidade e de freqüência. A aplicação desses elementos vibratórios foi avaliada antes dos experimentos por meio de um teste piloto, no qual somente os pesquisadores envolvidos participaram.

Neste experimento, os estímulos visuais, vibratórios e auditivos não estão sempre presentes em todos os comandos. Esses estímulos foram combinados ao longo do teste para que se possa estabelecer uma comparação entre os diferentes conjuntos de estímulos. Por exemplo, o participante se deparou com situações em que o assento vibrou do lado esquerdo e o som foi emitido à sua esquerda, mas em um próximo evento, ele se deparou com uma vibração à direita sem que nenhum som seja emitido.

O segundo experimento se propôs a responder às seguintes questões:

O alerta auditivo direcional ajuda o motorista?

O alerta vibratório direcional ajuda o motorista?

A conjunção dos alertas vibratório e auditivo tem efeito diferenciado? 
Qual o incômodo gerado pelos alertas?

\subsubsection{População do teste}

Para o segundo experimento, foram feitos testes com 23 sujeitos, tendo os mesmos pré-requisitos do primeiro experimento.

\subsubsection{Ambiente de simulação}

O ambiente de simulação para o segundo experimento foi composto pelos seguintes equipamentos:

- 1 volante Leadership para jogo

- 1 conjunto de pedais (freio e acelerador) Leadership para jogo

- 1 projetor

- 1 computador

- 1 assento

- 1 par de alto-falantes

- 1 rede de elementos vibratórios 


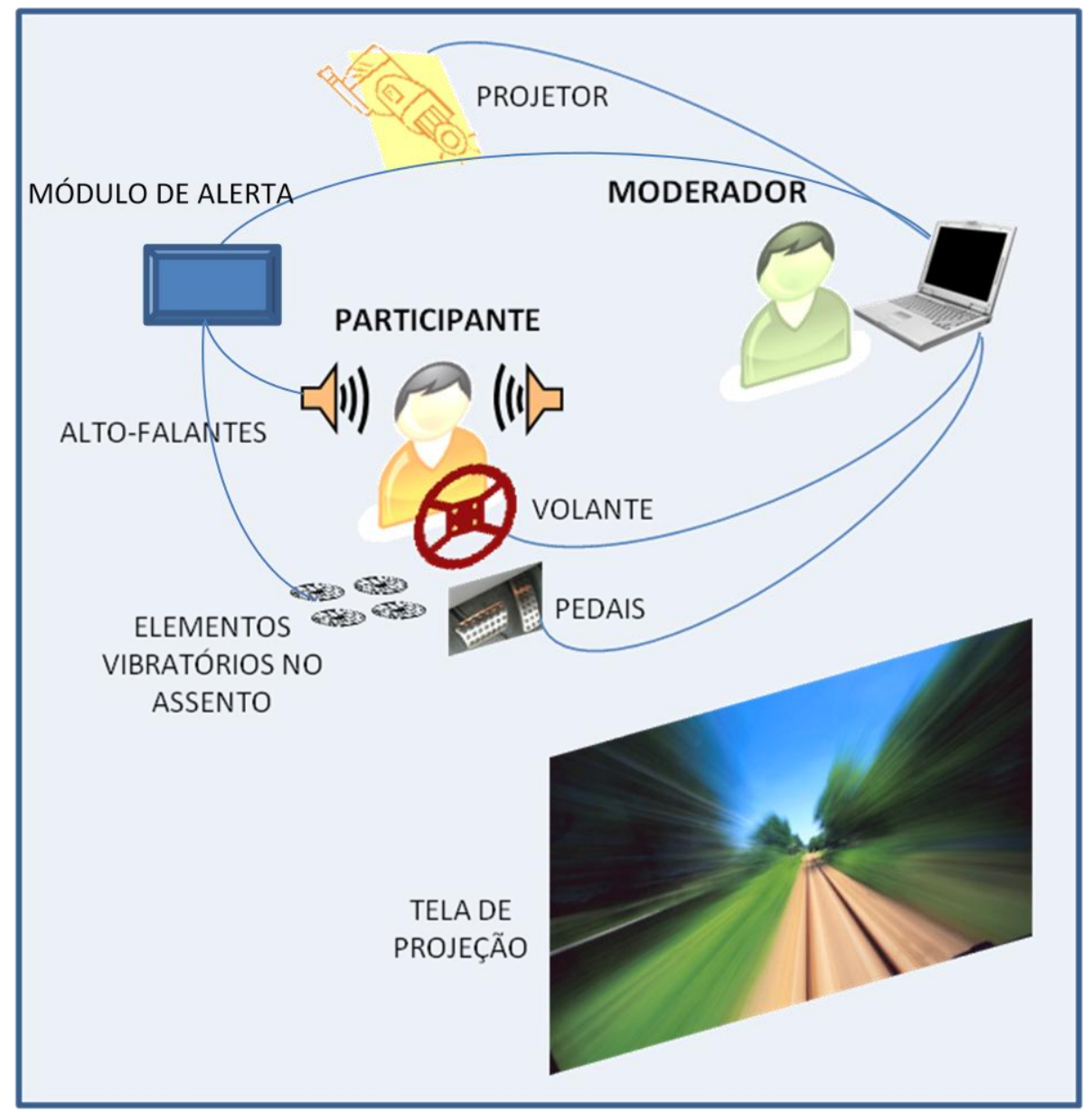

Figura 5 - Estrutura do ambiente de simulação. Fonte: autor

Na Figura 6 é possível ver a distribuição dos elementos no ambiente de simulação. Abaixo, o computador usado pelo moderador do teste e à direita, o projetor. Na parte esquerda, pode-se ver, a tela de projeção, o volante, os pedais e o assento. 


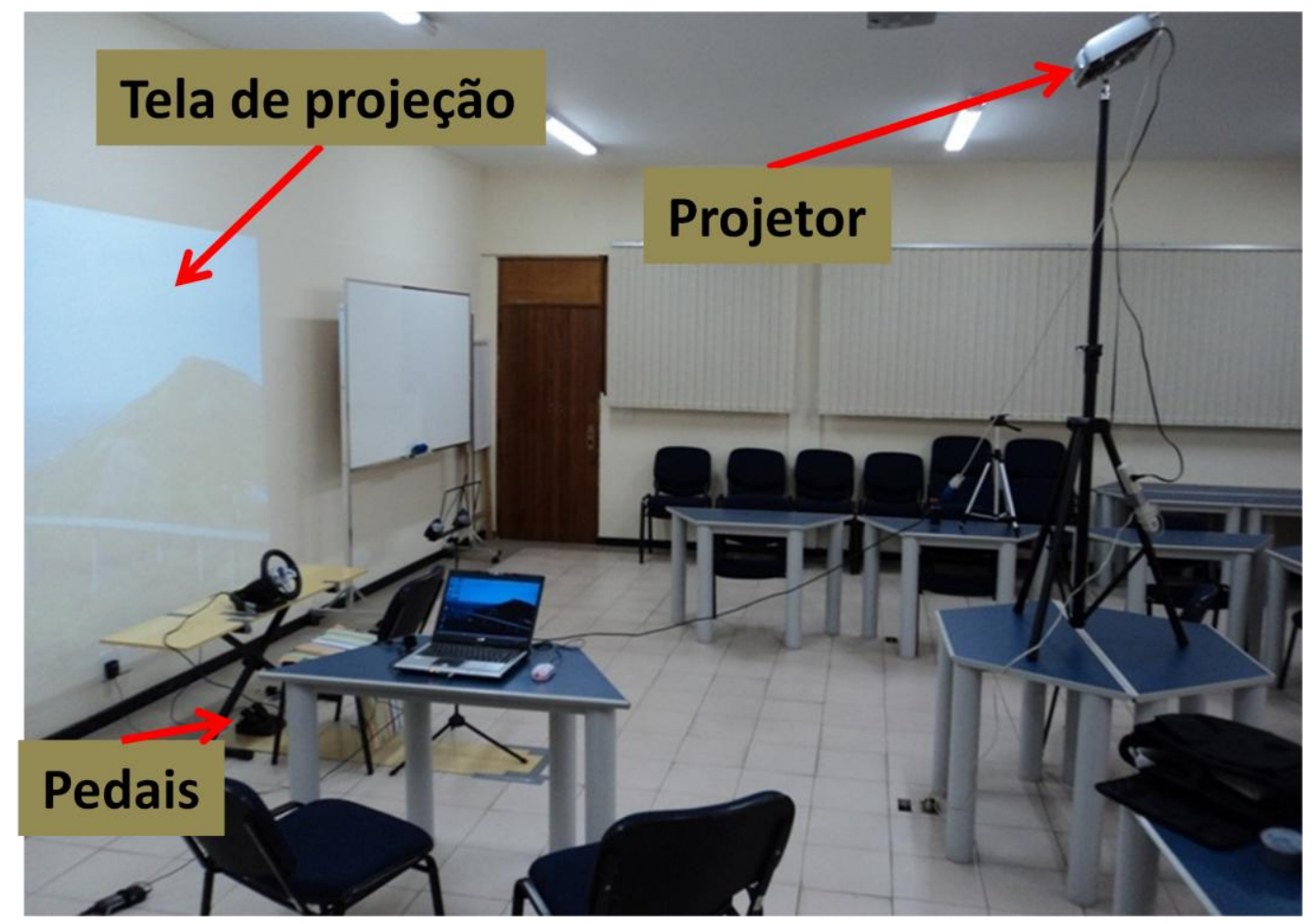

Figura 6 - Visualização do ambiente de simulação. Fonte: autor

\subsubsection{Questionário pós-teste segundo experimento}

Após a execução do segundo experimento, foi realizado um questionário pós-teste, com as seguintes questões:

1) Quão útil foi o estímulo auditivo para chamar a sua atenção?

(1 representa nada útil e 5 representa muito útil)

\section{( )1 ( )2 ( ) 3 ( ) 4 ( ) 5}

2) Quão útil foi a vibração do assento para chamar a sua atenção?

(1 representa nada útil e 5 representa muito útil)

\section{( ) 1 ( ) 2 ( ) 3 ( ) 4 ( ) 5}

3) Quão incômodo foi o estímulo auditivo?

(1 representa nada incômodo e 5 representa muito incômodo)

\section{( )1 ( )2 ( )3 ( )4 ( ) 5}

4) Quão incômoda foi a vibração do assento?

(1 representa nada incômodo e 5 representa muito incômodo)

( )1 ( )2 ( ) 3 ( ) 4 ( ) 5 


\subsection{Montagem do ambiente de simulação}

Para a montagem do ambiente de simulação da Figura 5, tomou-se como base o software Raydium 3D Game Engine, uma ferramenta livre e colaborativa para desenvolvimento de jogos. O jogo de corrida de carros ManiaDrive desenvolvido no Raydium 3D Game Engine foi adaptado para os fins dos experimentos aqui propostos.

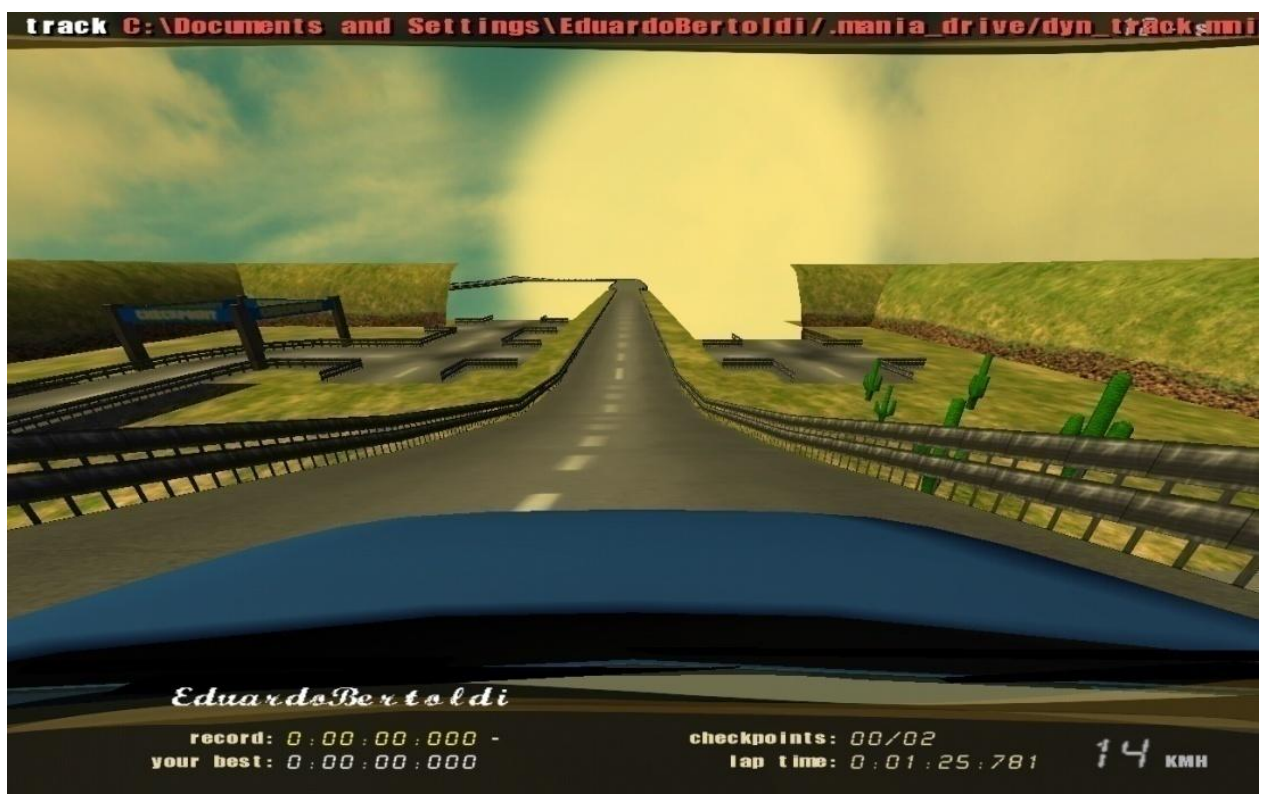

Figura 7 - Game Engine: Raydium / ManiaDrive. Fonte: autor

\subsubsection{Adaptações realizadas no ManiaDrive}

O jogo ManiaDrive já permitia a montagens de pista utilizando-se como elementos aclives, declives, curvas, retas, túneis e pontes. Inicialmente foi criada uma pista com circuito fechado com três curvas para a direita e três curvas para esquerda, conforme o layout mostrado na figura a seguir: 


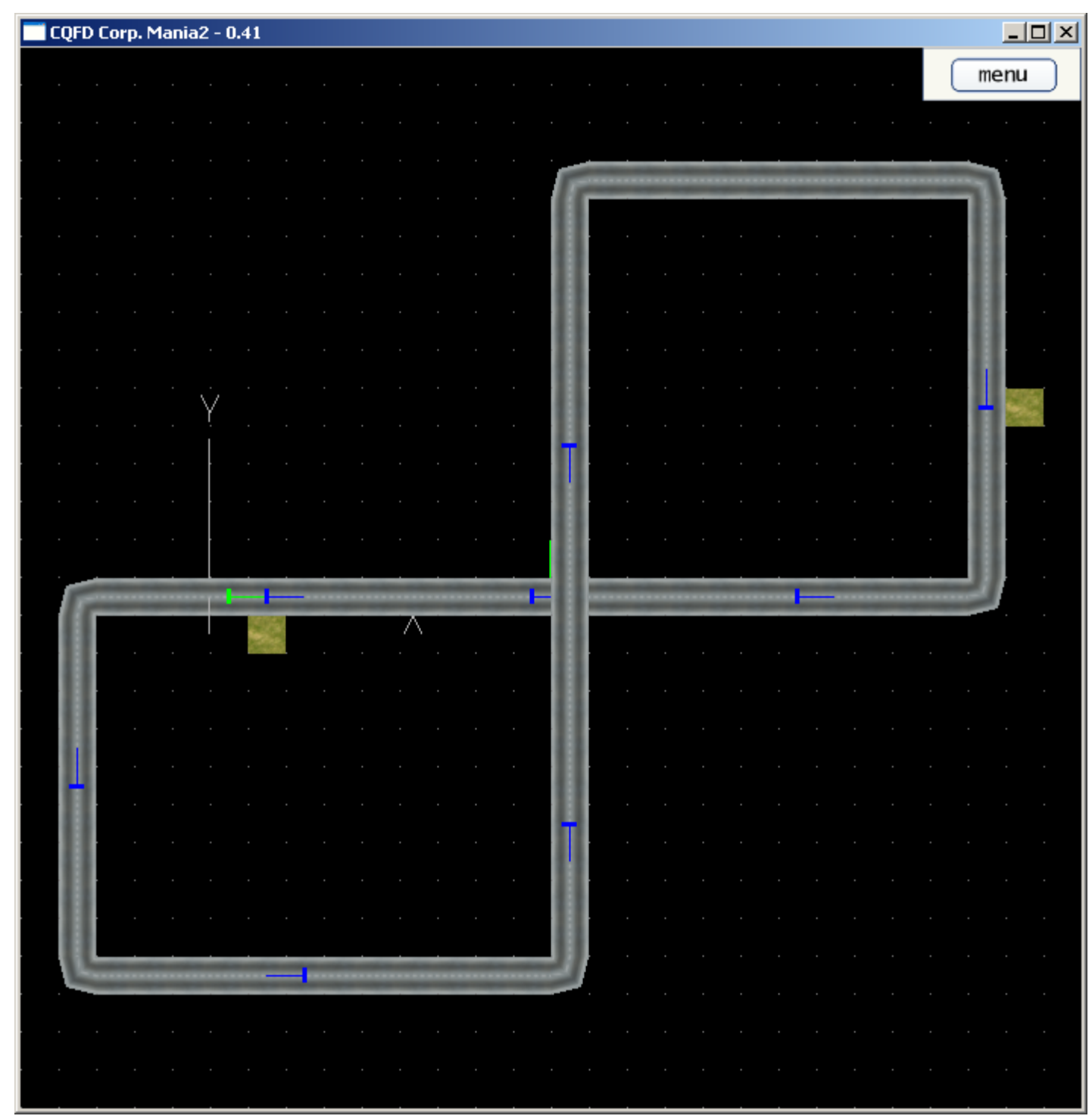

Figura 8 - Circuito fechado do ambiente de simulação. Fonte: autor

Após a criação da pista, fixou-se a visualização do participante para a posição de dentro do carro e configurou-se a cor do carro utilizado em vermelho. Criou-se um carro de cor azul que surge a cada vez que o carro vermelho passa pelas indicações em azul da pista da Figura 8. O carro azul surge sempre atrás do carro vermelho e na direita ou esquerda, de forma aleatória. Desenvolveu-se uma lógica de controle para que o carro azul persiga o carro vermelho procurando sempre colidir lateralmente ou dar uma fechada.

Conforme apresentado na seção 2.5, há evidências de que existe diferença no processamento da visão periférica e da visão focal. Por conta dessa diferenciação, acreditou-se ser importante reproduzir da forma mais fiel possível a percepção do 
motorista na situação acima. Para isso, foi desenvolvida também a apresentação de espelhos retrovisores com o uso de câmeras posicionadas nas laterais do carro vermelho e direcionadas para a parte traseira. A posição dos espelhos é mostrada na Figura 9. A figura ilustra uma aproximação do carro azul pela esquerda.

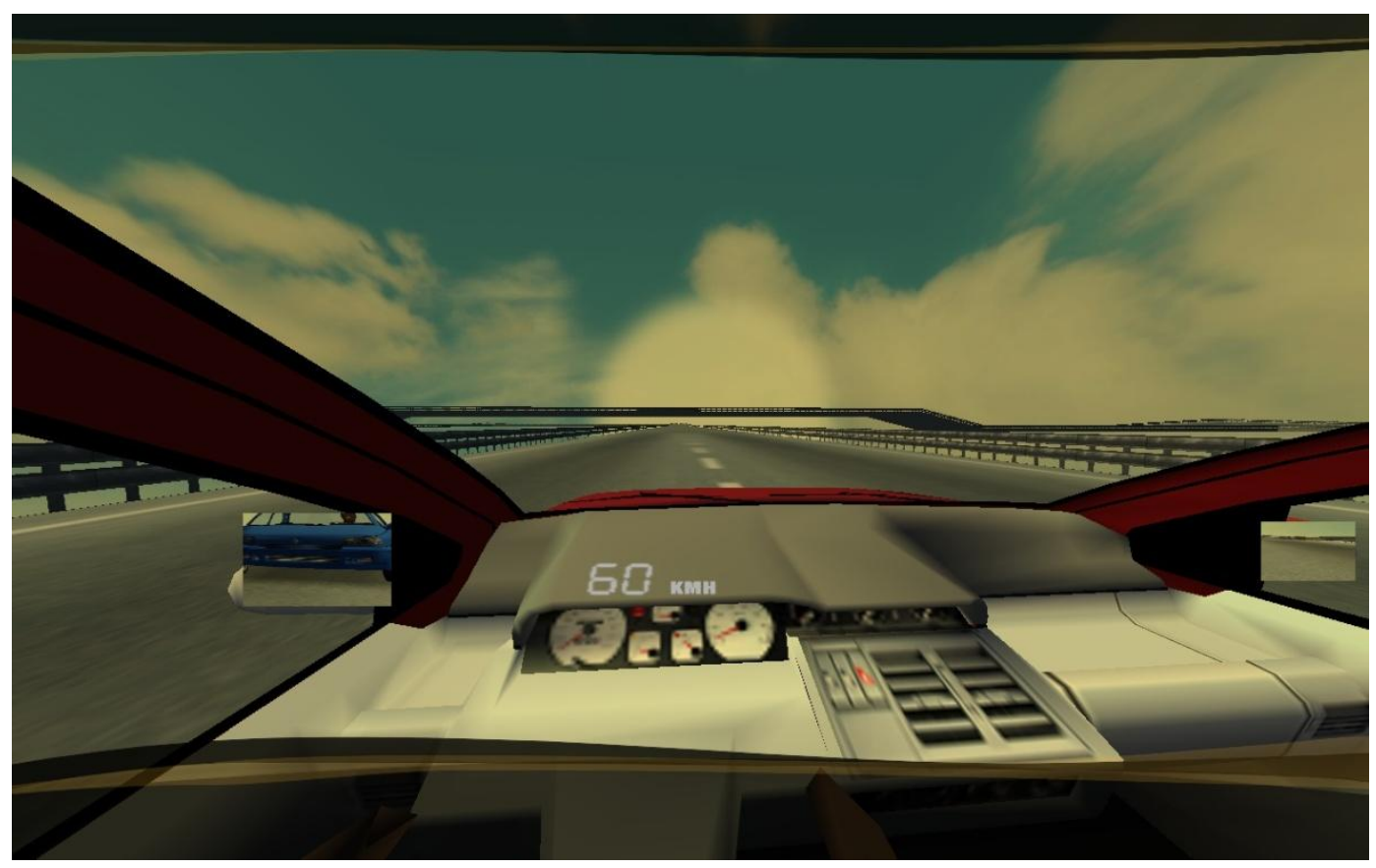

Figura 9 - Espelhos retrovisores no ManiaDrive. Fonte: autor

O software foi adaptado também para gravar, em um arquivo, dados do jogo, como posicionamentos e velocidade dos dois carros e distância entre eles. Também são gravados dados do controle do participante, como posição do volante e dos pedais. Esses dados são coletados a cada $50 \mathrm{~ms}$. A coleta desses dados permite uma análise do comportamento do participante em cada evento de aproximação do carro azul. O estudo dos gráficos de ação nos pedais e no volante resultantes desses dados permite avaliar se houve reação exagerada e possibilita o estudo dos tempos de reação dos participantes.

Com o software adaptado de acordo com o descrito acima, foi realizado o primeiro experimento. Para o segundo experimento, o jogo teve que ser adaptado para prover um sinal para que o módulo de alerta externo ao computador ativasse os alertas auditivo e/ou háptico sempre que a distância entre os carros se tornasse 
menor que 2000000, aproximadamente 40m. Para isso foi utilizada a saída de áudio do computador e a interface de áudio provida pelo software Raydium 3D Game Engine. De acordo com o padrão das duas linhas do canal de áudio estéreo, o módulo de alerta reconhece um pedido para ativar seis alertas diferentes: auditivo e háptico, somente auditivo ou somente háptico. Para direita ou para a esquerda.

Além disso, passou a ser gravada também a informação de que alerta estava ativo a cada momento.

Em resumo, as seguintes modificações foram feitas no jogo para adaptá-lo aos propósitos dos experimentos:

i) Criação uma pista monótona para manter o participante ocupado com o percurso;

ii) Perseguição do carro azul para servir de estímulo a uma reação evasiva;

iii) Apresentação de espelhos retrovisores para estímulo à visão periférica;

iv) Saída de controle para o módulo de alerta. Permite a sincronização da projeção com os alertas auditivo e háptico.;

v) Gravação dos dados para posterior análise.

\subsubsection{Desenvolvimento do módulo de alerta}

Para ativação dos elementos vibratórios e dos alto-falantes, foi necessário se desenvolver um módulo eletrônico capaz de se comunicar com computador para receber requisições de alertas e ser capaz de ativar os componentes auditivos e hápticos. Para isso foi utilizada uma placa de desenvolvimento com 0 microcontrolador NEC V850. O projeto do módulo é apresentado na Figura 10. 


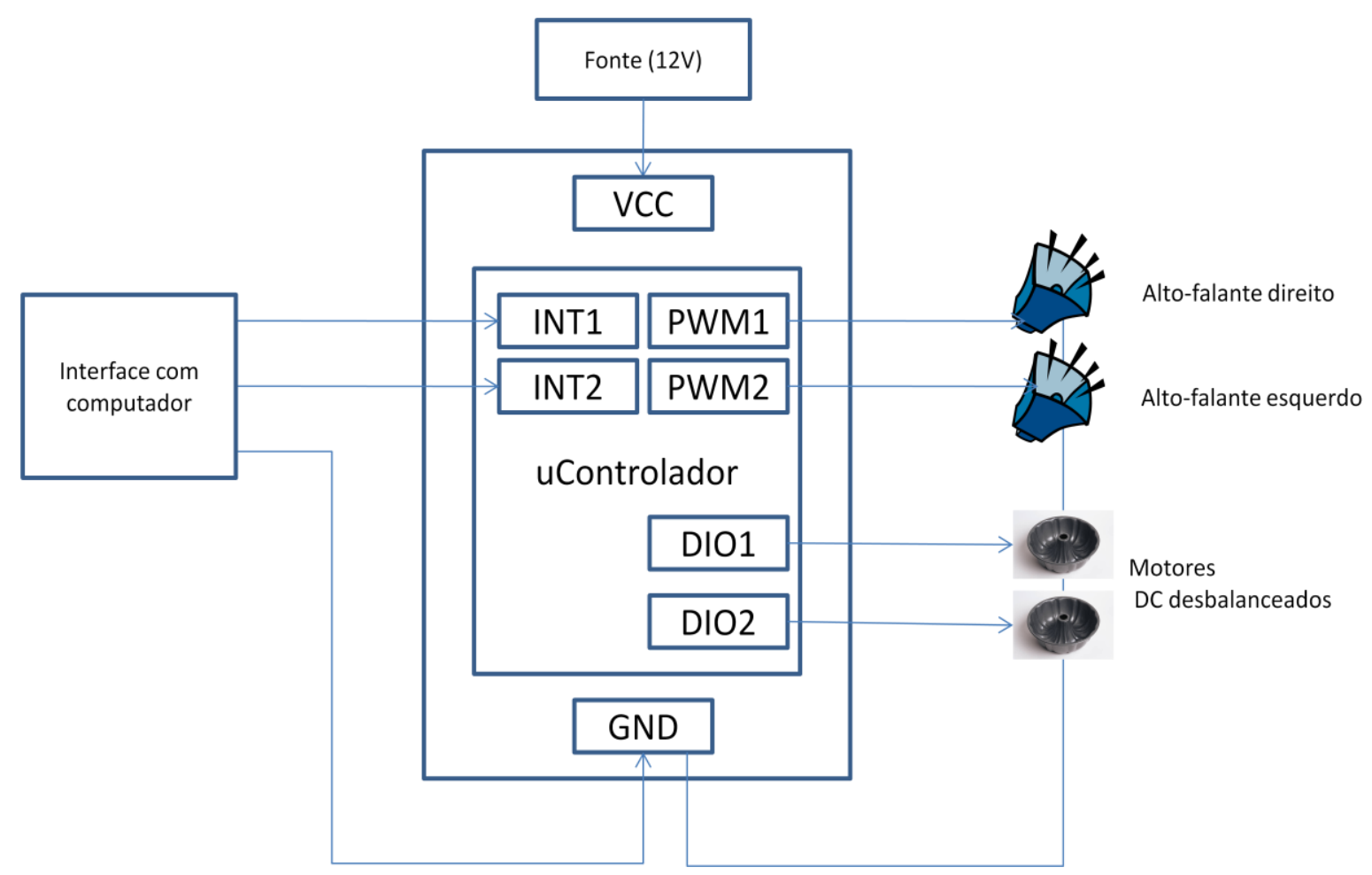

Figura 10 - Projeto do módulo de alerta. Fonte: autor

Esse módulo ficou posicionado em um compartimento abaixo do assento utilizado pelo participante durante o teste, indicado na Figura 11. É possível ver também o posicionamento dos alto-falantes, atrás do assento, e do volante, à frente do assento. Os dois motores DC desbalanceados estão fixados no assento nas posições indicadas pelas setas vermelhas. 


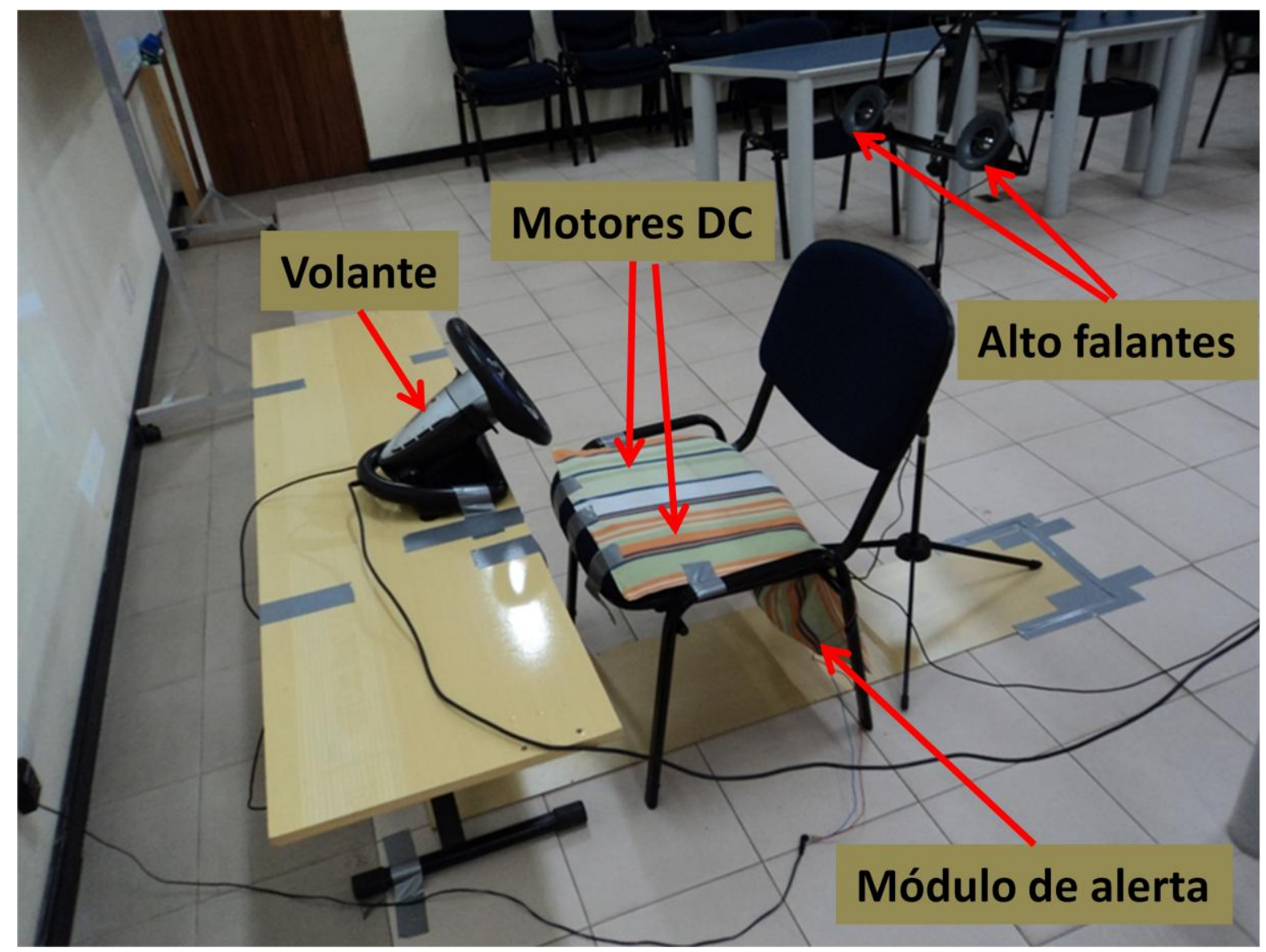

Figura 11 - Posicionamento dos elementos de alerta. Fonte: autor

Os alto-falantes são acionados na frequência de $1 \mathrm{KHz}$, considerada de média a alta prioridade, conforme os estudos de Suied et al. (2005) e de Ulfvengren (2007). O posicionamento dos alto-falantes implica um método de referência absoluta, onde a fonte de som é fixa, conforme descrito na seção 3.3. Este método tem como vantagem o efeito de tridimensionalidade independente da posição da cabeça do usuário. O posicionamento dos alto-falantes e o volume do som foram adequados empiricamente para que o alerta sonora fosse perceptível sem ser excessivamente intenso.

De forma coerente com o descrito na seção 4.1, o posicionamento dos elementos vibratórios foi feito de forma que estejam sempre em contato com as pernas dos participantes. Por meio de avaliações piloto, a intensidade da vibração foi ajustada de tal maneira que não gere muito incômodo, mas que seja perceptível quando o participante estiver usando roupas comuns, como calças jeans, bermudas ou saias de tecido. 


\subsection{Método de avaliação}

Para avaliação da técnica proposta, são usadas tanto informações quantitativas quanto qualitativas. Uma vez que ativações desnecessárias ou excessivas dos alertas - falso-alarme - podem incomodar e estressar o motorista, é muito importante considerar a compreensão e as impressões dos usuários.

Adell et al. (2007) usaram três procedimentos para avaliar alertas visuais, auditivos e hápticos:

i) perguntar aos participantes, em um teste de estimativa de compreensão, a porcentagem dos motoristas que rapidamente entenderiam a mensagem transmitida; ii) registrar numa escala de cinco graus (muito ruim / ruim / nem ruim nem bom / bom / muito bom) as impressões de cada motorista para cada alerta e iii) escrever a interpretação, apresentando seu significado e graduando do melhor ao pior.

Verbist (2009) considerou o desvio médio da faixa central como um parâmetro para avaliar a eficiência do seu sistema de feedback auditivo para manutenção da faixa sob situação de baixa visibilidade. Ele também aplicou questionários para avaliar as preferências e o esforço desprendido do ponto de vista dos usuários.

Um tipo de medida absolutamente quantitativa foi usado por Emily (2004) para monitorar o tempo gasto na liberação do pedal do acelerador e no pressionamento do pedal de freio até a máxima desaceleração ser obtida. O objetivo era avaliar os efeitos de diferentes parâmetros de alerta sonoro na atitude do motorista.

No segundo experimento proposto, o parâmetro quantitativo usado para avaliar a eficácia de cada alerta é identificado no primeiro experimento, representando o tempo de reação do motorista em uma situação em que é necessário mudar rapidamente o curso do veículo devido a um obstáculo identificado na região lateral.

A escala de cinco níveis de Adell et al. (2007) é usada para a análise qualitativa de cada alarme. Pede-se aos sujeitos responderem algumas questões relativas às suas impressões: 
- Quão útil foi o estímulo auditivo para chamar a sua atenção? ( 5 = muito útil, 0 = nada útil)

- Quão útil foi a vibração do assento para chamar a sua atenção?

- Quão incômodo foi o estímulo auditivo? ( 5 = muito incômodo, 0 = nada incômodo)

- Quão incômodo foi a vibração do assento?

\subsubsection{Avaliação dos dados coletados}

Os gráficos de cada um dos eventos críticos foram analisados para se entender a ação dos sujeitos quando ocorre a aproximação do carro azul. Os gráficos registram, na linha vermelha, a distância entre os dois veículos; na linha verde, o esterçamento do volante, onde valores positivos significam esterçamento para a direita e valores negativos, esterçamento para a esquerda; na linha azul, a posição dos pedais de freio e aceleração, onde valores positivos significam aceleração e valores negativos significam frenagem. As variáveis de esterçamento do volante e posição dos pedais têm como valor máximo a 1000000 , referente ao ponto em que o volante tem seu máximo esterçamento e os pedais têm seu máximo pressionamento. Na unidade de distância utilizada, o valor 1000000 , corresponde a aproximadamente $20 \mathrm{~m}$. $\mathrm{Na}$ unidade de tempo utilizada, cada unidade representa cerca de $50 \mathrm{~ms}$.

No gráfico abaixo é apresentado um exemplo de registro de um evento. Nesse evento, o gráfico vermelho indica a aproximação do carro azul de 4000000 até aproximadamente 0 . No gráfico, observa-se que, neste evento, quando a distância é cerca de 1000000, o participante despressiona o pedal de aceleração (linha azul passa a mostrar 0 ) e movimento o volante totalmente para a esquerda (linha verde mostra -1000000). É possível se observar também um pequeno movimento do volante para a direita (linha verde ligeiramente acima de 0) aproximadamente quando a distância entre os veículos é 4000000. 


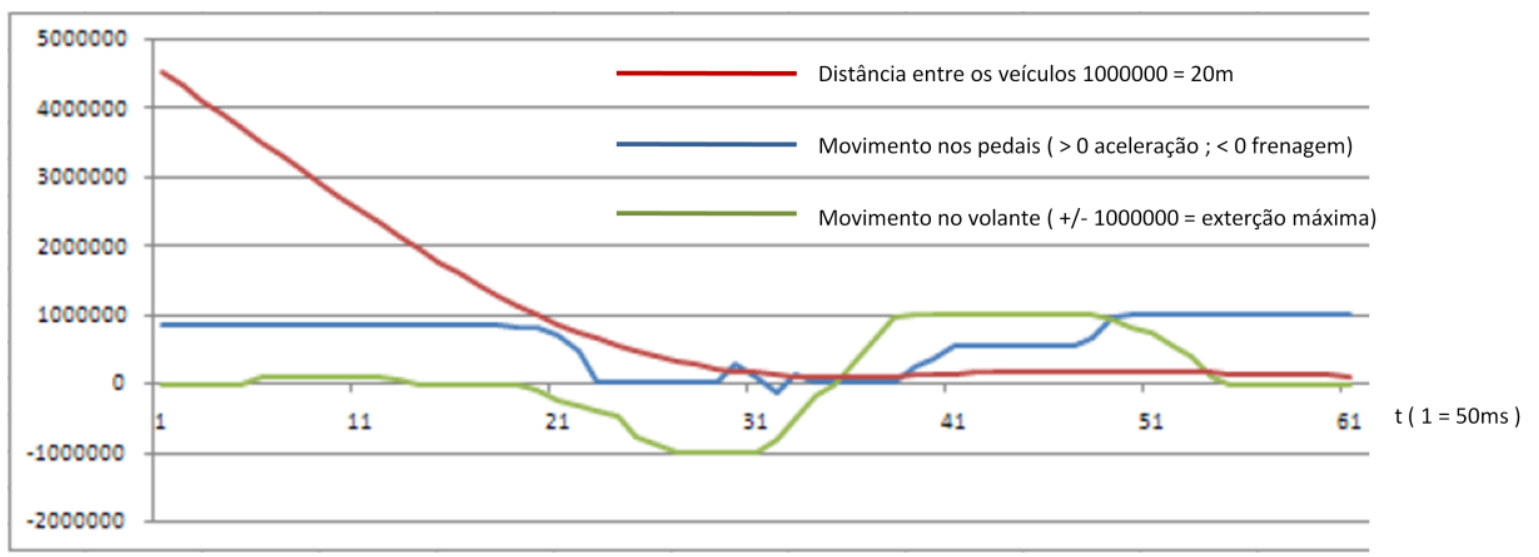

Gráfico 2 - Exemplo de evento registrado. Fonte: autor

A observação das ações dos participantes permitiu a constatação de que a referência na distância 1000000 se mantinha ao longo dos eventos. Ou seja, as ações de fuga dos participantes acontecem na proximidade dessa distância. Em vista disso, foi feito um registro do tempo que o participante leva para iniciar a ação no volante e nos pedais com referência na distância 1000000. No gráfico acima, por exemplo, registra-se que -15 para movimento do volante e 0 para movimento dos pedais.

A Tabela 2 mostra um exemplo do registro dos eventos ocorridos em um teste em que os alertas auditivos e hápticos foram utilizados. O número registrado representa a demora para o participante tomar a ação com referência à distância 1000000 , número negativos significam que a ação foi tomada antes de a distância chegar a esse valor. Quando o número é substituído por um traço "-“, não foi observada nenhuma ação neste controle devido à aproximação do carro azul neste evento. Neste teste, aconteceram 29 eventos. A coluna "Alerta" indica qual o tipo de alerta foi utilizados em cada evento: 0 e 1 significam que ambos os alertas auditivo e háptico foram acionados, 2 significa que somente o alerta háptico foi acionado e 3 significa que somente o alerta auditivo foi acionado.

Adicionalmente, são registradas nas colunas "Frenagem" e "Ext. Máxima", os casos em que se identificou reação exagerada nos controles de pedal e de volante respectivamente. Para os controles de pedal, a reação é considerada exagerada quando além de retirar o pé do acelerador, o sujeito pisa do pedal de freio, e, para o volante, é considerada exagerada a esterção completa até + ou - 1000000. Esse 
registro é feito de forma a permitir a comparação entre os eventos com e sem alertas e para identificar se os alertas propostos induzem o participante a uma reação exagerada.

\begin{tabular}{|c|c|c|c|c|}
\hline \multicolumn{5}{|c|}{ Teste_01 } \\
\hline \multicolumn{3}{|c|}{ Dist $=1000 \times$ Movimento } & \multirow[b]{2}{*}{ Frenagem } & \multirow[b]{2}{*}{ Ext Máxima } \\
\hline 01_Pedal & 01_Volante & Alerta & & \\
\hline- & 23 & 2 & - & 0 \\
\hline 15 & 15 & 1 & 1 & 0 \\
\hline-11 & -5 & 0 & 0 & 0 \\
\hline- & 18 & 2 & - & 0 \\
\hline 18 & 25 & 2 & 1 & 1 \\
\hline 18 & 18 & 1 & 0 & 0 \\
\hline- & 12 & 0 & - & 0 \\
\hline- & 12 & 0 & - & 0 \\
\hline- & -8 & 2 & - & 0 \\
\hline- & - & 3 & - & - \\
\hline 20 & 14 & 0 & 1 & 1 \\
\hline 15 & - & 2 & 1 & - \\
\hline 20 & 20 & 1 & 1 & 1 \\
\hline 22 & 20 & 3 & 1 & 1 \\
\hline 13 & 12 & 1 & 1 & 1 \\
\hline 16 & 18 & 3 & 1 & 1 \\
\hline 16 & 18 & 0 & 1 & 1 \\
\hline- & - & 2 & - & - \\
\hline- & 20 & 2 & - & 0 \\
\hline- & 19 & 0 & - & 1 \\
\hline 17 & 10 & 2 & 1 & 1 \\
\hline- & 14 & 1 & - & 1 \\
\hline- & 18 & 3 & - & 1 \\
\hline- & - & 2 & - & - \\
\hline- & - & 3 & - & - \\
\hline- & - & 3 & - & - \\
\hline- & - & 2 & - & - \\
\hline- & -12 & 2 & - & 0 \\
\hline- & 18 & 2 & - & 0 \\
\hline
\end{tabular}

O tempo de reação é uma medida fundamental para a análise da eficiência do sistema proposto, pois ele pode ser relacionado diretamente com a capacidade de o motorista reduzir o risco de acidente. Considere, por exemplo, um veículo a $60 \mathrm{Km} / \mathrm{h}$. No intervalo de tempo de 100ms, esse veículo percorre uma distância aproximada 
de $1,7 \mathrm{~m}$, um espaço que pode ser determinante para evitar uma colisão. Isso indica que, em termos de tempo de reação do motorista, frações de segundos são extremamente relevantes. 


\section{RESULTADOS}

Nesta seção, são apresentados os resultados obtidos no primeiro e no segundo experimentos. Tanto dados qualitativos quanto os dados quantitativos são apresentados para posterior discussão.

\subsection{Primeiro experimento}

Para o primeiro experimento, foram convocados 12 voluntários. A média de idade desses voluntários é de 33 anos, com desvio padrão 9,8 anos. A maior idade é 50 anos e a menor 20 anos. $O$ grupo é constituído de $41,7 \%$ de mulheres e $58,3 \%$ de homens.

\subsubsection{Questionário Pré-Teste}

O questionário apresentado na seção 6.2 .3 foi realizado com cada um dos participantes do primeiro experimento. Os resultados obtidos são mostrados a seguir.

\subsubsection{Experiência de direção}

A média de experiência de direção do grupo avaliado é de 15 anos com desvio padrão de 9,7 anos. A menor experiência registrada foi de 2 anos e a maior de 30 anos.

\subsubsection{Direção por semana}

Dos voluntários, $58 \%$ relataram dirigir entre 2 e 10 horas por semana e $42 \%$ disseram dirigir mais que 10 horas por semana.

\subsubsection{Dispositivos eletrônicos}

O resultado da questão sobre quais dispositivos eletrônicos o voluntário possui no carro que mais dirige é mostrado na tabela abaixo: 


\begin{tabular}{|l|c|}
\hline Rádio & $100 \%$ \\
\hline Ar condicionado & $50 \%$ \\
\hline Computador de bordo & $42 \%$ \\
\hline GPS & $8 \%$ \\
\hline Câmbio automático & $8 \%$ \\
\hline Sensor de estacionamento & $0 \%$ \\
\hline Outros & $17 \%$ \\
\hline
\end{tabular}

Tabela 3 - Dispositivos eletrônicos no carro mais usado. Fonte: autor

\subsubsection{Experiência com jogos}

O gráfico abaixo mostra a experiência dos voluntários com jogos de computador:

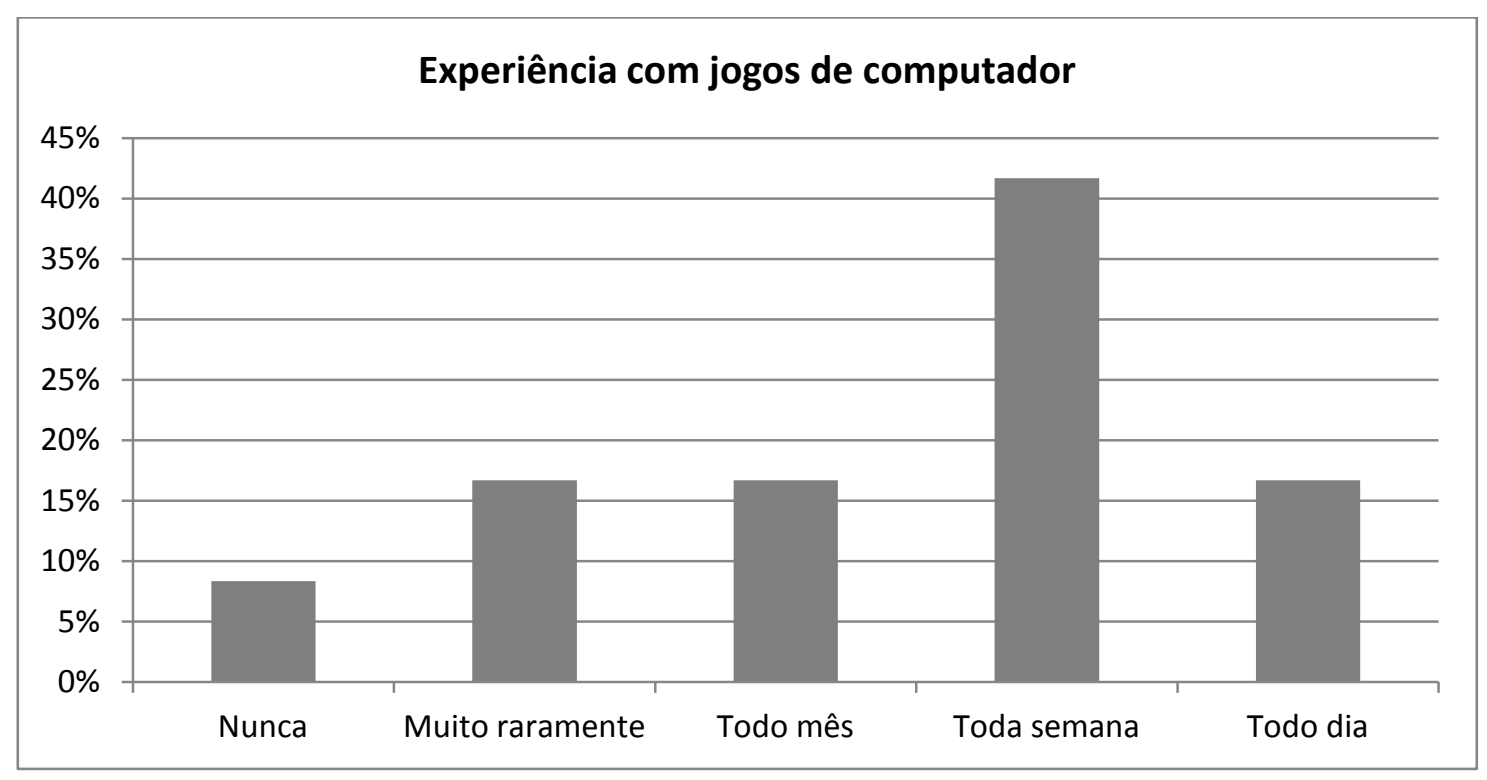

Gráfico 3 - Experiência com jogos de computador. Fonte: autor 


\subsubsection{Tipos de jogos}

O gráfico a seguir caracteriza a população do teste em termos das plataformas e tipos de jogos mais utilizados.

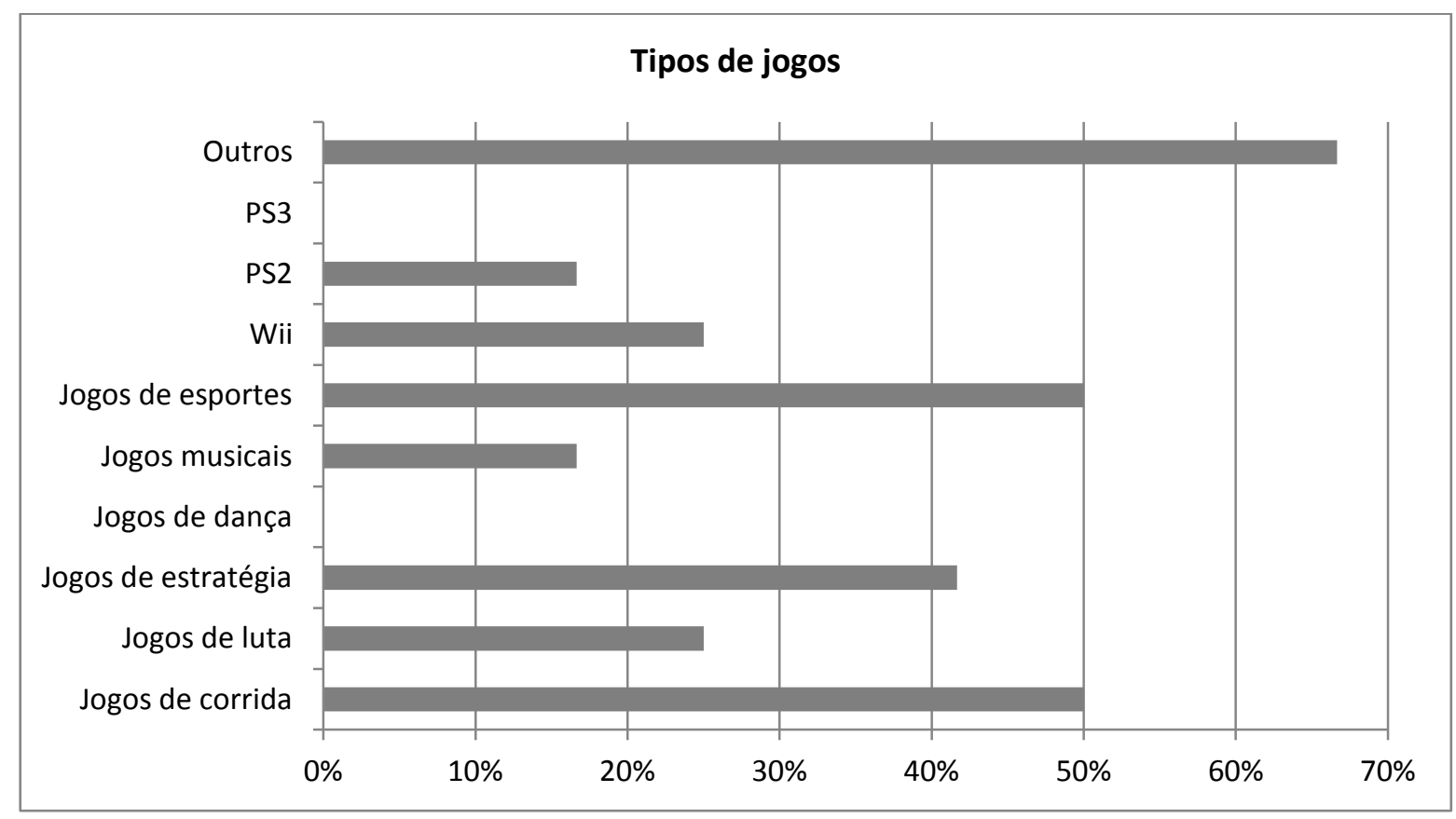

Gráfico 4 - Tipos de jogos de computador. Fonte: autor

\subsubsection{Dados Coletados}

Foram coletados dados de 250 eventos. A seguir são apresentados os resultados.

\subsubsection{Reação preferencial medida}

Registrando-se os dados conforme descrito na seção 6.6.1, foi possível se identificar os tempos de reação aos estímulos em todos os eventos em que houve reação. Dos 250 eventos analisados, 188 ou $75 \%$ apresentaram ao menos uma reação.

Em 31 eventos, somente foi observada reação no pedal. Em 57, somente no volante. Em 100 eventos, foram observadas reações em ambos os controles, sendo que em 32, primeiramente ocorreu a ação no pedal, em 52, primeiramente a ação foi no volante e em 16 casos, ambos os controles foram acionados simultaneamente. Nenhuma reação foi observada em 62 eventos. 
O gráfico abaixo ilustra em termos percentuais a distribuição dos eventos quanto à categoria da reação observada: só pedal $(12,22 \%)$; só volante $(21,48 \%)$; primeiro pedal $(14,07 \%)$; primeiro volante $(20,74 \%)$; pedal e volante ao mesmo tempo $(6,67 \%)$ e nada $(24,81 \%)$.

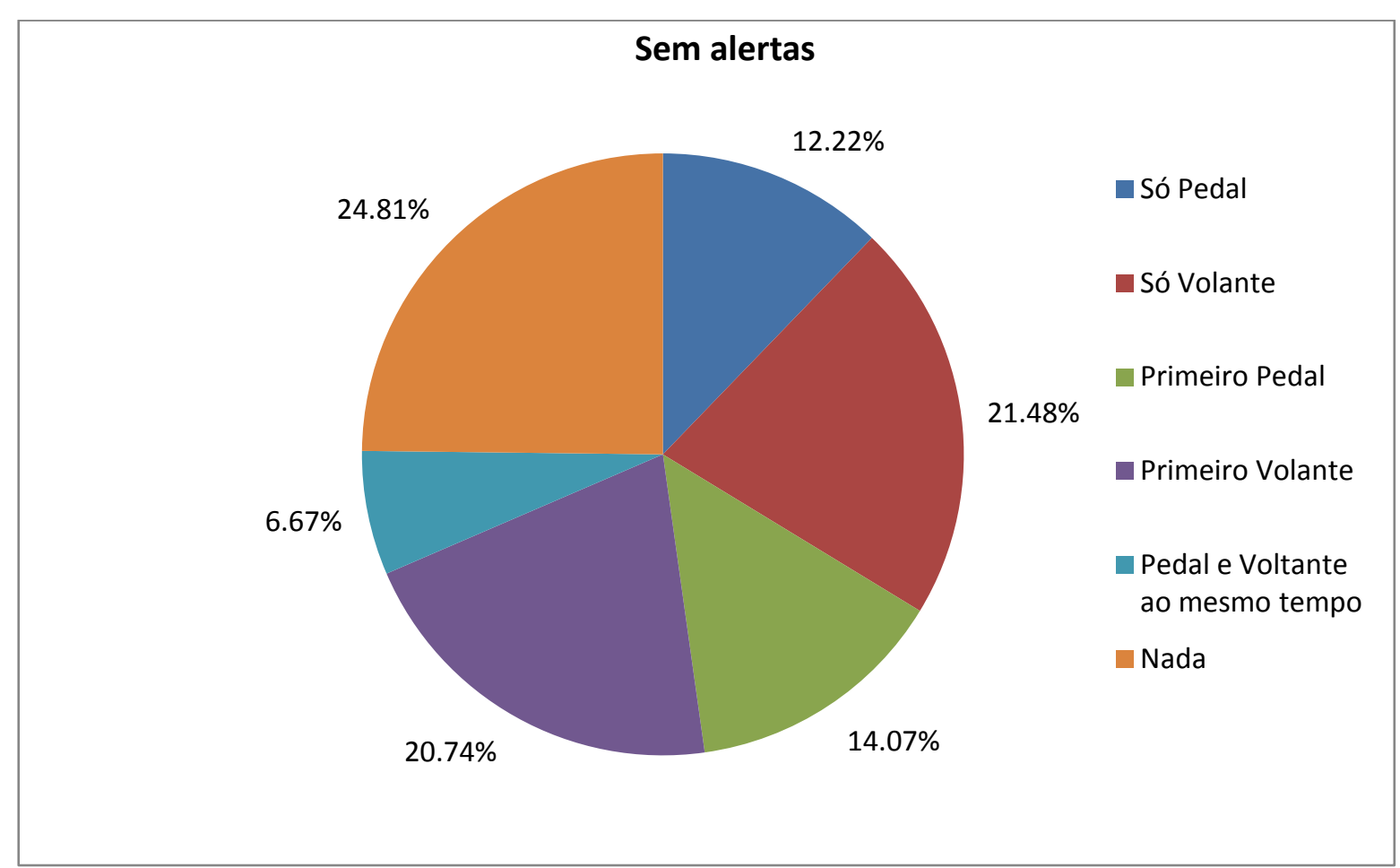

Gráfico 5 - Distribuição do tipo de ação no primeiro experimento. Fonte: autor

Comparativamente, pode-se observar que a ação preferida ao se deparar com a situação problema é o esterçamento do volante. O gráfico abaixo mostra que em $42,22 \%$ dos eventos o esterçamento do volante foi a única reação ou a reação inicial, enquanto que em apenas $26,30 \%$ dos eventos, houve apenas ação nos pedais ou inicialmente nos pedais. 


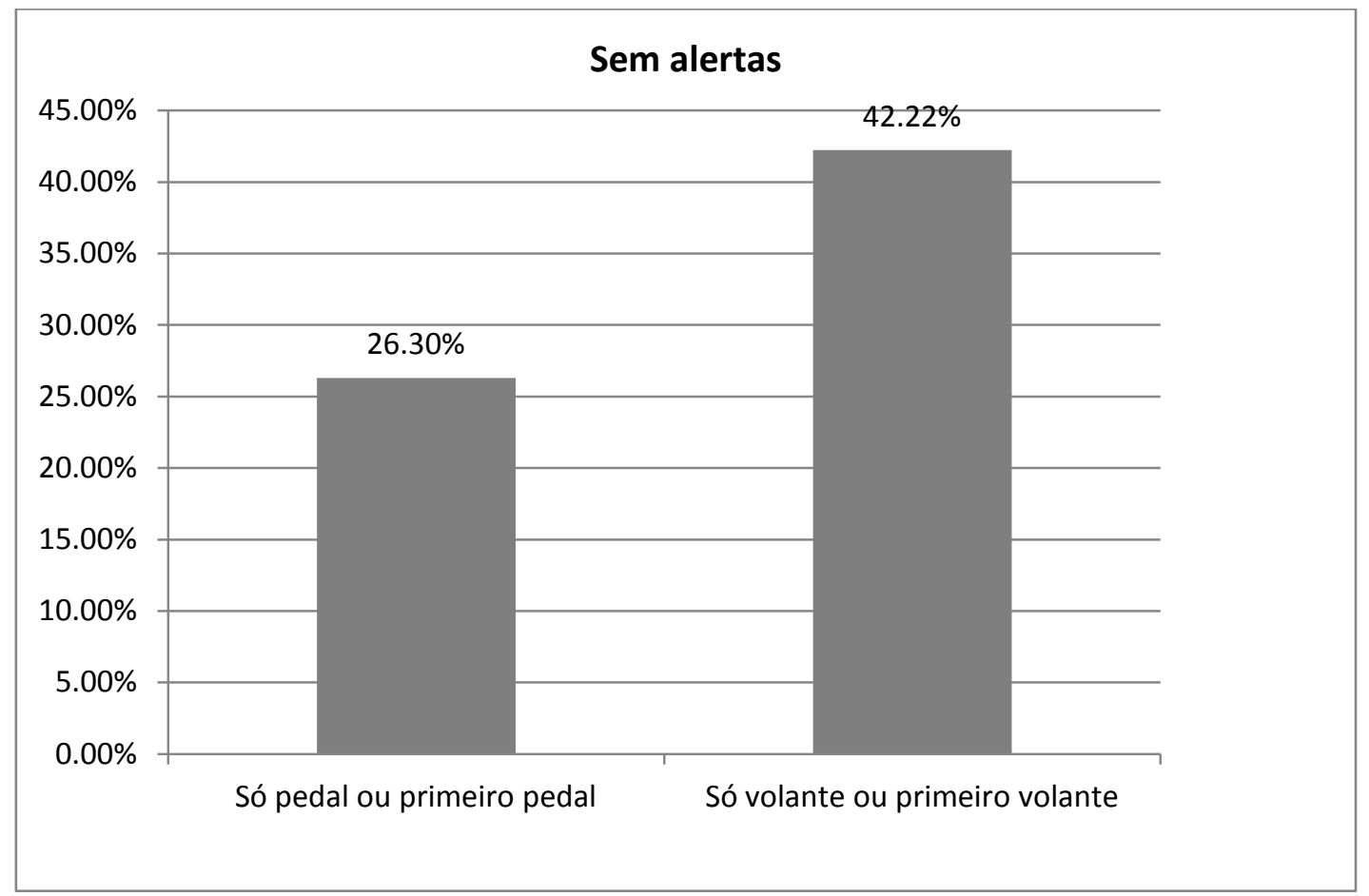

Gráfico 6 - Ação preferencial medida no primeiro experimento. Fonte: autor

\subsubsection{Tempo de reação}

Dentre os eventos em que houve reação, o tempo médio para a primeira reação foi de 3,8 unidades ou $190 \mathrm{~ms}$ e o desvio padrão foi 8,9 ou $445 \mathrm{~ms}$, tendo como referência o momento em que a distância foi de 1000000 unidades de distância ou aproximadamente $20 \mathrm{~m}$. Dentre os eventos em que a ação preferencial de esterçamento do volante foi observada inicial ou isoladamente, o tempo de reação foi de 4,2 unidades ou $210 \mathrm{~ms}$ e o desvio padrão foi 8,7 ou $435 \mathrm{~ms}$. 


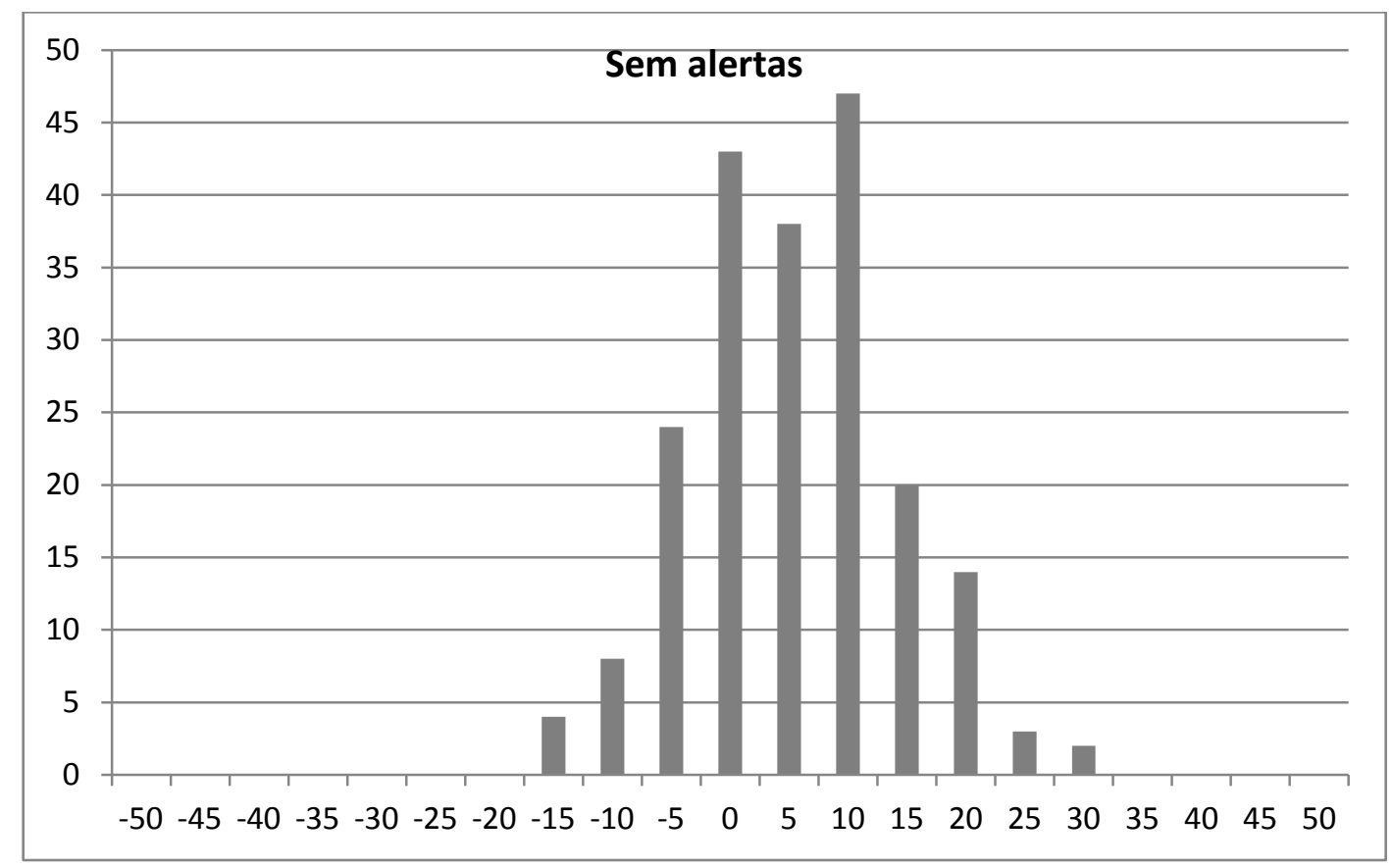

Gráfico 7 - Histograma dos tempos de resposta no primeiro experimento (cada unidade representa $50 \mathrm{~ms}$ ). Fonte: autor

\subsubsection{Reação exagerada}

O gráfico a seguir apresenta o percentual de eventos em que foi observada reação exagerada nos pedais ou no volante, conforme definição na seção 6.6.1. Esses resultados são discutidos, em comparação com o segundo experimento na seção 7.3.7.

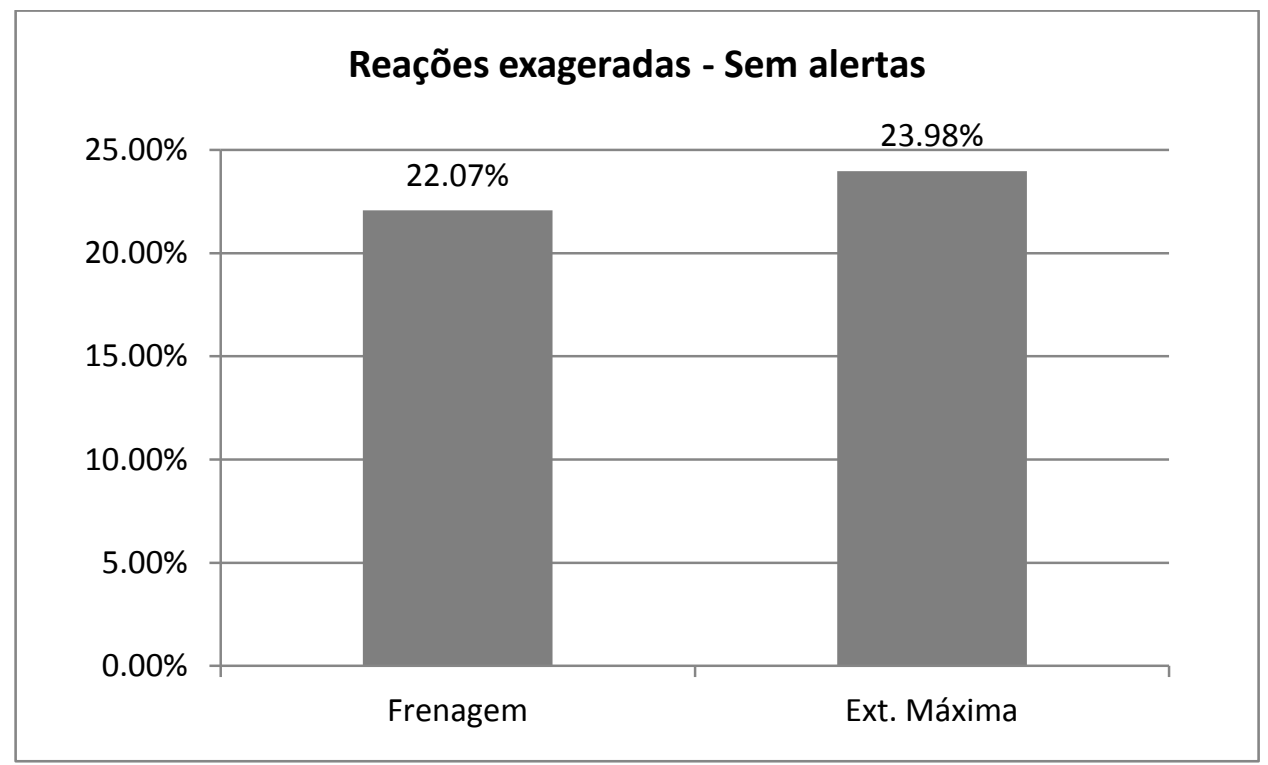

Gráfico 8 - Registro de ações exageradas nos pedais e nos volantes. Fonte: autor 


\subsubsection{Questionário pós-teste}

Após os dados serem coletados, o voluntário foi entrevistado de acordo com 0 questionário pós-teste da seção 6.3.3. Os resultados são mostrados a seguir.

\subsubsection{Avaliação do ambiente de simulãa}

Os voluntários avaliaram o ambiente de simulação em 6 categorias apresentadas a seguir. Metade dos voluntários avaliou o ambiente de simulação como "Bom".

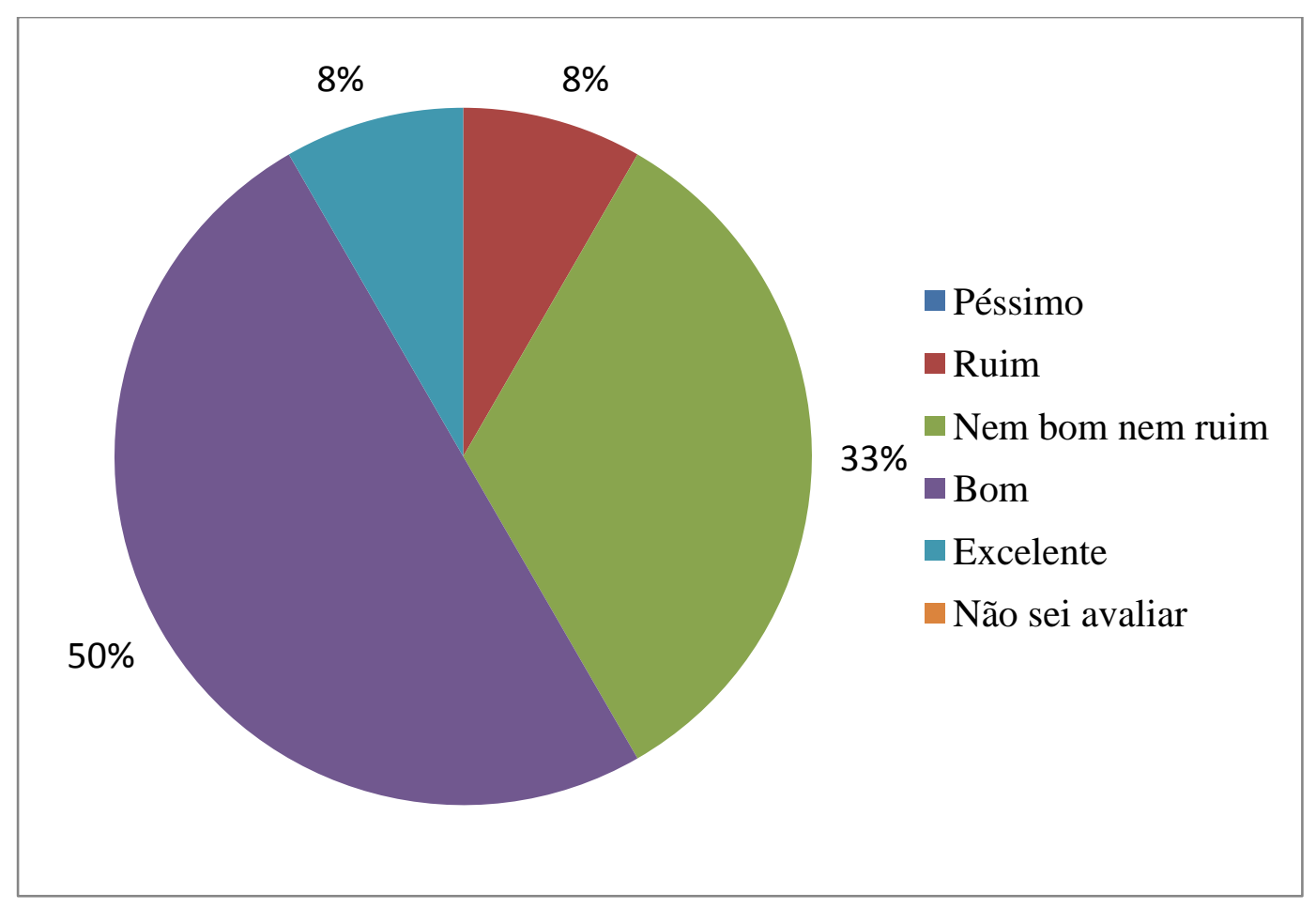

Gráfico 9 - Avaliação do ambiente de simulação. Fonte: autor

\subsubsection{Atenção destinada ao carro azul}

Quando questionados se o carro azul chamou o participante à atenção, 25\% responderam que o carro azul chamou "Pouco" à atenção e 75\% responderam que o carro azul chamou "Muito" à atenção. 


\subsubsection{Percepção do carro azul}

Quando perguntado se o participante percebeu todas as vezes que o carro azul apareceu, 50\% disseram que "Provavelmente sim". Todas as respostas estão na tabela abaixo.

\begin{tabular}{|c|c|}
\hline Certamente sim & $33 \%$ \\
\hline Provavelmente sim & $50 \%$ \\
\hline Provavelmente não & $8 \%$ \\
\hline Certamente não & $8 \%$ \\
\hline
\end{tabular}

Tabela 4 - Percepção do carro azul no primeiro experimento. Fonte: autor

\subsubsection{Reação preferencial declarada}

O gráfico abaixo mostra as reações descritas pelos participantes ao término do primeiro experimento. A reação mais citada foi "Girei o volante".

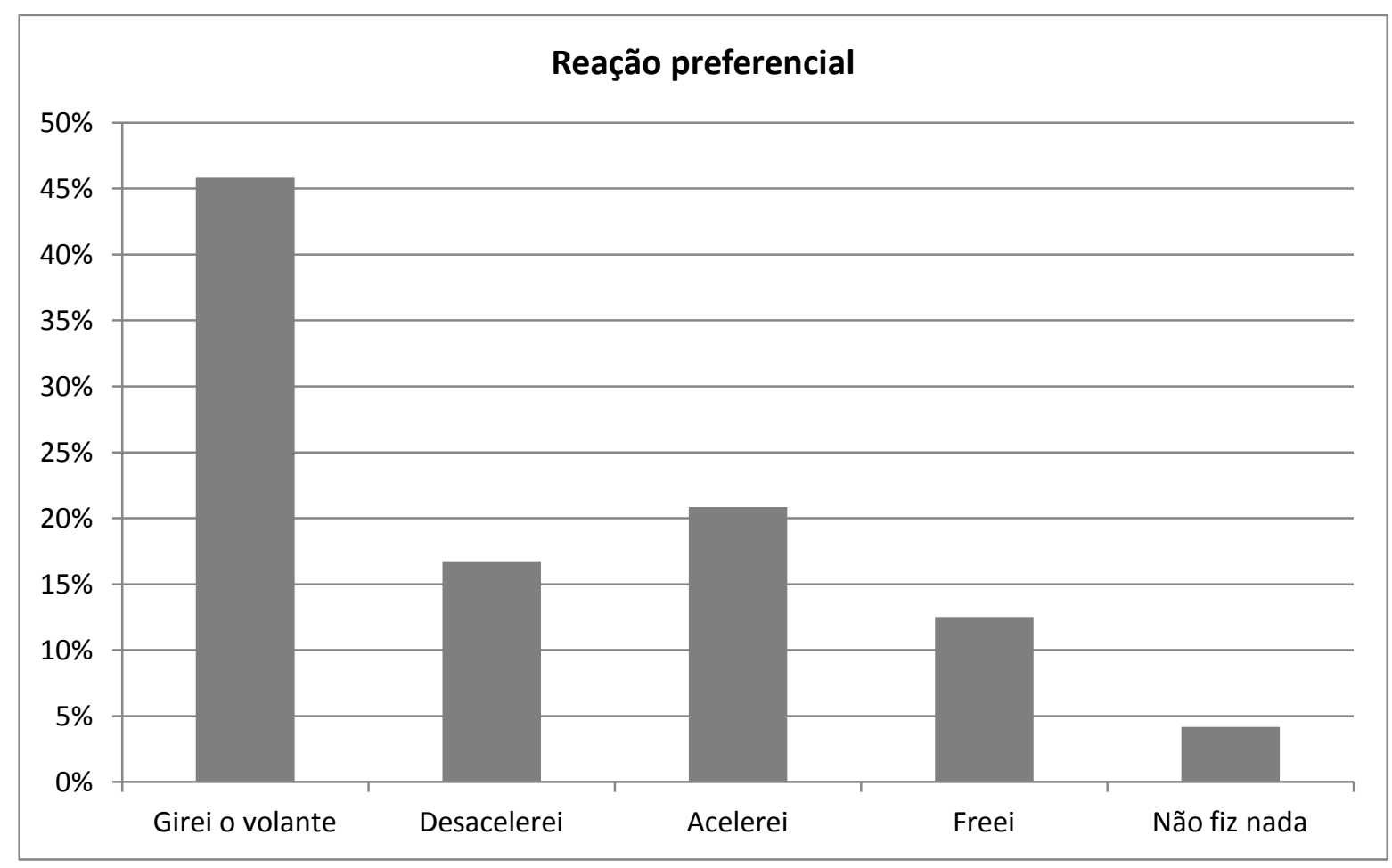

Gráfico 10 - Reação preferencial declarada. Fonte: autor 


\subsubsection{Reações adversas}

Três voluntários ou 25\% dos doze voluntários que fizeram o primeiro experimento relataram tontura ou enjôo leve após o término do teste. Nesses casos, os voluntários foram monitorados e acompanhados até se sentirem bem novamente.

\subsection{Segundo experimento}

Para o segundo experimento, foram convocados 23 voluntários. A média de idade desses voluntários é de 30 anos, com desvio padrão 6,5 anos. A maior idade é 51 anos e a menor 20 anos. O grupo é constituído de $21,7 \%$ de mulheres e $78,3 \%$ de homens.

\subsubsection{Questionário pré-teste}

O questionário apresentado na seção 6.2.3 também foi realizado com cada um dos participantes do segundo experimento. Os resultados obtidos são mostrados a seguir.

\subsubsection{Experiência de direção}

A média de experiência de direção para esse grupo é de 11,5 anos com desvio padrão de 7,2 anos. A menor experiência registrada foi de 2 anos e a maior de 30 anos.

\subsubsection{Direção por semana}

Dos voluntários, $48 \%$ relataram dirigir entre 2 e 10 horas por semana e $52 \%$ disse dirigir mais que 10 horas por semana.

\subsubsection{Dispositivos eletrônicos}

O resultado da questão sobre quais dispositivos eletrônicos o voluntário possui no carro que mais dirige é mostrado na tabela abaixo: 


\begin{tabular}{|l|r|}
\hline Rádio & $96 \%$ \\
\hline Ar condicionado & $70 \%$ \\
\hline Computador de bordo & $30 \%$ \\
\hline GPS & $61 \%$ \\
\hline Câmbio automático & $22 \%$ \\
\hline Sensor de estacionamento & $4 \%$ \\
\hline Outros & $39 \%$ \\
\hline
\end{tabular}

Tabela 5 - Dispositivos eletrônicos no carro mais usado. Fonte: autor

\subsubsection{Experiência com jogos}

O gráfico abaixo mostra a experiência dos voluntários com jogos de computador:

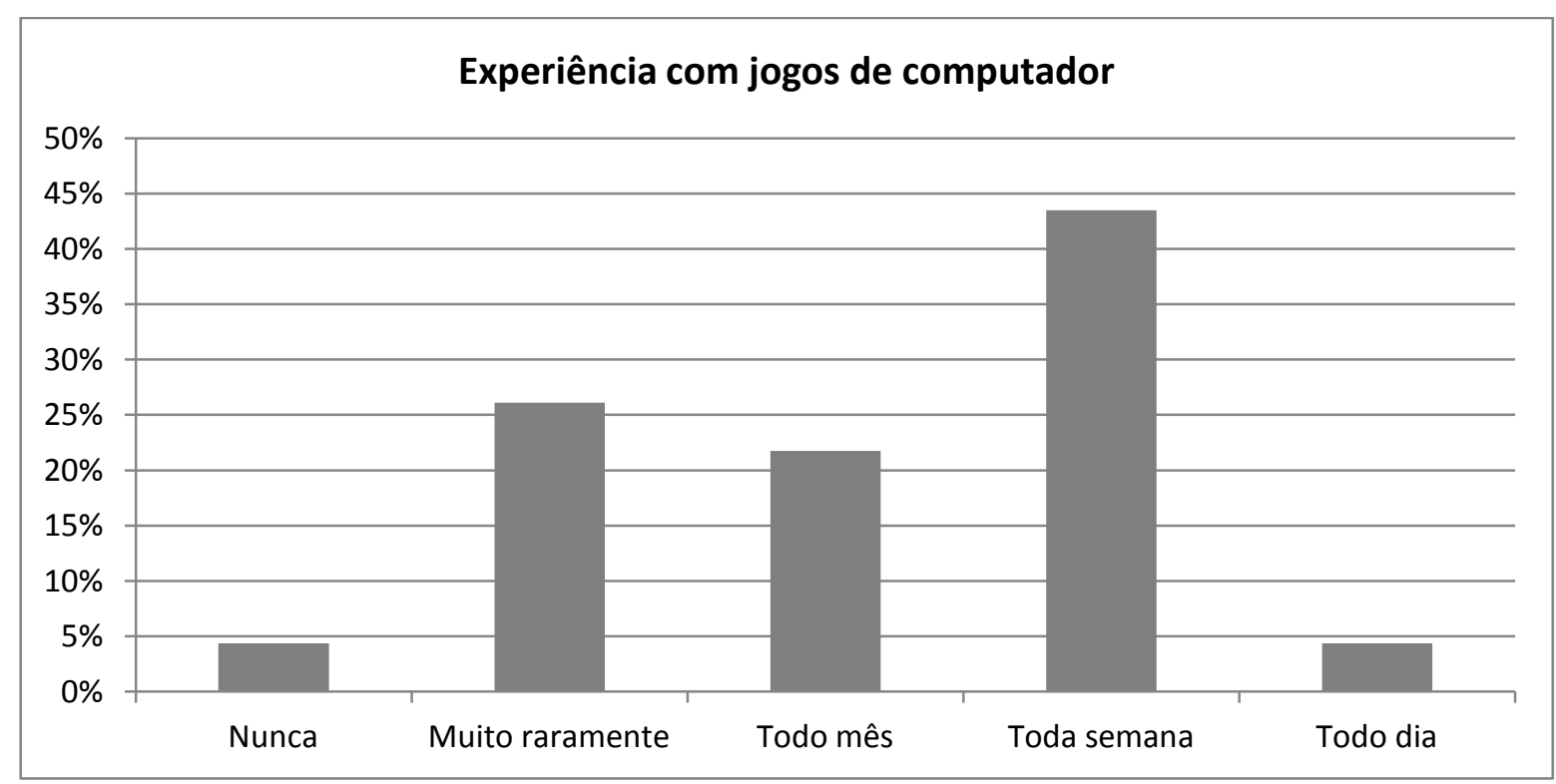

Gráfico 11 - Experiência com jogos de computador. Fonte: autor

\subsubsection{Tipos de jogos}

O gráfico a seguir caracteriza a população do teste em termos dos tipos de jogos mais utilizados. 


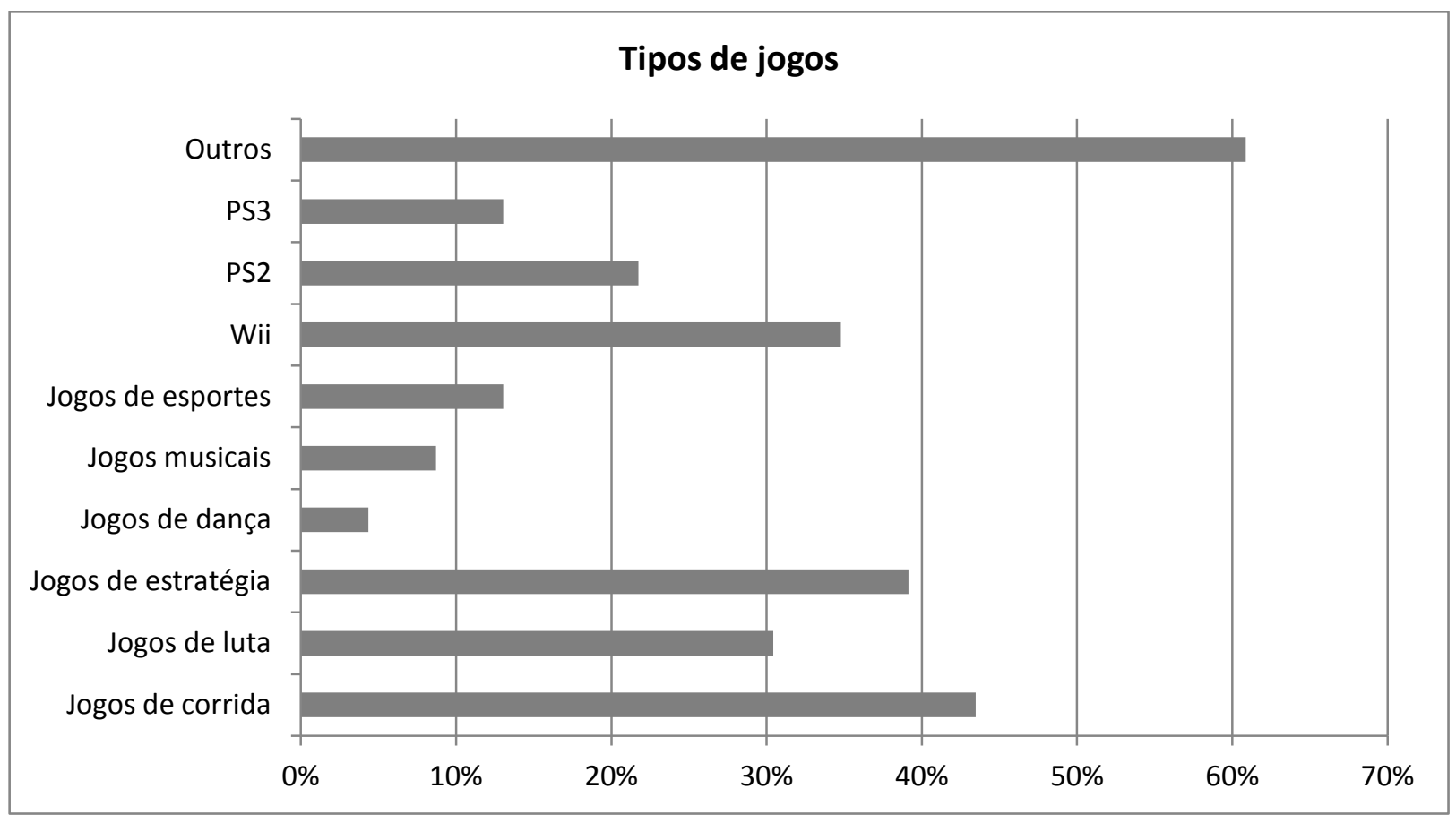

Gráfico 12 - Tipos de jogos de computador. Fonte: autor

\subsubsection{Dados coletados}

Foram coletados 487 eventos críticos, dos quais 227 utilizaram ambos os alertas auditivo e háptico, 139 somente o háptico e 121 somente o auditivo. Os resultados são apresentados a seguir e discutidos em comparação com o primeiro experimento na seção 7.3.

\subsubsection{Reação preferencial medida}

Dos 588 eventos analisados no segundo experimento, 487 ou 83\% apresentaram ao menos uma reação.

Em 22 eventos, somente foi observada reação no pedal. Em 174, somente no volante. Em 249 eventos, foram observadas reações em ambos os controles, sendo que em 101, primeiramente ocorreu à ação no pedal, em 148, primeiramente a ação foi no volante e em 42 casos, ambos os controles foram acionados simultaneamente. Nenhuma reação foi observada em 101 eventos. 
O gráfico a seguir ilustra em termos percentuais a distribuição dos eventos quanto à categoria da reação observada: só pedal (3,74 \%); só volante (29,59\%); primeiro pedal $(17,18 \%)$; primeiro volante $(25,17 \%)$; pedal e volante ao mesmo tempo $(7,14$ $\%)$ e nada (17,18\%). A análise comparativa dos dados com o primeiro experimento é feita na seção 7.3 .

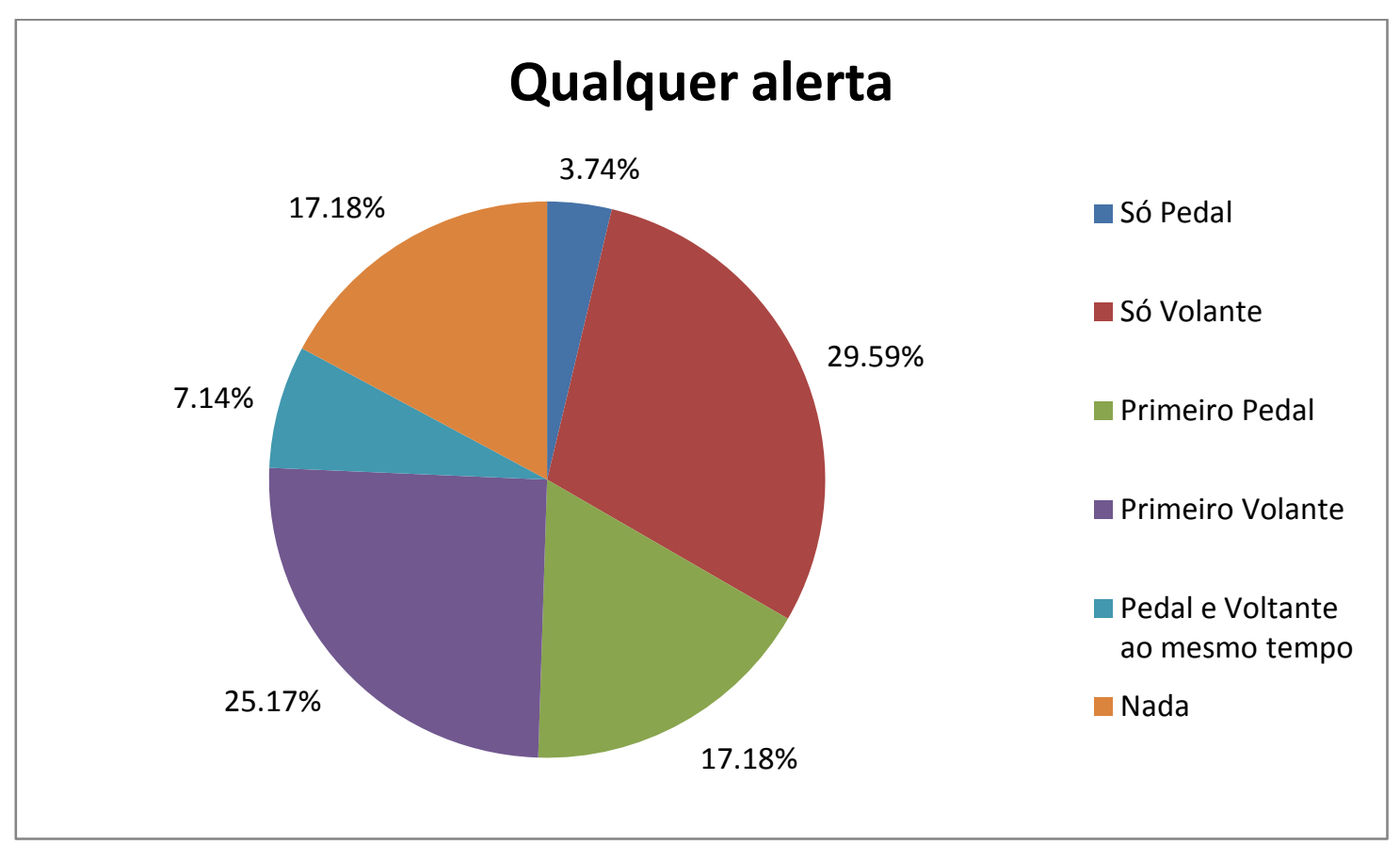

Gráfico 13 - Distribuição dos tipos de reação com algum alerta presente. Fonte: autor

Podemos ver no Gráfico 14 que a reação preferencial, neste caso, foi no volante. 


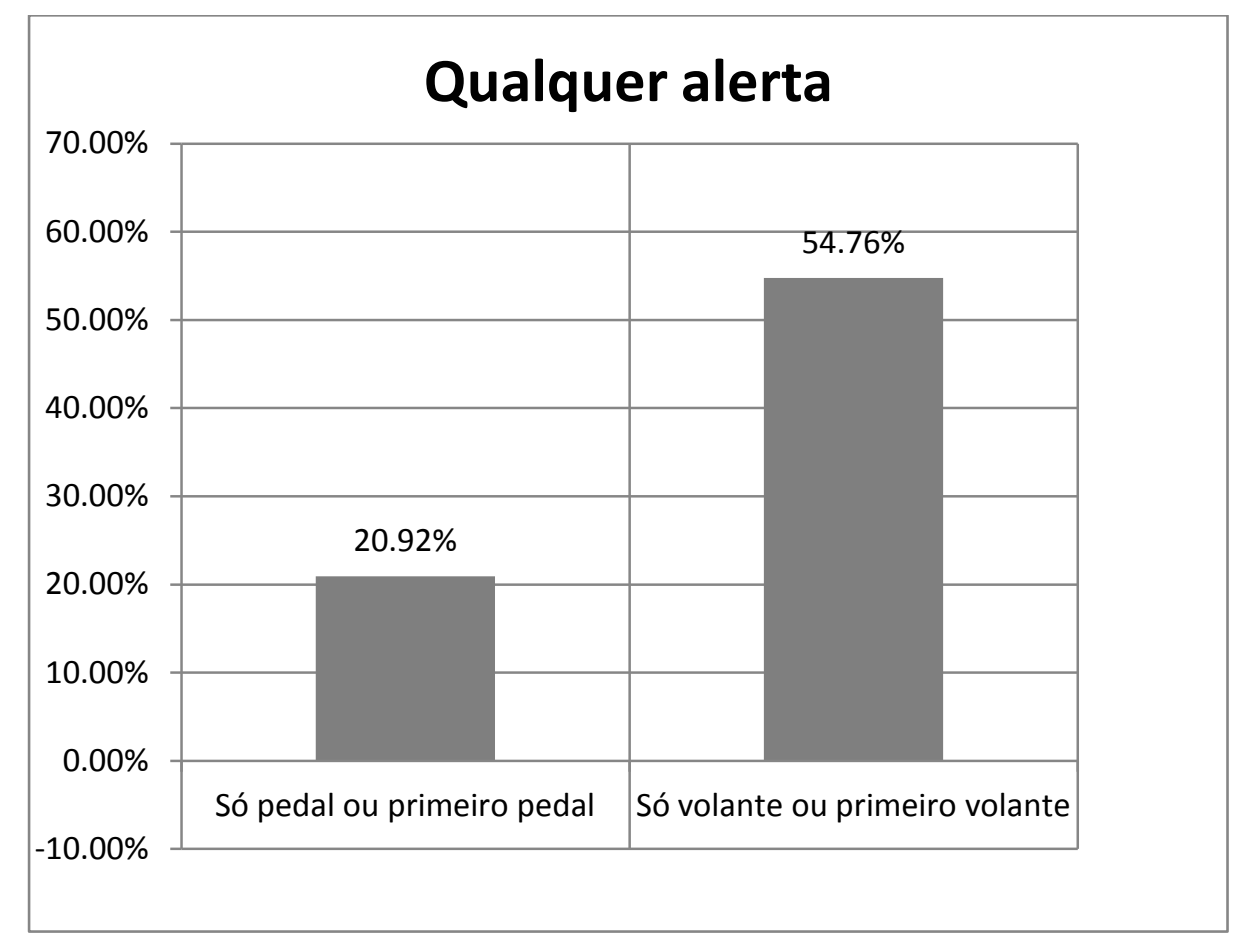

Gráfico 14 - Reação preferencial com algum alerta presente. Fonte: autor

Analisando-se somente aqueles eventos em que o alerta aconteceu com ambos os estímulo auditivo e háptico, houve uma proporção ainda menor de eventos sem reação, 45 ou $16,54 \%$

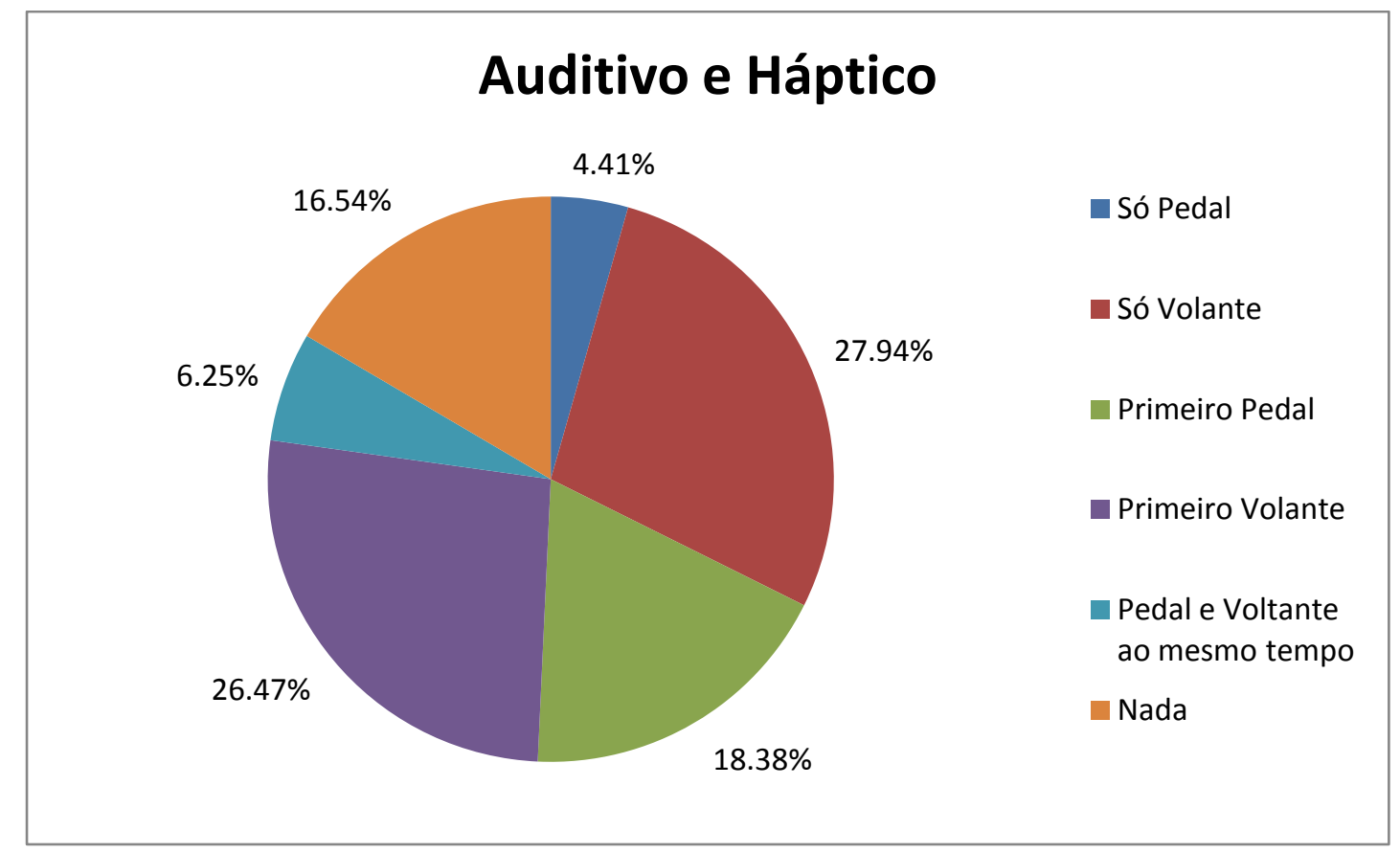

Gráfico 15 - Distribuição dos tipos de reação com ambos os alertas presentes. Fonte: autor 
Neste caso, também a reação no volante foi preferencial, conforme ilustra o gráfico abaixo.

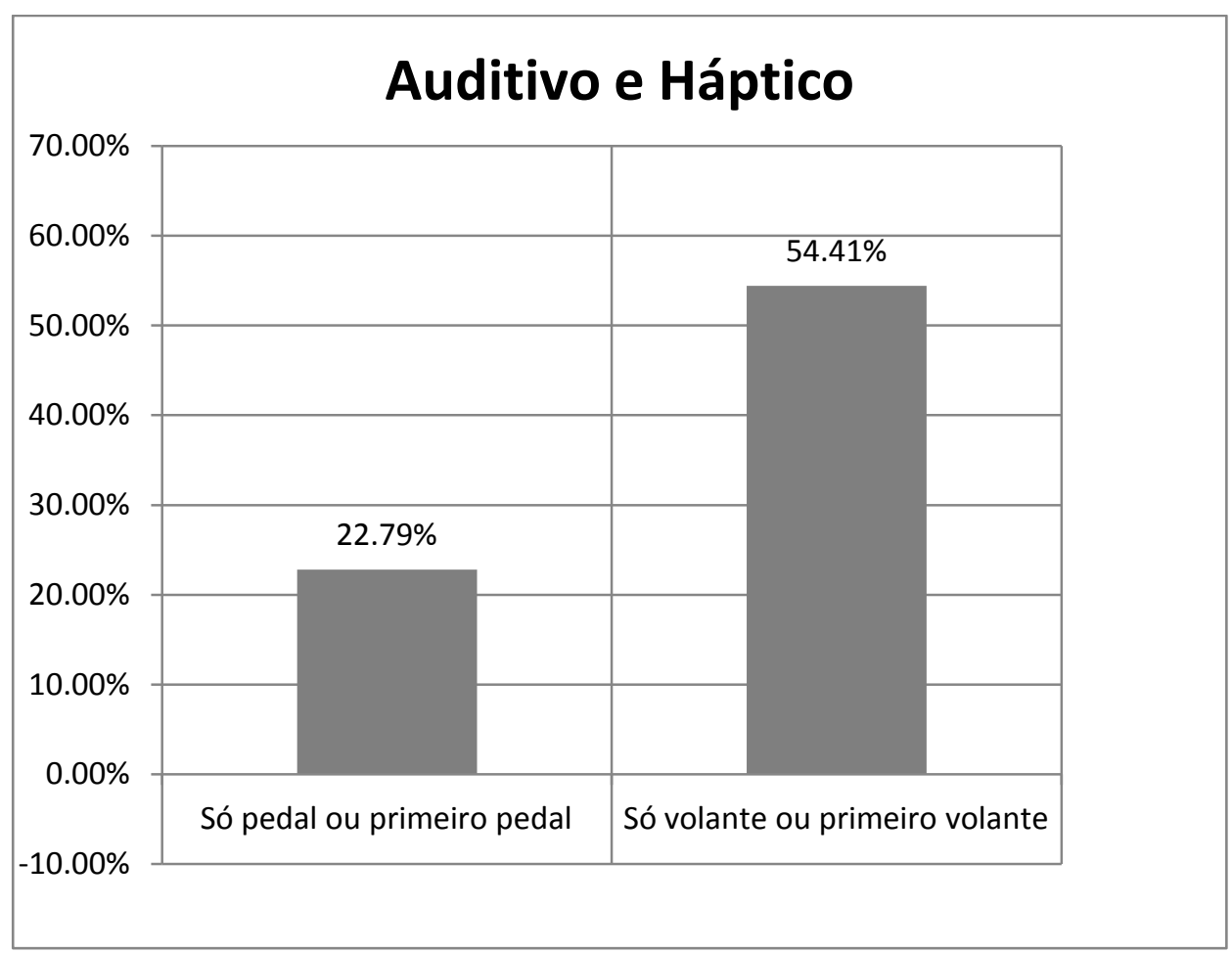

Gráfico 16 - Reação preferencial com ambos os alertas presentes. Fonte: autor

Quando somente o alerta háptico é usado a proporção das reações é conforme o Gráfico 17. 


\section{Háptico}

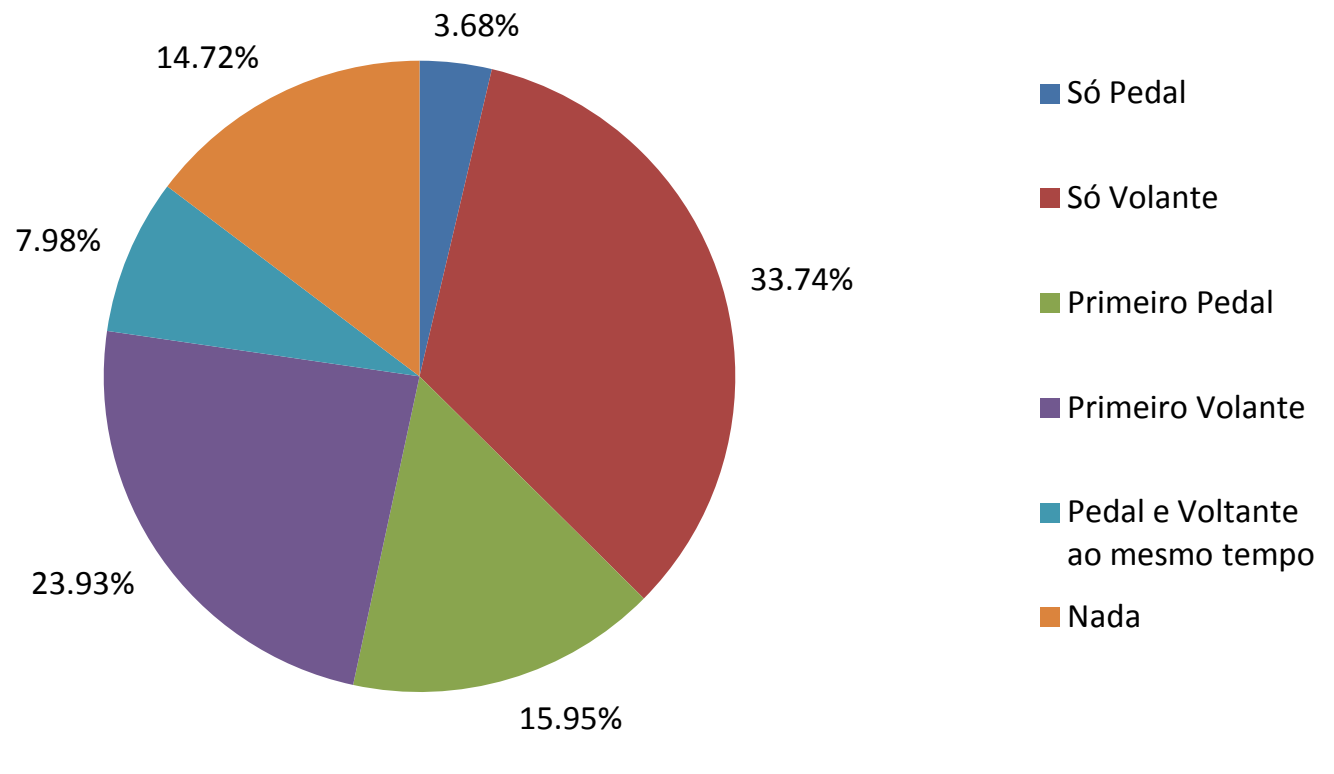

Gráfico 17 - Distribuição dos tipos de reação com alerta háptico presente. Fonte: autor

Novamente, a reação preferencial é o esterçamento volante.

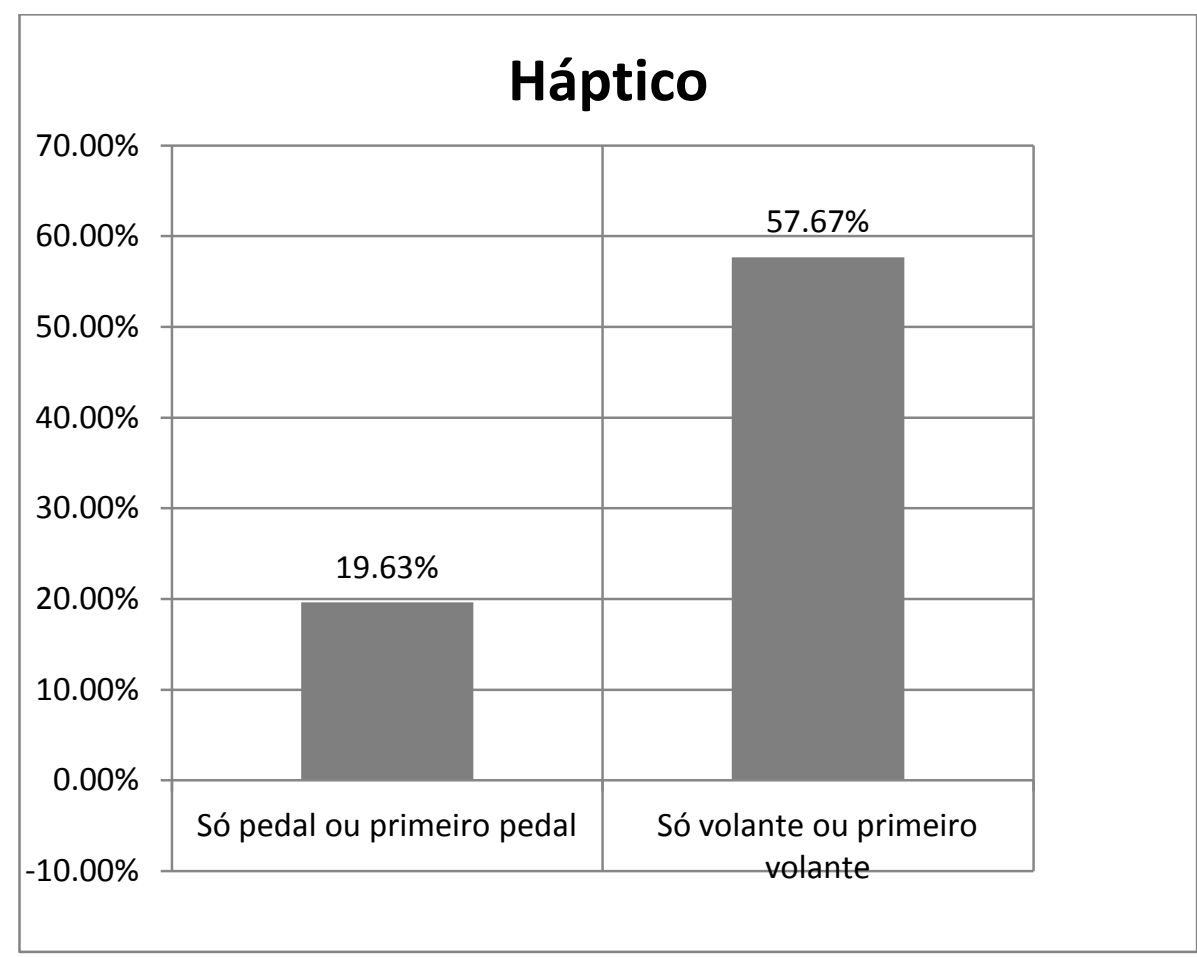

Gráfico 18 - Reação preferencial com alerta háptico presente. Fonte: autor 
O Gráfico 19 apresenta a distribuição dos tipos de reação quando somente o alerta auditivo é uso.

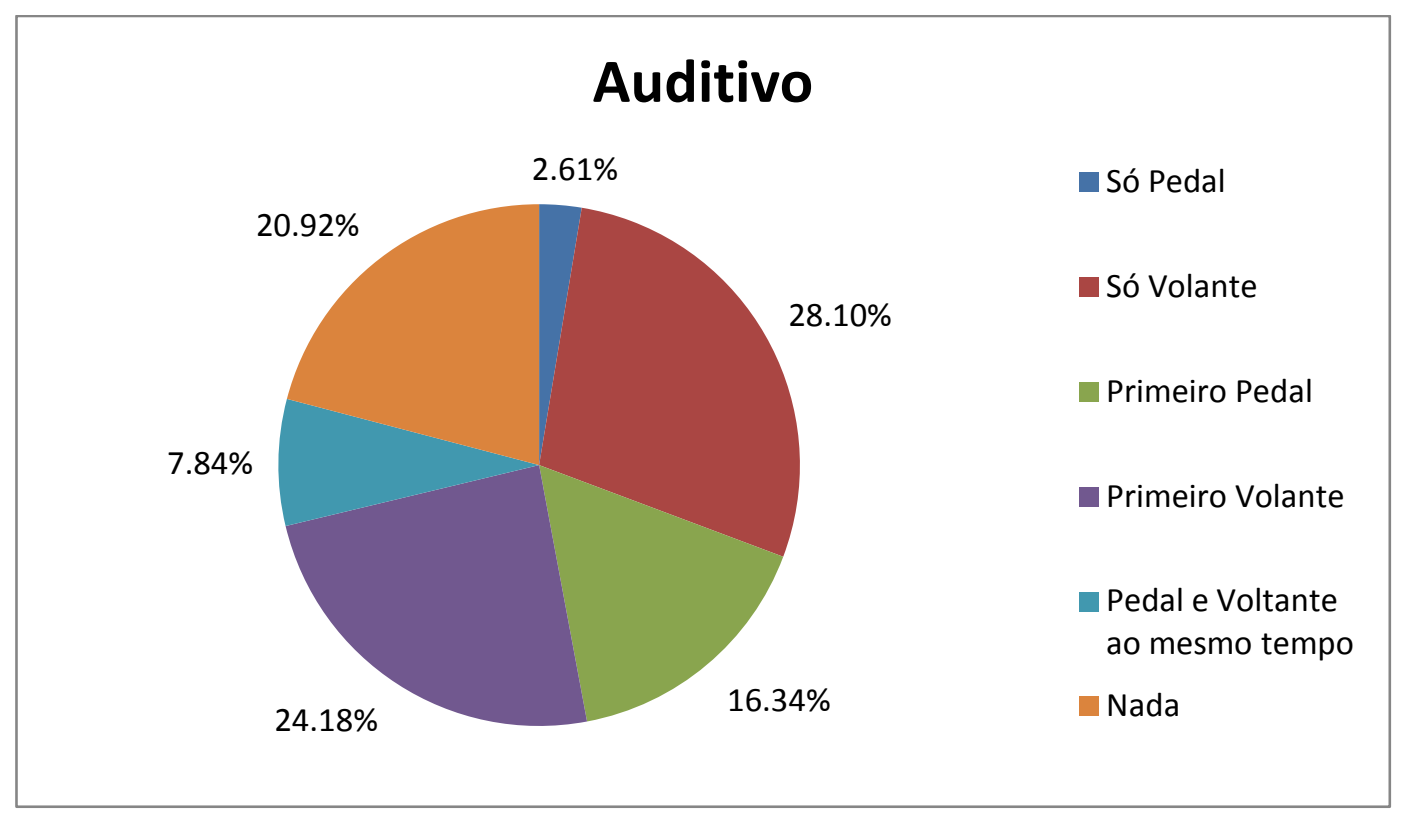

Gráfico 19 - Distribuição dos tipos de reação com alerta auditivo presente. Fonte: autor

Neste caso, a proporção de reações somente no volante ou primeiro no volante é de $52,29 \%$ enquanto a reação somente no pedal ou primeiro no pedal é de $18,95 \%$.

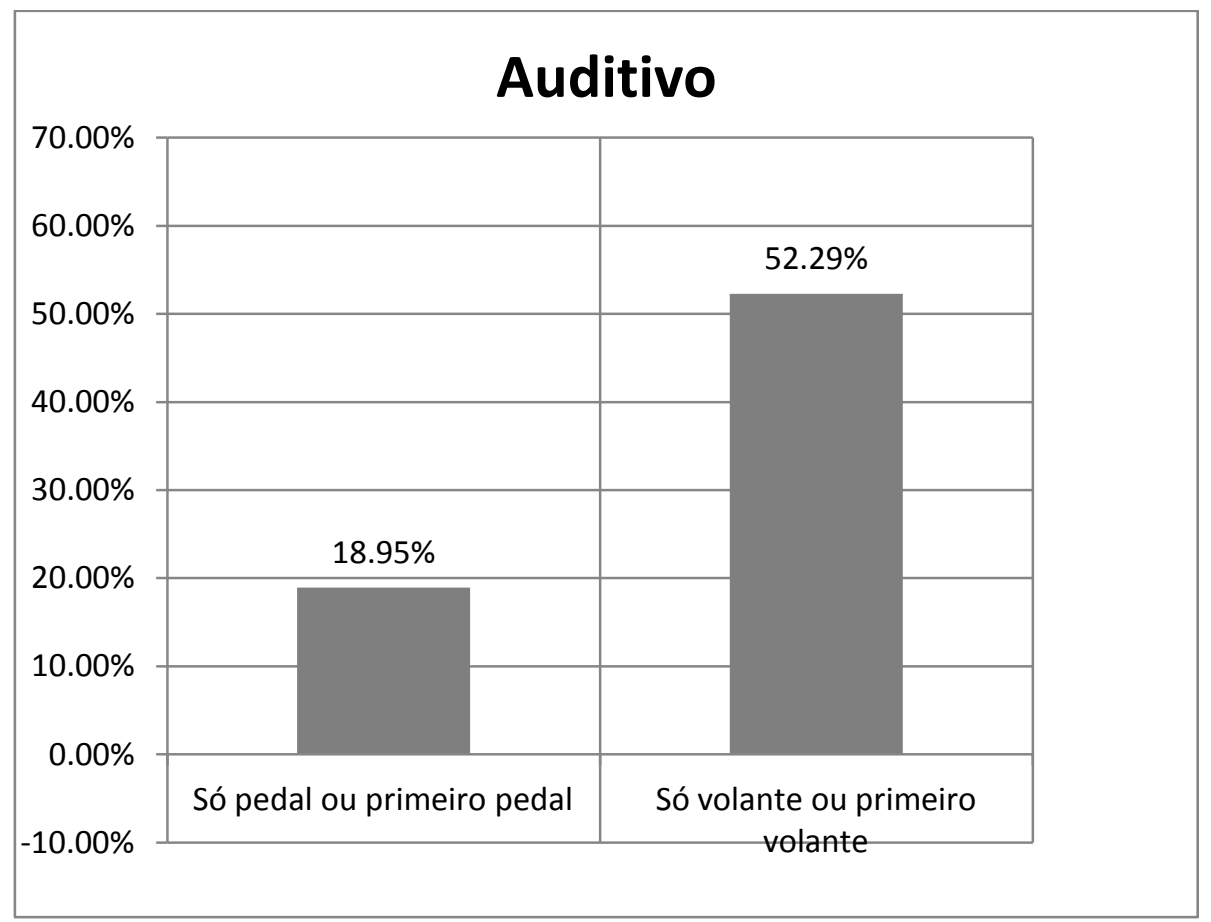

Gráfico 20 - Reação preferencial com alerta auditivo presente. Fonte: autor 


\subsubsection{Tempo de reação}

Nos mesmos critérios do primeiro experimento, foram medidos os tempos de reação a partir do ponto correspondente a $20 \mathrm{~m}$. Os alertas são ativados na distância de aproximadamente $40 \mathrm{~m}$. Os gráficos a seguir apresentam os tempos médios observados nas situações em que qualquer tipo de alerta é utilizado (individuais ou em conjunto), em que ambos os alertas auditivo e háptico são utilizados, em que somente o alerta háptico é utilizado e em que somente o alerta auditivo é utilizado.

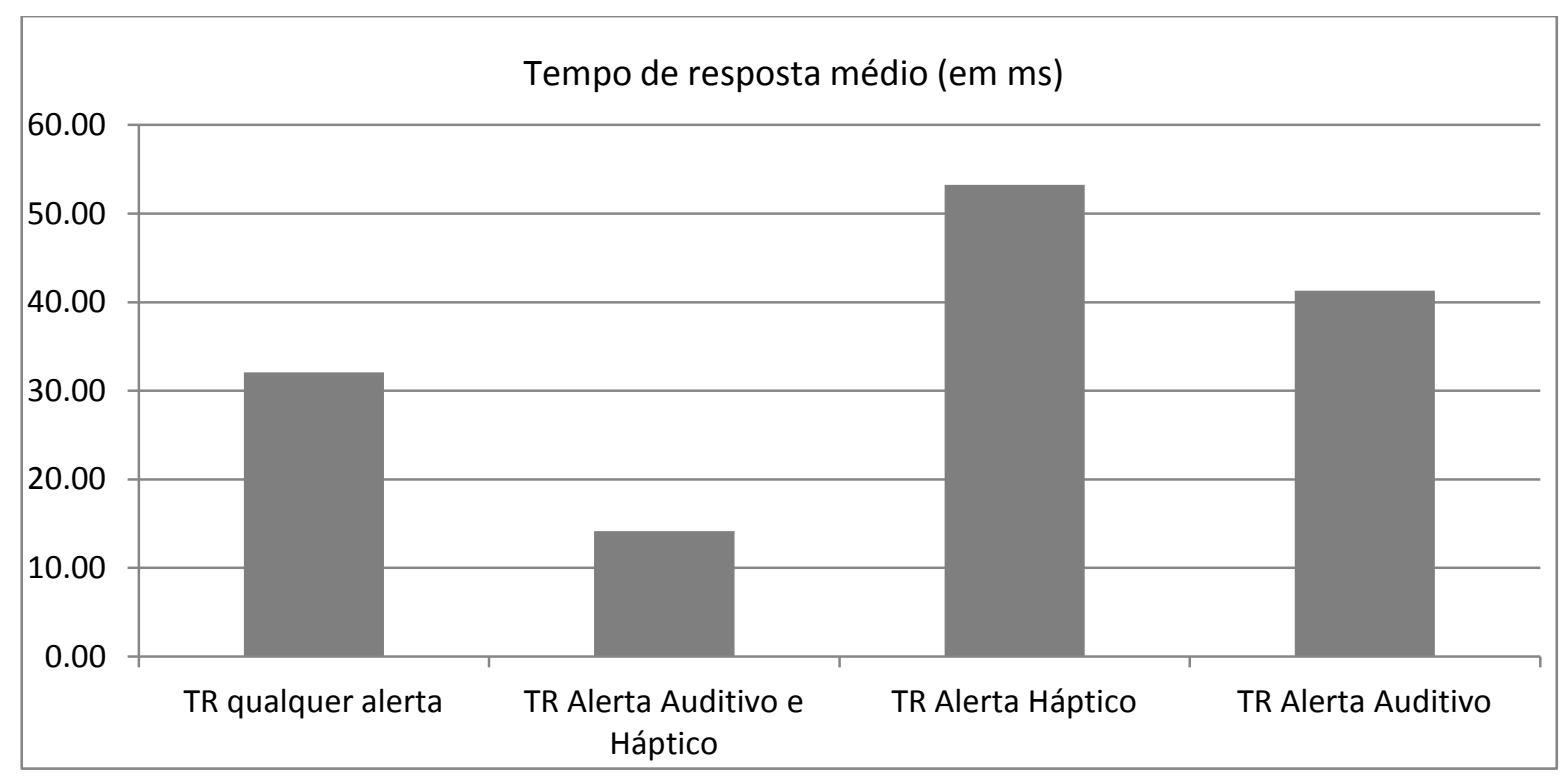

Gráfico 21 - Tempo médio de resposta com alertas presentes. Fonte: autor

Dentre os eventos em que a ação preferencial de esterçamento do volante foi observada inicialmente ou isoladamente, o tempo de reação foi de 0,1 unidades ou $5 \mathrm{~ms}$ e o desvio padrão foi 12,7 ou $635 \mathrm{~ms}$.

Os gráficos a seguir mostram a distribuição dos tempos de reação dentro de faixas de 5 unidades ou $250 \mathrm{~ms}$ para as situações em que qualquer tipo de alerta é utilizado (individuais ou em conjunto), em que ambos os alertas auditivo e háptico são utilizados, em que somente o alerta háptico é utilizado e em que somente o alerta auditivo é utilizado, respectivamente. 


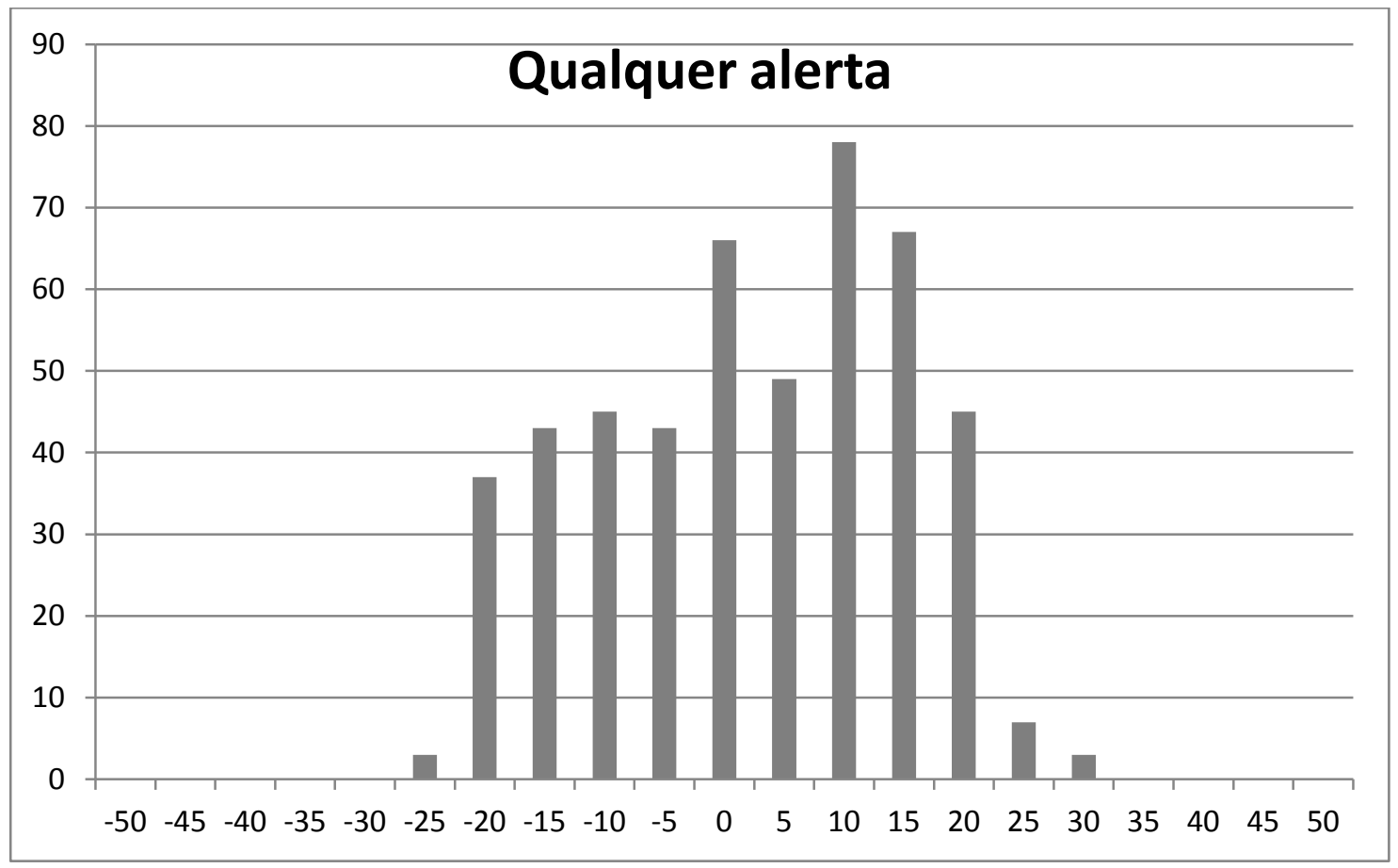

Gráfico 22 - Histograma dos tempos de resposta com algum alerta presente (cada unidade representa $50 \mathrm{~ms})$. Fonte: autor

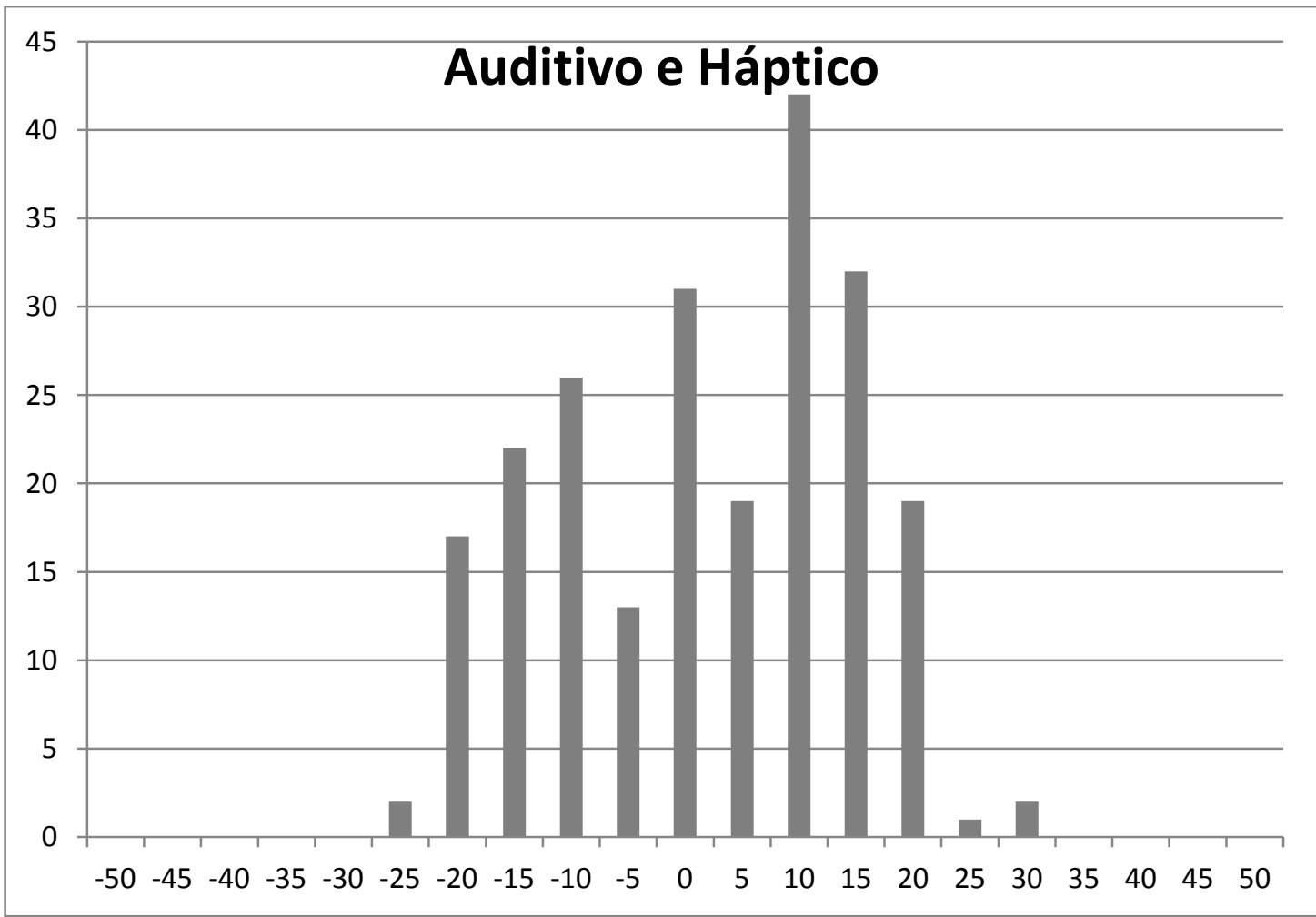

Gráfico 23 - Histograma dos tempos de resposta ambos os alertas presentes (cada unidade representa 50ms). Fonte: autor 


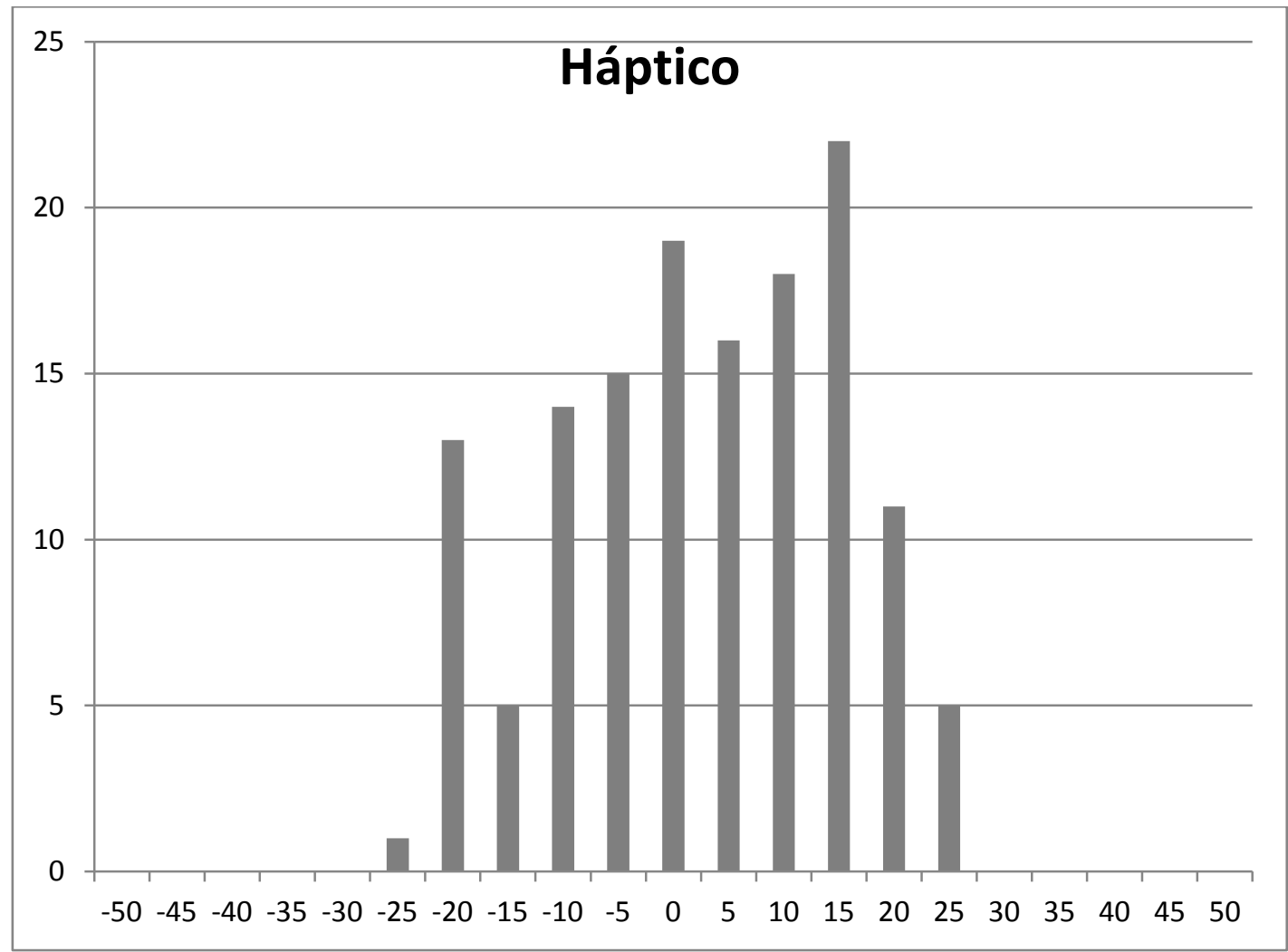

Gráfico 24 - Histograma dos tempos de resposta com o alerta háptico presente (cada unidade representa 50ms). Fonte: autor

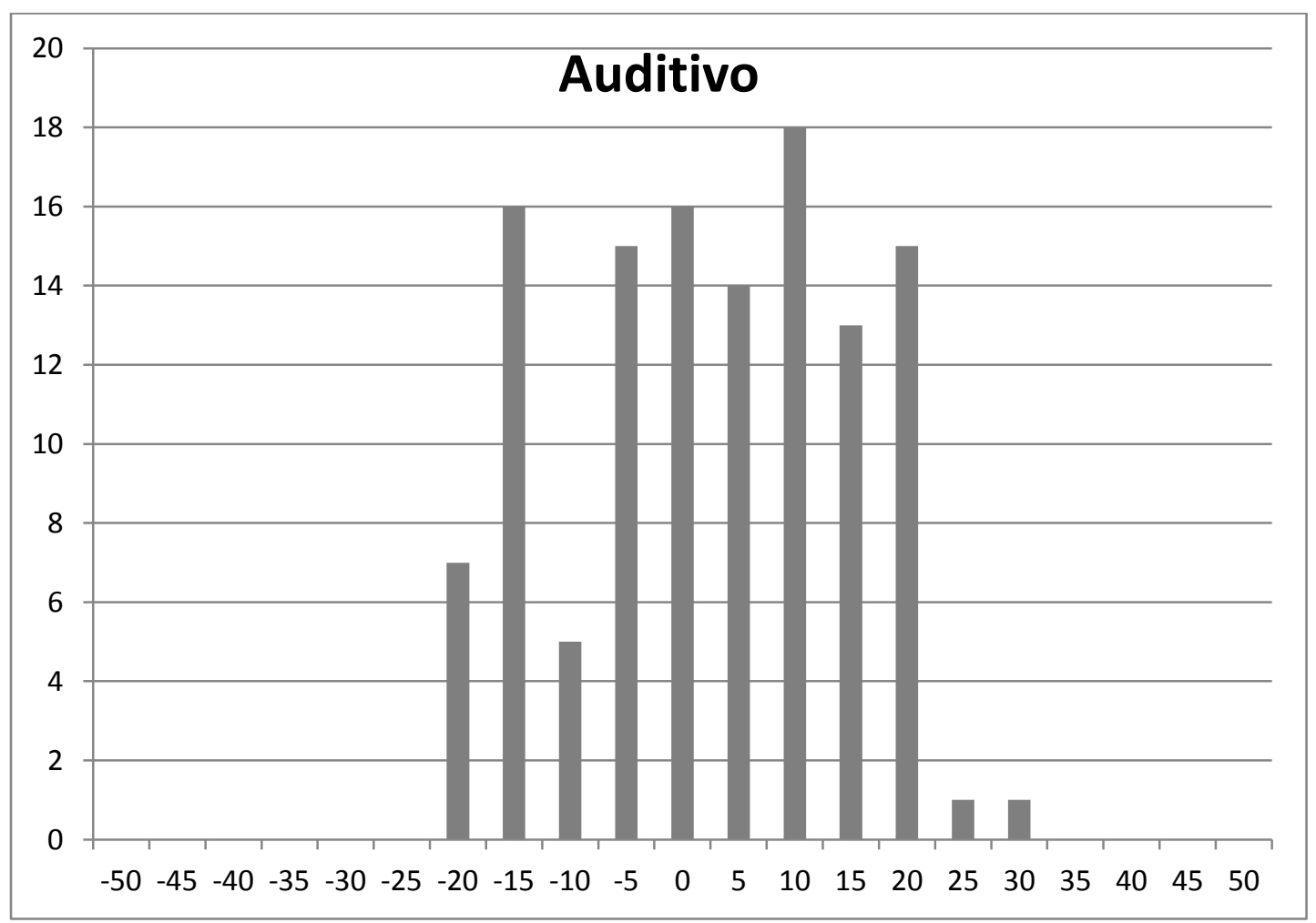

Gráfico 25 - Histograma dos tempos de resposta com o alerta auditivo presente (cada unidade representa 50ms). Fonte: autor 


\subsubsection{Reação exagerada}

Os gráficos a seguir mostram a proporção de eventos em que houve reação exagerada nos controles por parte dos participantes. A coluna da esquerda representa a proporção de eventos com frenagem dentre os eventos em que houve reação no pedal e a coluna da direita é a proporção de eventos com esterçamento máxima do volante dentre os eventos em que houve reação no volante.

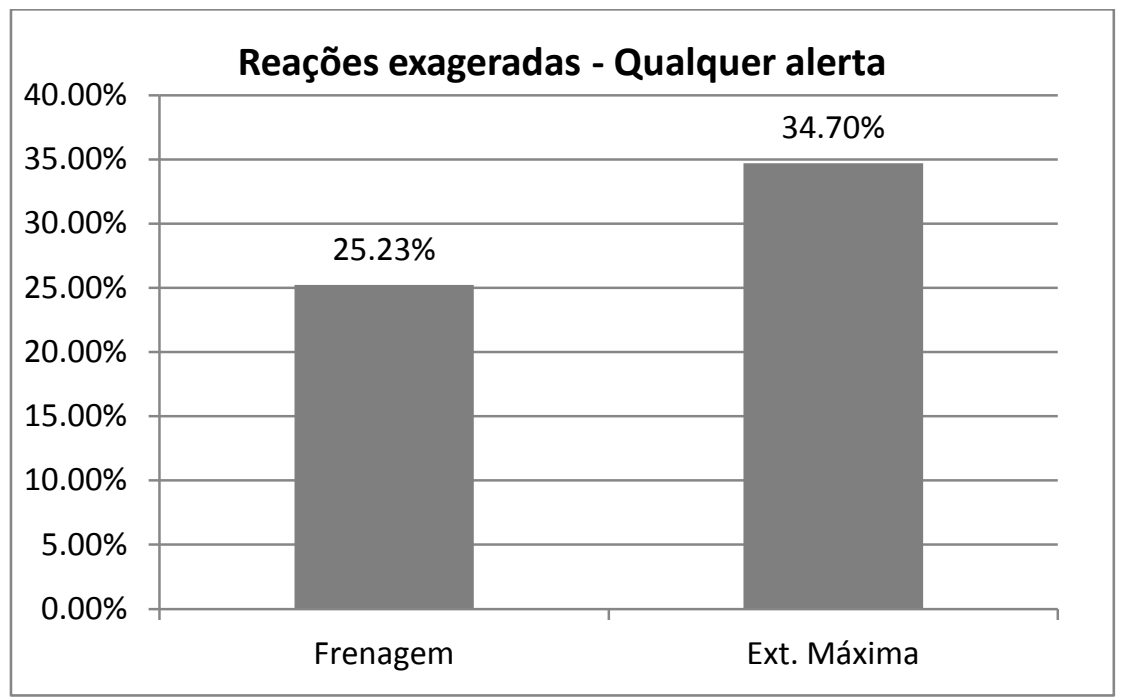

Gráfico 26 - Registro de ações exageradas com algum alerta presente. Fonte: autor

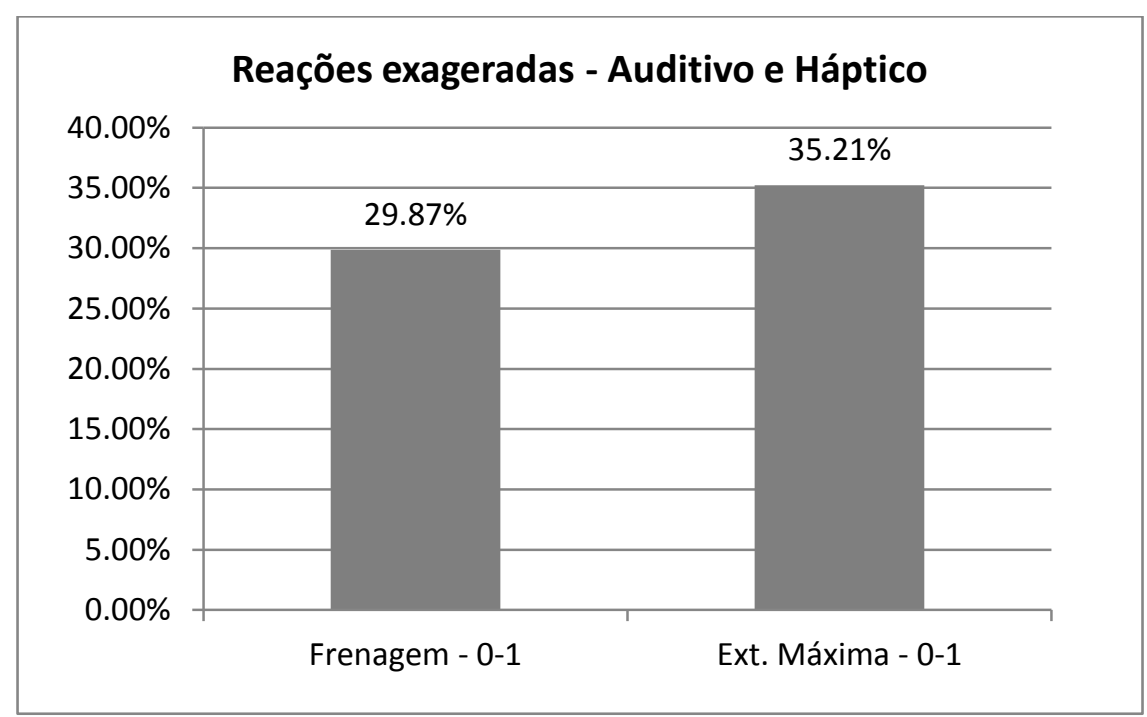

Gráfico 27 - Registro de ações exageradas com ambos os alertas presentes. Fonte: autor 


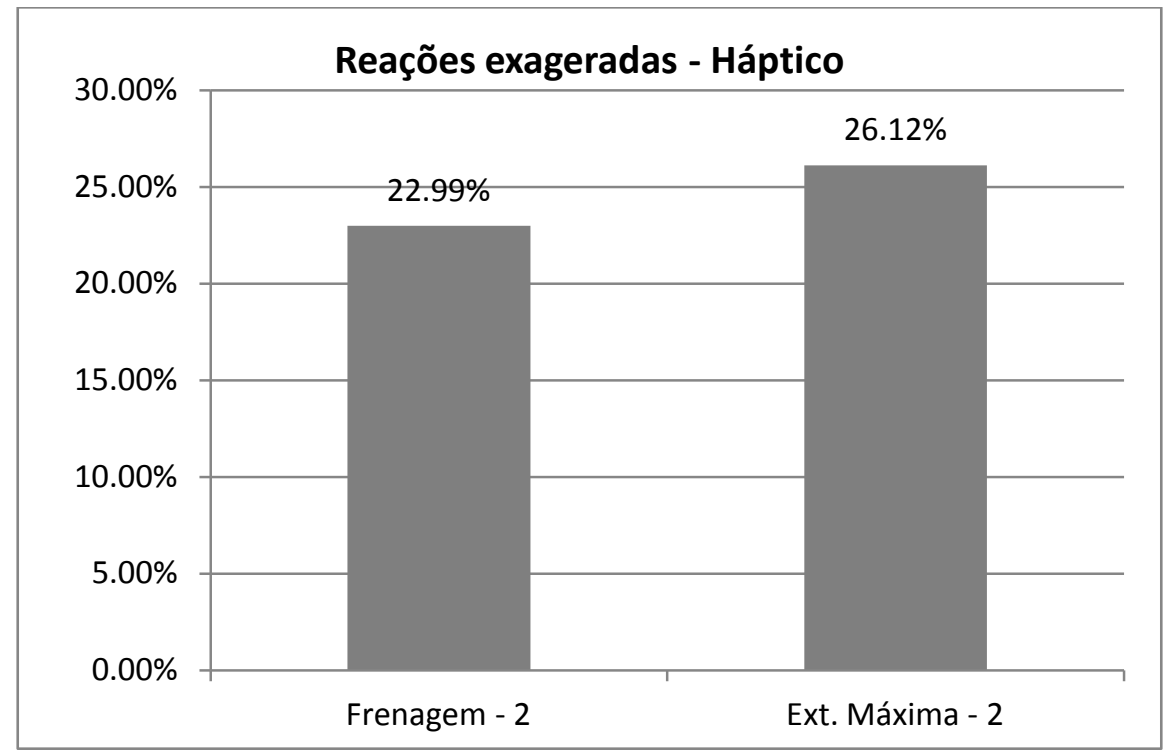

Gráfico 28 - Registro de ações exageradas com o alerta háptico presente. Fonte: autor

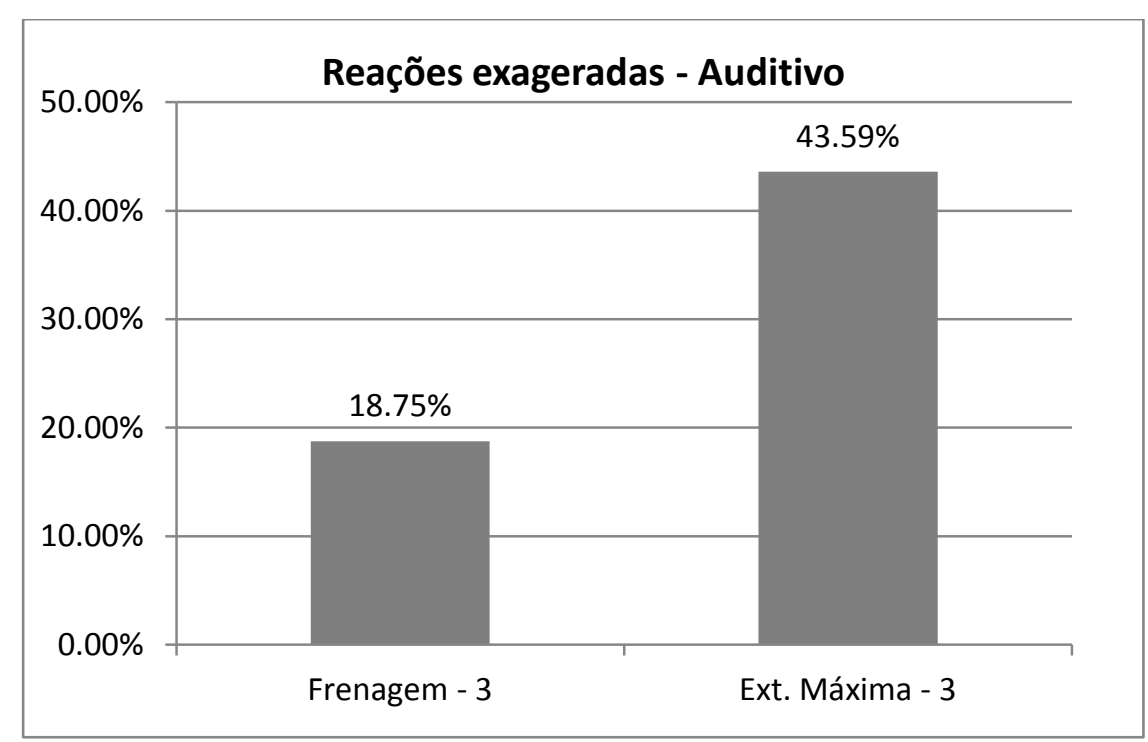

Gráfico 29 - Registro de ações exageradas com o alerta auditivo presente. Fonte: autor

\subsubsection{Questionário pós-teste}

Após os dados serem coletados, o voluntário foi entrevistado de acordo com 0 questionário pós-teste da seção 6.4.3. Os resultados são mostrados a seguir. 


\subsubsection{Utilidade dos alertas}

Quando questionados sobre a utilidade do alerta auditivo, os participantes deram uma nota média de 3,57, em uma escala de 1 a 5 , sendo $1=$ nada útil e $5=$ muito útil, conforme o gráfico a seguir.

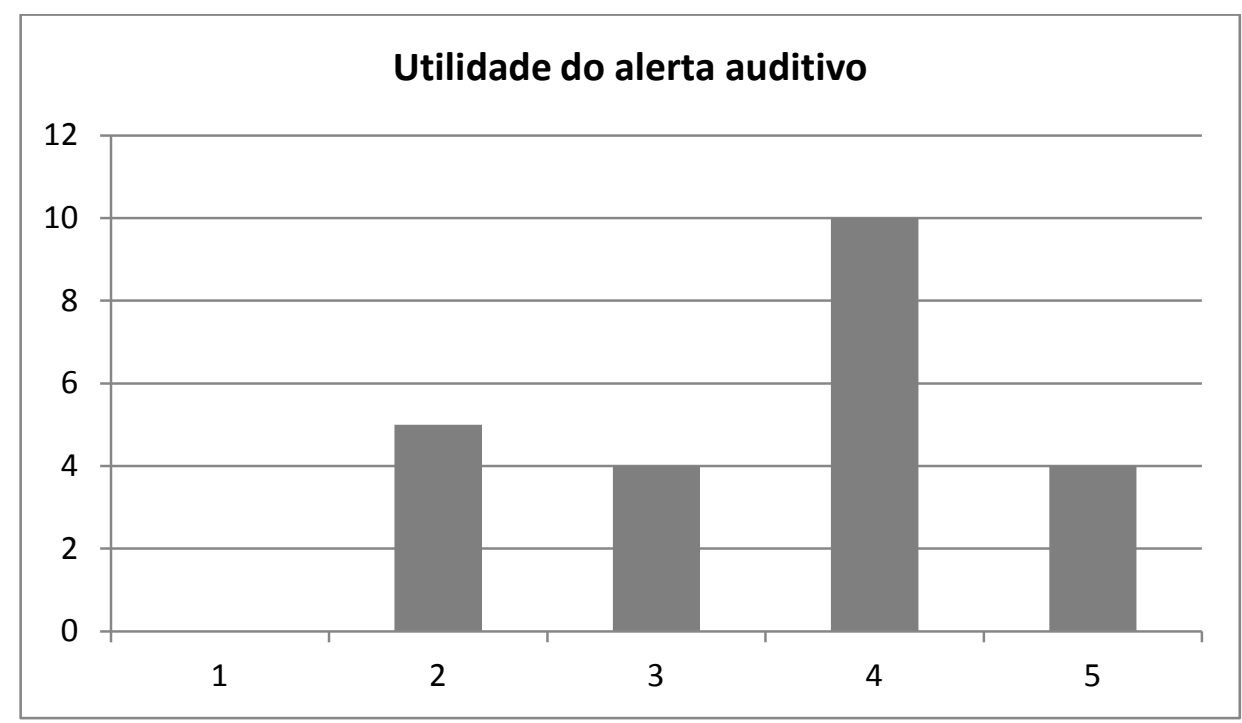

Gráfico 30 - Distribuição da percepção de utilidade do alerta auditivo. Fonte: autor

Quando questionados sobre a utilidade do alerta háptico, a nota média foi de 3,65. Veja o Gráfico 31.

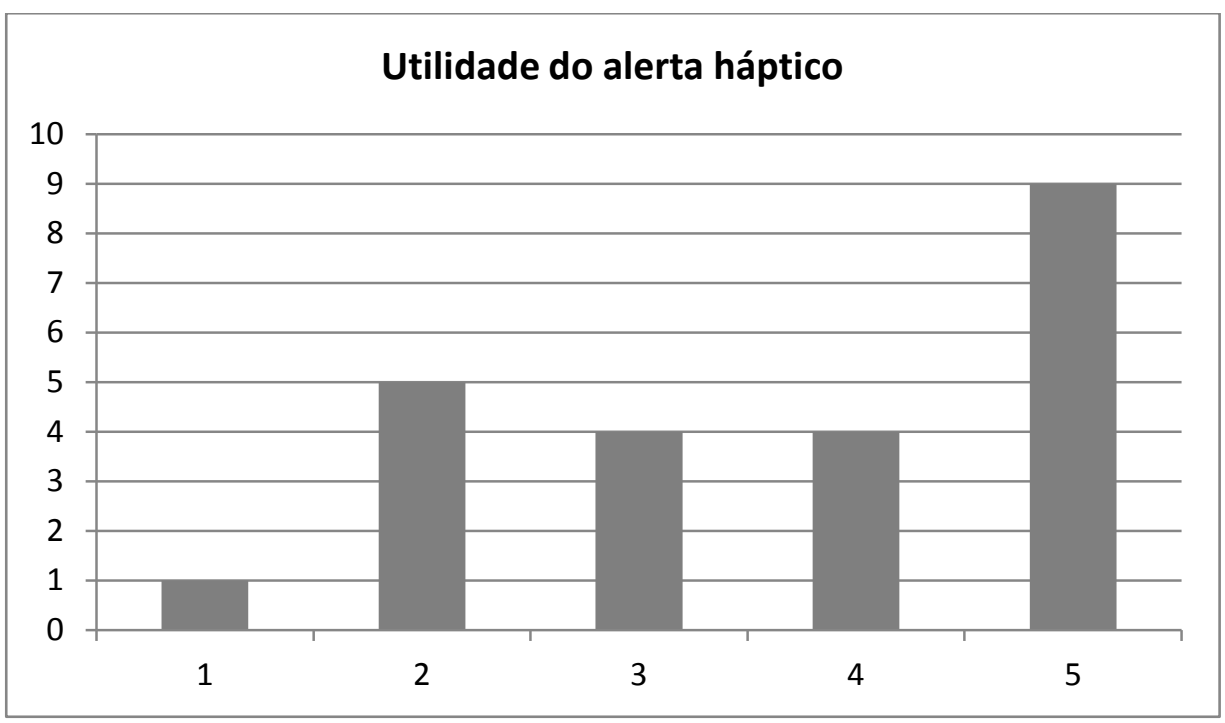

Gráfico 31 - Distribuição da percepção de utilidade do alerta háptico. Fonte: autor 
Como mostra o gráfico abaixo, não houve diferença no número de participantes que preferiu o alerta auditivo e o número que preferiu o alerta háptico.

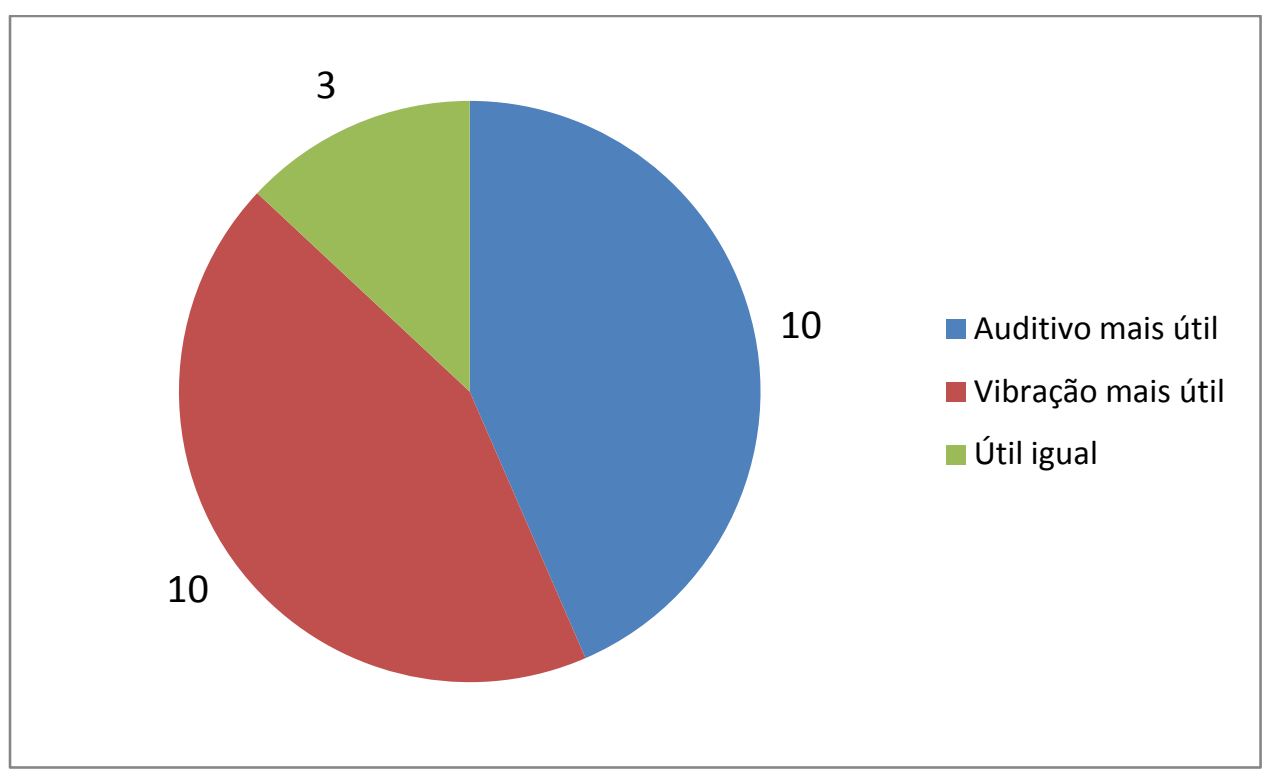

Gráfico 32 - Percepção de utilidade dos alertas. Fonte: autor

\subsubsection{Incômodo dos alertas}

Quando questionados sobre o incômodo do alerta auditivo, os participantes deram uma nota média de 2,57, em uma escala de 1 a 5 , sendo 1 = nada incômodo e 5 = muito incômodo, conforme o gráfico a seguir.

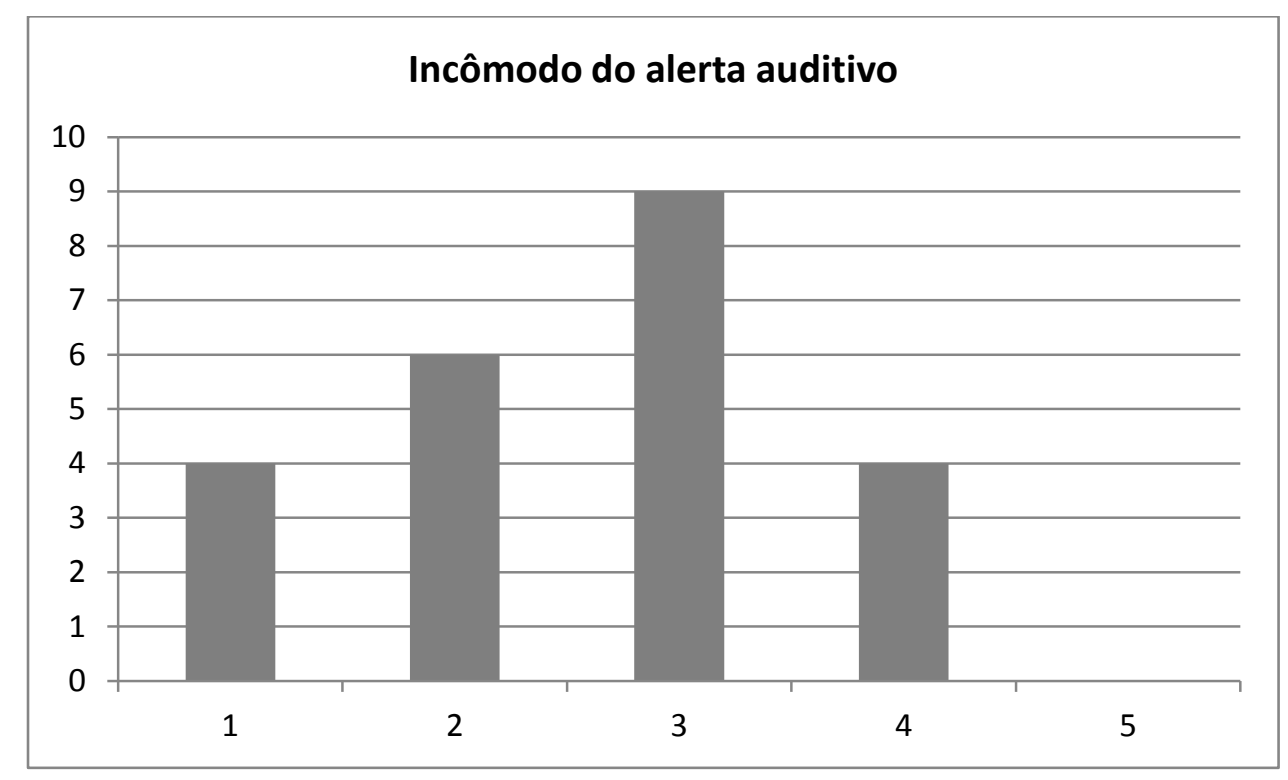

Gráfico 33 - Distribuição da percepção de incômodo do alerta auditivo. Fonte: autor 
Quando questionados sobre o incômodo do alerta háptico, a nota média foi de 2,00.

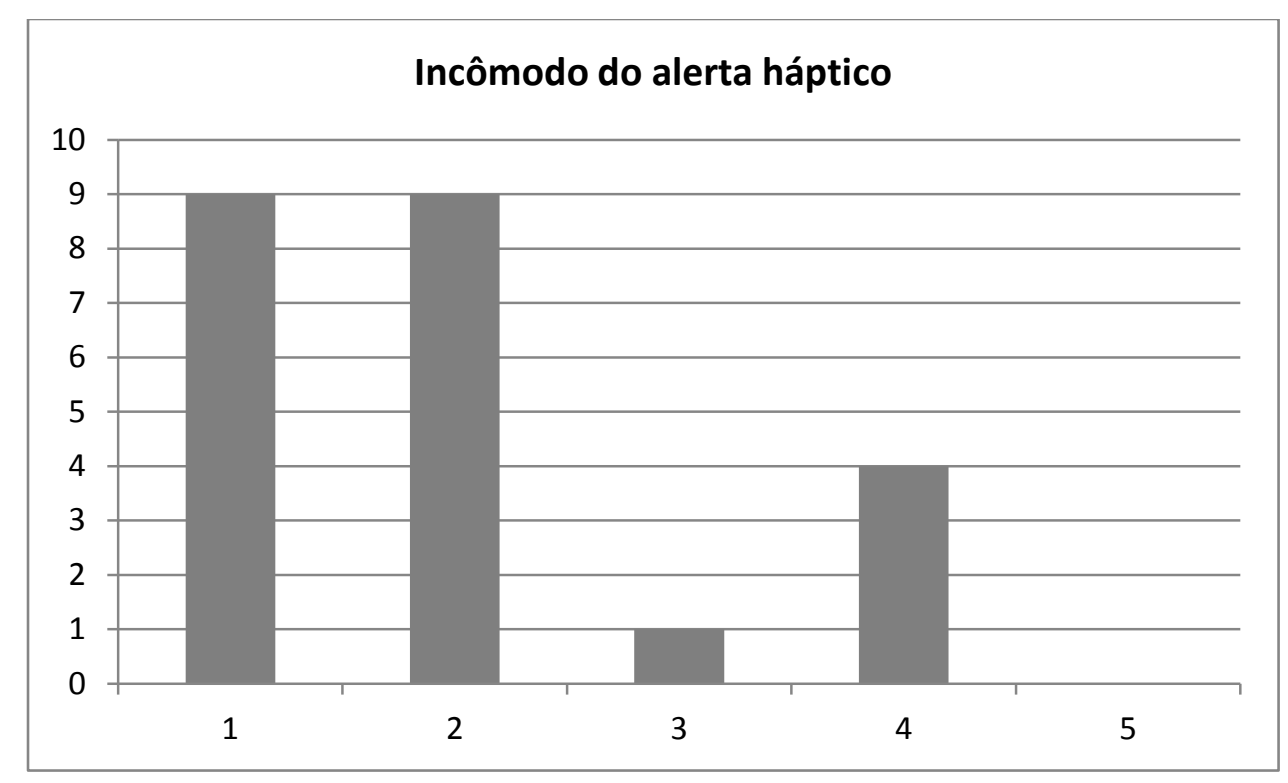

Gráfico 34 - Distribuição da percepção de incômodo do alerta háptico. Fonte: autor

Nenhum dos participantes categorizou os alertas como muito incômodos, mas a maioria disse que o alerta auditivo incomoda mais do que o háptico. Conforme o Gráfico 35, 60\% consideram o alerta auditivo mais incômodo que o háptico e somente $21 \%$ consideram o háptico mais incômodo.

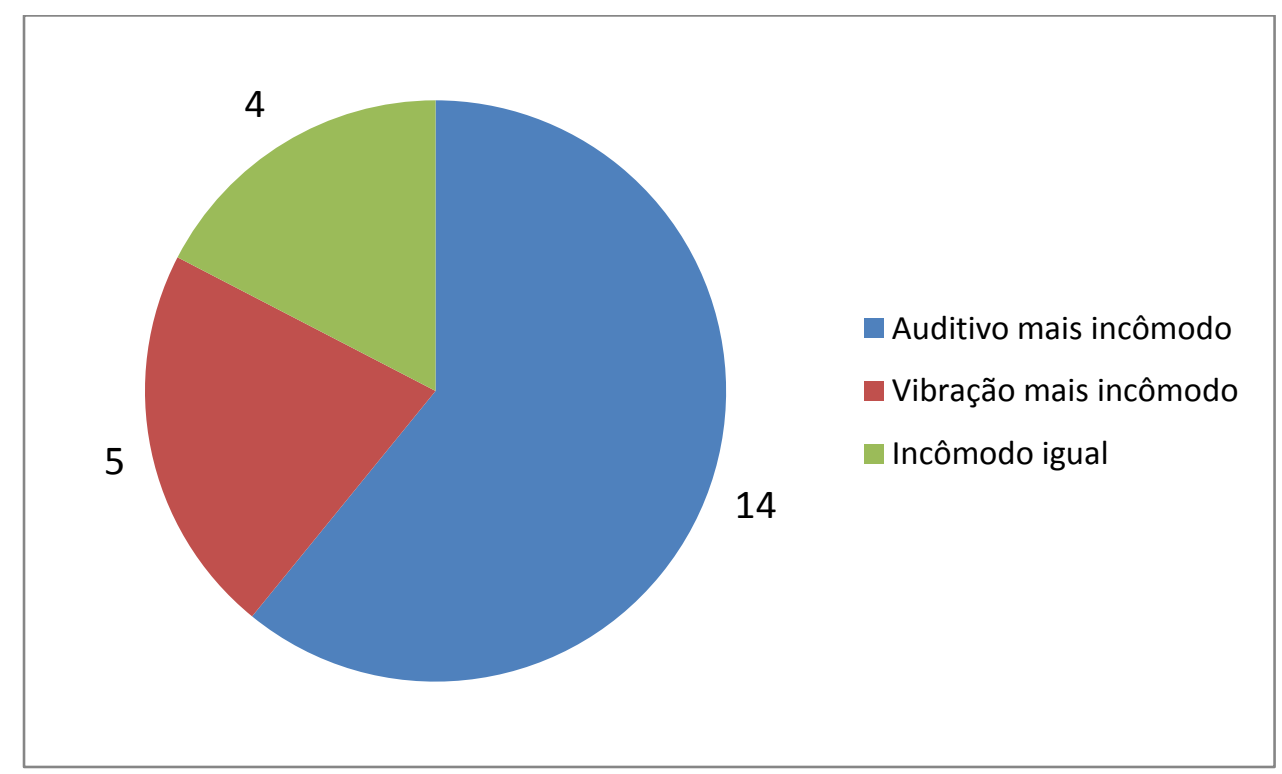

Gráfico 35 - Percepção de incômodo dos alertas. Fonte: autor 


\subsubsection{Percepção geral}

$\mathrm{Na}$ entrevista pós-teste foi possível coletar ainda algumas informações sobre a percepção geral que os participantes tiveram sobre o sistema de alertas. $22 \%$ deles relataram que em algum momento do teste tiveram um "susto" quando os alertas foram acionados. $52 \%$ disseram que os alertas causaram uma sensação de "confusão" e citaram o fato de os alertas serem intercalados de forma aleatória entre auditivos, hápticos e conjugados como algo confuso. Apesar disso, $65 \%$ relatam que teriam interesse no sistema de alertas e acreditam que esse sistema pode ajudar a reduzir acidentes.

\subsubsection{Reações adversas}

Não houve registro de mal estar em nenhum dos voluntários participantes do segundo experimento.

\subsection{Comparação entre resultados}

Nessa seção, são apresentados alguns resultados gerais, considerando os dois experimentos e são feitos alguns cruzamentos de resultados entre o primeiro experimento e o segundo experimento.

\subsubsection{Relação da idade com o tempo de resposta}

O gráfico abaixo mostra a distribuição das médias dos tempos de reação por idade dos participantes. Não há tendência clara de variação do tempo de reação com a idade. 


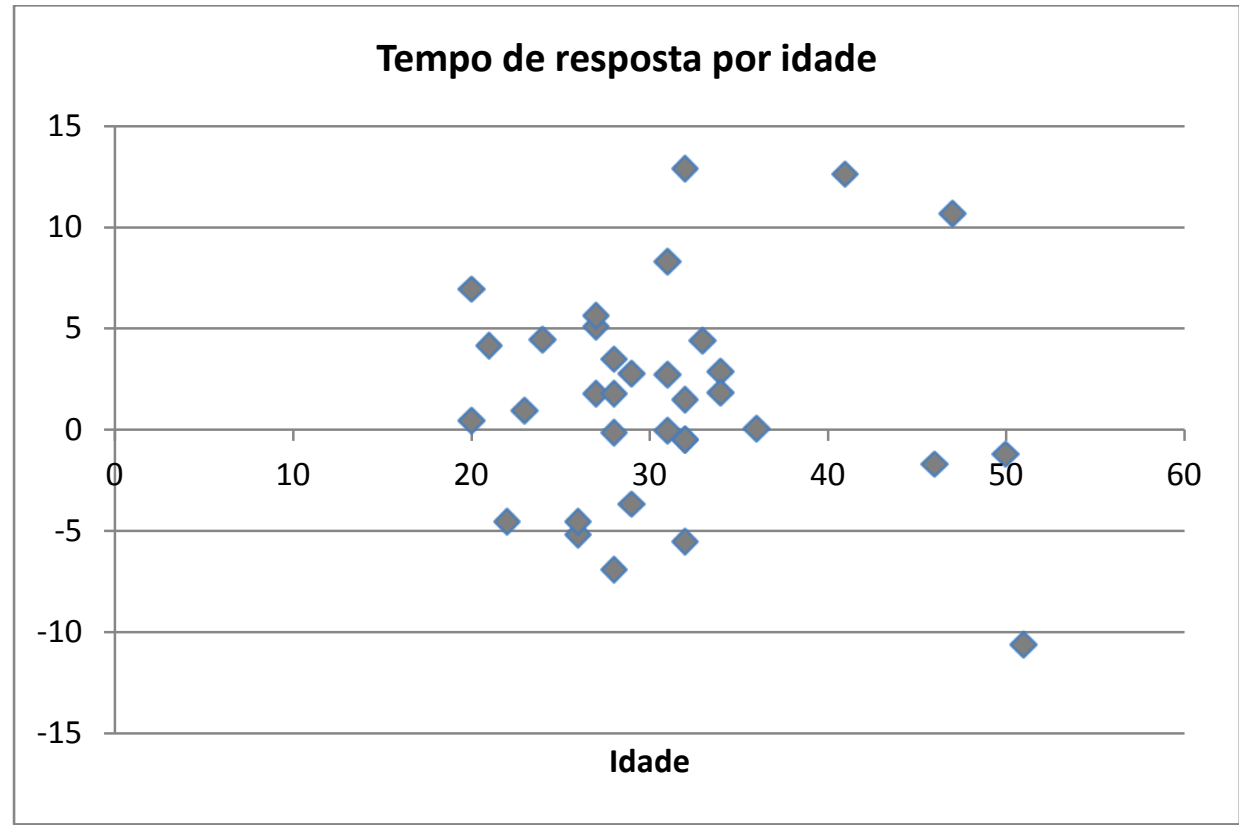

Gráfico 36 - Relação do tempo de resposta com a idade (unidade anos na horizontal e 50ms na vertical). Fonte: autor

\subsubsection{Relação da experiência com o tempo de resposta}

O gráfico abaixo mostra que também não há variação no padrão dos tempos de reação com a experiência de direção.

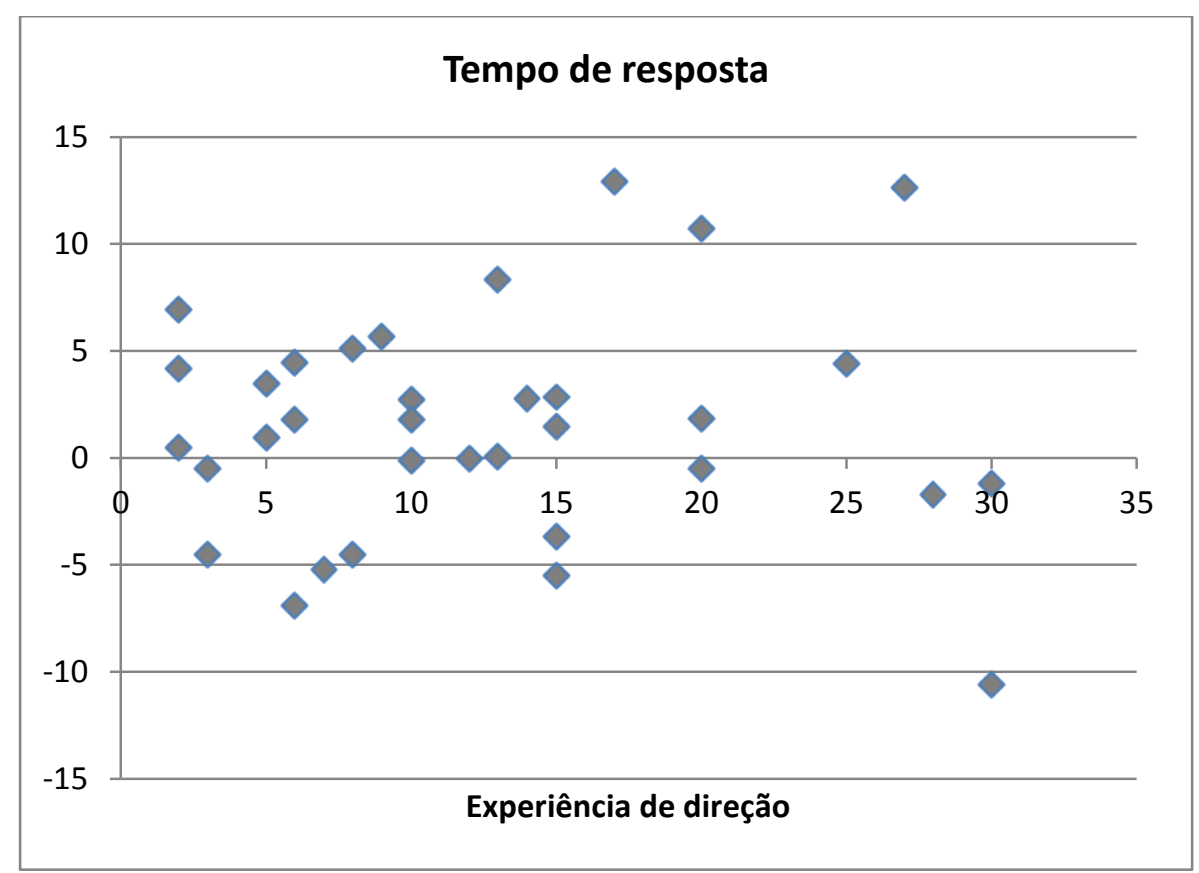

Gráfico 37 - Relação do tempo de resposta com a experiência (unidade anos na horizontal e $50 \mathrm{~ms}$ na vertical) . Fonte: autor 
7.3.3 Relação do uso de jogos com o tempo de resposta

No gráfico abaixo, são apresentadas as médias dos tempos de reação para cada categoria de experiência com jogos. Não é possível identificar algum padrão significativo.

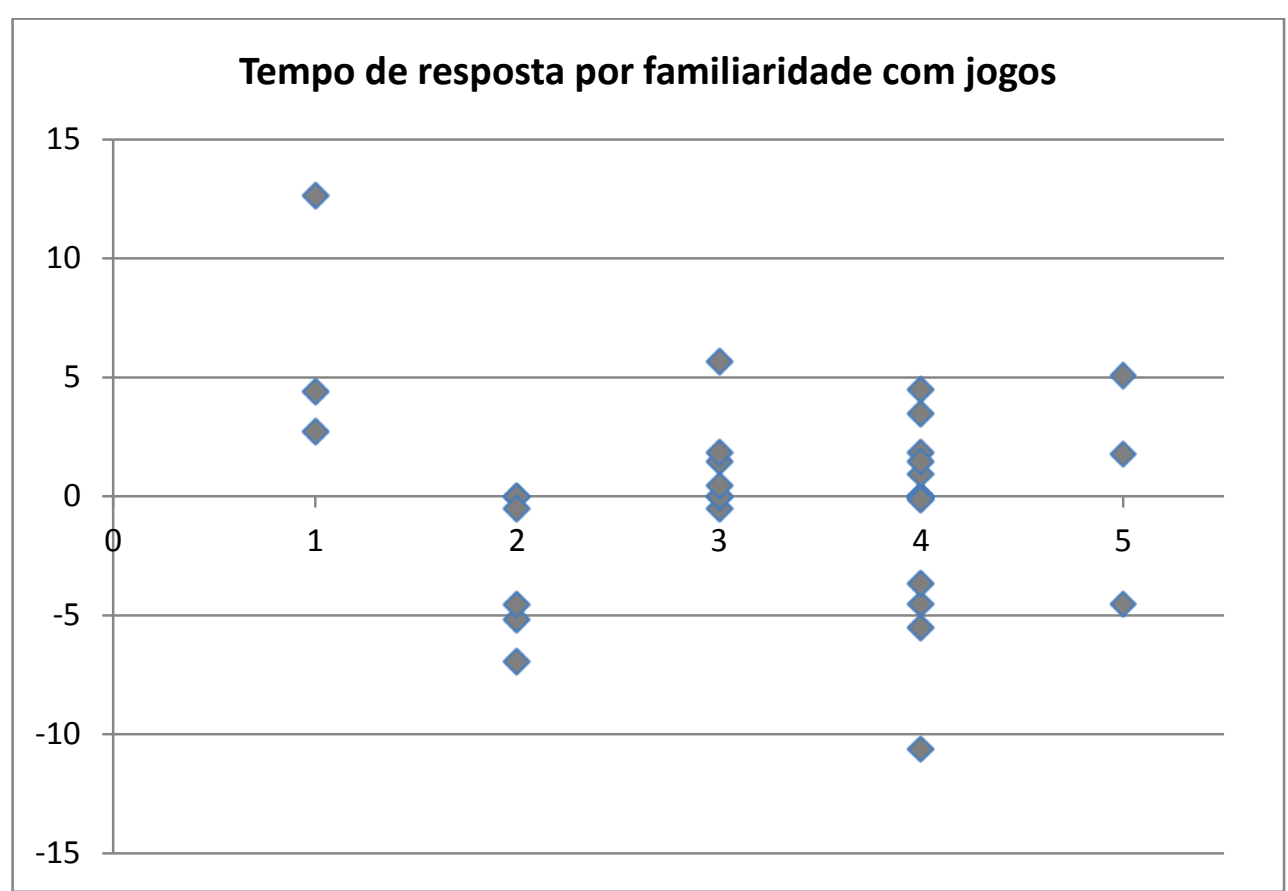

Gráfico 38 - Relação do tempo de resposta com o uso de jogos (na horizontal experiência crescente com jogos e $50 \mathrm{~ms}$ na vertical). Fonte: autor 
7.3.4 Relação dos tempos de resposta com e sem alertas

O Gráfico 39 mostra a relação entre as médias dos tempos de reações observadas em cada situação.

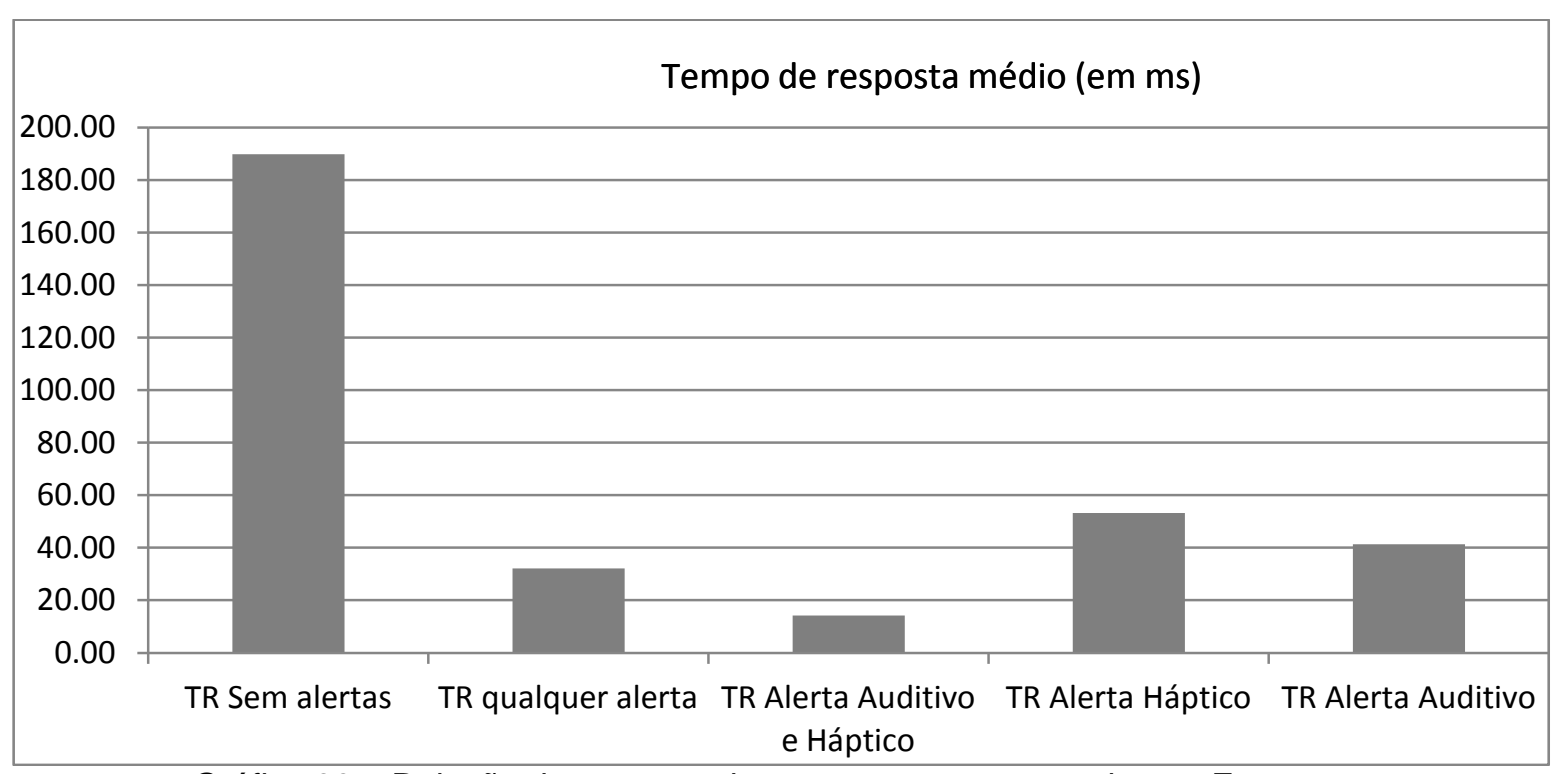

Gráfico 39 - Relação dos tempos de resposta com e sem alertas. Fonte: autor

Considerando as distribuições dos tempos de reação dentro de cada uma das categorias de alerta, mostras nos histogramas Gráfico 7, Gráfico 22, Gráfico 23, Gráfico 24 e Gráfico 25, temos, segundo Downing (2003), que o intervalo de confiança para a diferença das médias pode ser dada por:

$$
I C\left(\mu_{1}-\mu_{2}, 1-\alpha\right)=\left((\bar{X}-\bar{Y})-t_{(\nu, \alpha / 2)} \sqrt{\frac{s_{1}^{2}}{n_{1}}+\frac{s_{2}^{2}}{n_{2}}} ;(\bar{X}-\bar{Y})+t_{(\nu, \alpha / 2)} \sqrt{\frac{s_{1}^{2}}{n_{1}}+\frac{s_{2}^{2}}{n_{2}}}\right)
$$

onde

$\mu$ é a média populacional

$\mathrm{s}_{1}{ }^{2}$ é a variância amostral

$\bar{X}$ é a média amostral

n é o tamanho da amostra

$\mathrm{t}_{(\mathrm{v}, \mathrm{a} / 2)}$ é o valor da tabela de distribuição $\mathrm{t}$ de Student $\nu$

$(1-\alpha)$ é o coeficiente de confiança 
Considerando

$$
1-\alpha=0,99
$$

temos que a diferença entre as médias sem alerta e com alerta para cada tipo de alerta são dadas pela tabela abaixo:

\begin{tabular}{|l|c|c|}
\hline & Intervalo inferior $(\mathrm{ms})$ & Intervalo superior (ms) \\
\hline TR qualquer alerta & 48.8 & 266.8 \\
\hline TR Alerta Auditivo e Háptico & 40.2 & 311.2 \\
\hline TR Alerta Háptico & -23.9 & 297.2 \\
\hline TR Alerta Auditivo & -16.0 & 313.2 \\
\hline
\end{tabular}

Tabela 6 - Intervalo de confiança da diferença das médias comparado a "sem alertas" (99\%). Fonte: autor

Para

$$
1-\alpha=0,95
$$

temos

\begin{tabular}{|l|c|c|}
\hline & Intervalo inferior $(\mathrm{ms})$ & Intervalo superior $(\mathrm{ms})$ \\
\hline TR qualquer alerta & 75.0 & 240.6 \\
\hline TR Alerta Auditivo e Háptico & 72.8 & 278.7 \\
\hline TR Alerta Háptico & 14.7 & 258.6 \\
\hline TR Alerta Auditivo & 23.5 & 273.6 \\
\hline
\end{tabular}

Tabela 7 - Intervalo de confiança da diferença das médias comparado a "sem alertas" (95\%). Fonte: autor

Ou seja, podemos afirmar com 99\% de certeza que a diferença entre as médias populacionais dos tempos reações sem e com alertas está na faixa de 48,8ms a $266,8 \mathrm{~ms}$. Isso significa que há fortes evidências de que os tempos de reação com os alertas presentes são menores do que sem os alertas presentes.

Para o alerta auditivo e háptico conjugados, também é possível afirmar com $99 \%$ de certeza que os tempos de reação com o alerta são menores. 
Nos alertas individuais, o critério de 99\% apresenta valores na faixa negativa. Ainda assim, é possível afirmar, pela Tabela 7, que há 95\% de certeza de que a presença do alerta contribui para a redução dos tempos de reação.

A diferença dos tempos reação com e sem alertas nos casos em que a ação preferencial de esterçamente do volante foi observada inicialmente ou isoladamente é também significativa. Observou-se $210 \mathrm{~ms}$ para o caso sem alertas e $5 \mathrm{~ms}$ no caso com alertas, o que, em conjunto com o desvio padrão e com o número de eventos permite concluir com $99 \%$ de certeza que a inclusão dos alertas reduz os tempos de reação.

\subsubsection{Relação dos tempos de resposta de cada alerta}

No Gráfico 39, é possível observar que a média amostral para o tempo de reação com os alertas auditivo e háptico conjugados é menor que o tempo de reação com os alertas individuais auditivo ou háptico.

Assim como foi calculado o intervalo de confiança das médias na seção 7.3.4, é possível fazer o mesmo para comparar se realmente a diferença entre as médias do tempo de reação com os alertas individuais e conjugados é significativa.

Para

$$
1-\alpha=0,95
$$

temos que o intervalo de confiança da diferença entre as médias do tempo de reação dos alertas individuais para o alerta conjugado é conforme a Tabela 8.

\begin{tabular}{|l|c|c|}
\hline & Intervalo inferior $(\mathrm{ms})$ & Intervalo superior $(\mathrm{ms})$ \\
\hline TR Alerta Háptico & -95.0 & 173.2 \\
\hline TR Alerta Auditivo & -109.8 & 164.1 \\
\hline
\end{tabular}

Tabela 8 - Intervalo de confiança da diferença da média para o alerta conjugado (95\%). Fonte: autor

Os limites inferiores negativos indicam que não é possível afirmar com $95 \%$ de certeza que a presença do alerta conjugado contribui para a redução no tempo de reação. Ou seja, a diferença entre as médias amostrais para o tempo de reação com 
os alertas auditivo e háptico conjugados e com os alertas individuais auditivo ou háptico do Gráfico 39 não tem significância estatística.

Ainda podemos avaliar a diferença entre as médias do tempo de reação com o alerta háptico $(54,24 \mathrm{~ms})$ e com o alerta auditivo $(41,32 \mathrm{~ms})$.

Mais uma vez, para

$$
1-\alpha=0,95
$$

Temos que o intervalo de confiança para a diferença entre as médias do tempo de reação com o alerta háptico e com o alerta auditivo é

$$
(-139,8 ; 163,7)
$$

Ou seja, mais uma vez não há evidências estatísticas de que o alerta auditivo é mais eficiente do que o alerta háptico para reduzir o tempo de reação.

\subsubsection{Relação da reação preferencial}

Em todos os casos, a reação preferencial foi girar o volante, como pode ser visto nas seções 7.1.2.1 e 7.2.2.1. A diferença de $54,76 \%$ para $42,22 \%$ na preferência para a ação no volante do caso com algum alerta e no caso sem alertas, respectivamente é de $12,54 \%$.

Segundo Downing (2003), o intervalo de confiança para proporções pode ser dado por:

$$
I C(p, 1-\alpha)=\left(\hat{p}-Z_{\alpha / 2} \sqrt{\frac{\hat{p}(1-\hat{p})}{n}}, \hat{p}+Z_{\alpha / 2} \sqrt{\frac{\hat{p}(1-\hat{p})}{n}}\right) .
$$

onde

p é a proporção medida

n é o tamanho da amostra

$Z_{\alpha / 2}$ é o valor da tabela de distribuição t de Student com $\infty$ graus de liberdade (1- $\alpha)$ é o coeficiente de confiança

no caso unilateral à direita, quando pode afirmar com dado grau de certeza que a proporção é maior que determinado valor: 


$$
I C(p, 1-\alpha)=\left(\hat{p}-Z_{\alpha} \sqrt{\frac{\hat{p}(1-\hat{p}}{n}} ; 1\right)
$$

e no caso unilateral à esquerda, quando pode afirmar com dado grau de certeza que a proporção é menor que determinado valor:

$$
I C(p, 1-\alpha)=\left(0 ; \hat{p}+Z_{\alpha} \sqrt{\frac{\hat{p}(1-\hat{p})}{n}}\right) .
$$

No mesmo critério das avaliações anteriores

$$
1-\alpha=0,95
$$

temos que a porcentagem de reação preferencial no volante para o caso com alertas pode ser de

$$
(50,34 \% ; 59,18 \%)
$$

ou, para caso unilateral à direita, de

$$
(51,05 \% ; 100 \%)
$$

E para o caso sem alertas pode ser de

$$
(35,43 \% ; 49,02 \%)
$$

ou, para caso unilateral à esquerda, de

$$
(0 \% ; 47,92 \%)
$$

Há, portanto, diferença estatisticamente significativa entre a preferência pela ação no volante entre os casos com alertas e sem alertas.

\subsubsection{Reações exageradas}

Nas seções 7.1.2.3 e 7.2.2.3, é possível ver que a presença de alertas modifica a proporção de reações exageradas nos pedais de $22,07 \%(0,00 \% ; 27,73 \%)$ para $25,23 \%(21,25 \% ; 100,00 \%)$ e no volante de $23,98 \%(0,00 \% ; 29,35 \%)$ para $34,70 \%$ $(31,06 \% ; 100,00 \%)$. Os valores entre parêntesis são os intervalos de confiança unilaterais calculados para um coeficiente de confiança $1-\alpha=0,95$. Há, portanto, evidências estatísticas de que a presença dos alertas aumenta a proporção de reações exageradas no volante. Não se pode afirmar o mesmo para a reação nos pedais. 
Especialmente no caso em que somente o alerta auditivo é usado a proporção de reações exageradas no volante atinge $43,59 \%(36,05 \% ; 100,00 \%)$, acima dos $29,35 \%$, o limite superior para o caso sem alertas. Comparado com a proporção de reação exageradas no volante quando o alerta háptico é usado $26,12 \%$ (19,88\% ; $100,00 \%$ ) há uma indicação de que especialmente o alerta auditivo pode causar um aumento na proporção de reações exageradas no volante.

\subsubsection{Relação entre a ausência de reação com e sem alertas}

A seção 7.1.2.1 e 7.2.2.1, mostra que há uma queda na proporção de eventos sem reação do participante quando os alertas estão presentes, o que indicaria uma eficácia do sistema de alertas em evitar que a aproximação de um veículo passe despercebido pelo motorista. A avaliação sob o ponto de vista estatístico apresentado nas tabelas a seguir, corrobora a afirmação de que a presença dos alertas reduz a proporção de eventos sem reação do participante, considerando 0 coeficiente de confiança $1-\alpha=0,95$. Veja que o limite superior do intervalo de confiança unilateral à esquerda, como definido na seção 7.3.6, para a proporção de eventos sem reação com qualquer alerta presente (19,74\%) é ligeiramente menor que o limite inferior do caso sem alertas unilateral à direita (20,49\%).

\begin{tabular}{|l|r|c|c|}
\hline Ausência de reação & Proporção & \multicolumn{2}{|c|}{$\begin{array}{c}\text { Intervalo de confiança } \\
(95 \%)\end{array}$} \\
\hline Sem alertas & $24.81 \%$ & $19.66 \%$ & $29.97 \%$ \\
\hline Qualquer alerta & $17.18 \%$ & $14.13 \%$ & $20.23 \%$ \\
\hline Alerta Auditivo e Háptico & $16.54 \%$ & $12.13 \%$ & $20.96 \%$ \\
\hline Alerta Auditivo & $14.72 \%$ & $9.28 \%$ & $20.16 \%$ \\
\hline Alerta Háptico & $20.92 \%$ & $14.47 \%$ & $27.36 \%$ \\
\hline
\end{tabular}

Tabela 9 - Proporção de ausência de reação e intervalo de confiança (95\%). Fonte: autor 
Para intervalo de confiança unilateral à direita temos:

\begin{tabular}{|l|c|c|}
\hline Ausência de reação & \multicolumn{2}{|c|}{$\begin{array}{c}\text { Intervalo de confiança } \\
(95 \%)\end{array}$} \\
\hline Sem alertas & $20,49 \%$ & $100,00 \%$ \\
\hline qualquer alerta & $14,62 \%$ & $100,00 \%$ \\
\hline Alerta Auditivo e Háptico & $12,84 \%$ & $100,00 \%$ \\
\hline Alerta Auditivo & $10,16 \%$ & $100,00 \%$ \\
\hline Alerta Háptico & $15,51 \%$ & $100,00 \%$ \\
\hline
\end{tabular}

Tabela 10 - Intervalo de confiança (95\%) unilateral à direita. Fonte: autor

Para intervalo de confiança unilateral à esquerda temos:

\begin{tabular}{|l|c|c|}
\hline Ausência de reação & \multicolumn{2}{|c|}{$\begin{array}{c}\text { Intervalo de confiança } \\
(95 \%)\end{array}$} \\
\hline Sem alertas & $0,00 \%$ & $29,14 \%$ \\
\hline qualquer alerta & $0,00 \%$ & $19,74 \%$ \\
\hline Alerta Auditivo e Háptico & $0,00 \%$ & $20,25 \%$ \\
\hline Alerta Auditivo & $0,00 \%$ & $19,29 \%$ \\
\hline Alerta Háptico & $0,00 \%$ & $26,32 \%$ \\
\hline
\end{tabular}

Tabela 11 - Intervalo de confiança (95\%) unilateral à esquerda. Fonte: autor

É possível, entretanto, notar que com a presença do alerta auditivo, o limite superior do intervalo de confiança unilateral à esquerda para a proporção de eventos sem reação $(19,29 \%)$ é ligeiramente menor que o limite inferior do caso sem alertas unilateral à direita $(20,49 \%)$. Sendo assim, podemos afirmar com $95 \%$ de certeza que o alerta auditivo contribui para a redução dos eventos sem reação. Neste caso, ainda não podemos afirmar o mesmo para o alerta háptico isolado. 


\section{DISCUSSÃO}

\subsection{O cenário dos experimentos}

O ambiente de simulação, conforme descrito nas seções 6.4 .2 e 6.5, utilizou como interface visual uma tela de projeção e como entrada de controles pedais e volante de jogo. A pista a ser percorrida é um circuito fechado com curvas, mas sem obstáculos, no qual somente dos carros estão presentes. Esse ambiente não se propõe a representar fielmente a situação real do motorista nas ruas. A resolução da apresentação visual, equivalente a uma tela de computador, não possui nenhum aspecto de alta definição. A dinâmica do veículo, com relação aos controles utilizados, pedais e volante, também não se assemelha com fidelidade ao caso real. Foi percebido que a rápida frenagem do veículo ao soltar o pedal de aceleração induziu os participantes a utilizar menos o pedal de freio.

Houve, entretanto, a preocupação em se manter uma distribuição espacial de elementos como volante, pedais, espelhos retrovisores e ângulo de visão compatível com o caso real. Assim garante-se que a observação dos espelhos retrovisores se dá pela visão periférica.

Quanto à escolha dos alertas, procurou seguir o que a pesquisa teórica indicou como boas práticas. A escolha do alerta sonoro, por exemplo, se referenciou na pesquisa de Suied et al. (2005), apresentado na seção 2.3.2 sobre percepções de urgência nos estímulos sonoros e na norma Human Factor Design Standard (2003), seção 3.4. Com base nessa norma, projetou-se o alerta sonoro de forma que ele pudesse: a) alertar o usuário de que um problema existe; b) informar o usuário da prioridade e da natureza do problema e c) guiar a resposta inicial do usuário. A última recomendação dessa norma "d) confirmar prontamente se a resposta do usuário corrigiu o problema" não foi levada em consideração no ambiente de teste, o que pode ter influenciado alguns comportamentos, pois, mesmo que a ação tenha sido tomada adequada e prontamente, o alerta sonoro continuava sendo acionado por um tempo determinado. 
A escolha do posicionamento e da natureza dos estímulos vibratórios é condizente com pesquisas anteriores, como Riener e Ferscha (2008), na seção 4 e se demonstrou eficaz, pois foram percebidos pelos participantes. Outras formas de estímulo háptico, como a vibração no volante, apresentada na seção 4.2, no trabalho de Suzuki e Jannson (2003) não foram abordadas nos experimentos e podem ser material de estudos em trabalhos futuros.

Acredita-se que as limitações no ambiente de simulação sejam aceitáveis, uma vez que a metodologia consiste em se comparar o comportamento o caso com os alertas presentes e o caso sem os alertas, bem como a diferenciação entre os tipos de alertas, sempre utilizando o mesmo ambiente.

\subsection{Perfil dos participantes}

Com relação à idade dos participantes houve uma amostragem bem variada dentre da faixa de 20 a 51 anos. A ausência de participantes com idade superior a 51 anos impede a extensão dos resultados para esta faixa de idade.

Em termos de experiência de direção, também houve uma variedade considerável de casos, entre 2 e 30 anos, bem distribuídos nos casos de menos uso do carro ( $<10$ horas por semana) e mais uso do carro ( $>10$ horas por semana).

Houve um predomínio de voluntários do sexo masculino.

Com relação à experiência com jogos, houve uma proporção considerável de voluntários familiarizados com jogos eletrônicos, com uso semanal dessa opção de entretenimento com predomínio de jogos de corrida, esportes e estratégia. Pelos dados coletados, entretanto, não pareceu haver distinção significativa entre o desempenho daqueles participantes familiarizados com jogos e aqueles menos familiarizados. 


\subsection{Metodologia}

Sobre a metodologia utilizada para coleta e análise dos dados, há algumas questões a serem discutidas.

A seção 6.6.1 descreve com foi realizada a extração e tabulação de dados de volante, pedais, alertas e distâncias do arquivo gerado automaticamente pela ferramenta Raydium. Parte desse processo é automático, como a identificação dos pontos em que a distância entre os dois carros foi reduzida a um valor menor que 1000000, indicando a aproximação do carro azul. Parte da tabulação, entretanto, é baseada numa complexa análise das curvas geradas com dados de distância, volante e pedais, juntamente com a observação dos vídeos.

Uma primeira tentativa de tabulação desses dados procurou automatizar esse processo, definindo limites de movimentação dos pedais e do volante para determinar se houve ação em determinado controle e, a partir disso, calcular automaticamente os tempos de reação sem o uso dos vídeos. Foram obtidos resultados desfavoráveis e inconsistentes com as observações feitas pelo moderador no decorrer dos testes, indicando não haver melhora significativa nos tempos de reação com a presença dos alertas.

Após os resultados dessa primeira tentativa, a análise dos vídeos mostrou que a forma automática de tabulação proposta era por demais simplificada, de forma que vários movimentos do volante eram tidos como reação à aproximação do carro, mas a análise dos vídeos mostravam que, na verdade, eram movimentos para execução de curvas ou para centralização do carro na faixa.

Além disso, a análise dos vídeos apontou que a presença dos alertas, muitas vezes, implicava um movimento inicial do volante de amplitude menor que o limite determinado pelo método automático, portanto, aumentando os tempos de reação no caso em que os alertas estavam presentes. 
Os resultados apresentados nessa dissertação são aqueles obtidos pela metodologia que inclui a análise dos vídeos no momento de tabular os dados de tempos de reação.

\subsection{Resultados}

Nessa seção, são discutidos os resultados obtidos nos experimentos.

\subsubsection{Tipos de reação}

Nos dois experimentos, houve uma predominância de reações no volante, em detrimento da reação nos pedais. A presença dos alertas também parece aumentar a preferência pela reação no volante como comprovado na seção 7.3.6. Conforme citado acima, há que se levar em conta que o ambiente de simulação de certa forma pode induzir esse comportamento, uma vez que as respostas observadas pelos participantes são diferentes do caso real.

No veículo real, podemos, portanto, ter significativa diferença nas proporções de reação preferenciais observadas. Parece ser mais interessante, nesse caso observar a proporção de eventos não percebidos e sem reação aparentemente. Isso é discutido a seguir, na seção 8.4.2.

\subsubsection{Eventos despercebidos}

Uma das justificativas do sistema proposto é o auxílio ao motorista na condição de zona-cega, em que há um veículo na região lateral-traseira, não visível pelo espelho retrovisor. A seção 7.3.8 apresenta resultados que nos permitem afirmar que a presença de alertas reduz a proporção de eventos não percebidos.

Pode-se dizer que esse resultado é altamente satisfatório e contribui para justificar o uso do sistema proposto, pois há evidências significativas de que o sistema de alertas pode evitar colisões em casos de distração ao volante, que segundo a pesquisa de Driver (2005), apresentada na seção 1.1, é responsável por 25\% dos acidentes. 
Os resultados diferenciados para o alerta auditivo, com redução ainda maior na proporção de eventos despercebidos, quando comparado com o alerta háptico, são coerentes com as vantagens da interface sonora apresentadas na seção 2.3.3.

\subsubsection{Tempos de reação}

Conforme as seções 7.3.1 e 7.3.2, não foi observada tendência de variação dos tempos de reação com a idade ou com a experiência de direção. A menos de poucos pontos fora do intervalo $(-5 ; 5)$, o tempo de resposta típico parece se manter ao longo das faixas de idades e de experiência.

Com relação ao uso de jogos, seção 7.3.3, também não há diferença significativa dentre os níveis de familiaridade com jogos, mesmo no caso em que os participantes declaram "Nunca" utilizar jogos eletrônicos. Apenas em um caso, os tempos de resposta são maiores.

A seção 7.3.4 confirma que a presença de alertas reduz os tempos de reação. Esse resultado, juntamente com o discutido na seção 8.4.2, justifica a aplicação do sistema proposto, pois além de ajudar na identificação de eventos que passariam despercebidos sem os alertas, há evidências de que a reação do motorista seria mais rápida, mesmo nos casos em que os eventos não passariam despercebidos. Isso contribui ainda mais para se evitar colisões, pois o motorista pode ter, neste caso, uma reação antecepada, reduzindo, assim, a chance de acidente.

Apesar de o tempo de reação no caso do alerta auditivo ser ligeiramente menor que no caso do alerta háptico, não se pode afirmar que essa diferença é estatisticamente significante. Esse resultado não confirma os estudos apresentados na seção 4, que afirmam que com o estímulo háptico haveria um tempo de resposta menor, pois esse estímulo induziria a uma ação motora mais rápida em comparação com o estímulo auditivo, que somente chamaria à atenção para a percepção visual.

Esse resultado, entretanto, pode ser influenciado pela escolha de quando apresentar os alertas e, em especial, pelo fenômeno de o carro azul ser visível mesmo antes de os alertas serem apresentados. Nesse caso, o ambiente de simulação e a 
metodologia teriam de ser modificadas para permitir avaliar esse aspecto do estímulo háptico.

\subsubsection{Reações exageradas}

Na seção 7.3.7, afirmamos que há evidências de que os alertas, em especial o alerta auditivo, podem induzir o motorista a reagir de forma indesejada, girando o volante ao extremo. Esse fenômeno pode se dar pela natureza emergencial do som escolhido para o alerta auditivo. Para ser utilizado em um veículo real, há necessidade de serem feitos mais estudos sobre a escolha do som mais apropriado.

Outro fator que pode ter influenciado esse resultado é o fato de que o algoritmo de perseguição implementado no simulador para o carro azul seguir o vermelho impele a ação do participante, não havendo maneira de fugir da colisão. Alguns participantes relataram tentar descobrir alguma forma de evitar a colisão, e não tiveram sucesso. O esterçamento exagerado pode ter sido uma forma desesperada de evitar a colisão. Se o algoritmo de perseguição fosse outro, mais próximo do caso real, em que uma pequena ação evasiva pudesse de fato evitar a colisão, os resultados, sob esse aspecto, poderiam ter sido diferentes.

\subsubsection{Avaliação de utilidade}

A seção 7.2.3.1 mostra que os alertas auditivo e háptico foram bem avaliados pelos participantes com notas médias 3,57 e 3,65, respectivamente. A seção 7.2.3.3 apresenta também que um elevado percentual de participantes, 65\%, considera o sistema possível de ser utilizado em veículos. Esse resultados sugerem que, com alguns estudos e otimizações adicionais, o sistema é útil e confirmam a capacidade que esse sistema de alerta pode ter em evitar colisões.

\subsubsection{Avaliação de incômodo}

O incômodo relatado pelos participantes ainda torna preocupante a utilização do sistema de alertas em veículos. Nesse ponto há ainda algumas questões a se pesquisar. Os relatos de "sustos" e de "confusão" apresentados na seção 7.2.3.3 
trazem à tona a problemática de como esses alertas podem ser interpretados pelo motorista na situação crítica de quase colisão. Há que se avaliar se a ativação desses alertas não podem causar, na verdade, um desvio de atenção do motorista, justamente quando seu canal de percepção visual é mais demandado.

Os relatos de incômodo relativo ao alerta auditivo, descritos na seção 7.2.3.2 parecem ser mais simples de serem resolvidos, uma vez que o som escolhido para esse teste é propositalmente emergencial para chamar o participante à atenção, podendo ser facilmente modificado nos seus atributos de timbre, frequência, volume e cadência. Além disso, deve-se considerar que a quantidade de vezes que o alerta auditivo foi utilizado durante os dez minutos do experimento é muito maior do que o esperado na condição real. O que certamente contribui para a percepção de incômodo. Neste caso, estudos também têm de ser feitos no módulo de detecção, responsável por identificar a condição de perigo, para garantir um mínimo possível de falsos alarmes. 


\section{CONCLUSÕES}

O objetivo desse trabalho foi avaliar o uso de alertas auditivos e hápticos em um sistema de alerta intra-veicular de colisão lateral. O sistema de alertas foi montado em um ambiente de simulação e várias medidas foram realizadas. Com base nessas medidas, pode-se concluir que o uso de alertas auditivos e hápticos em um sistema anti-colisão tem o potencial de contribuir para a redução do número de colisões.

Especialmente em condições de baixa visibilidade e de desatenção, o sistema proposto pode auxiliar o motorista. Esse resultado é condizente com o apresentado nos trabalhos de Verbist (2009) e de Bellotti et al. (2002), nos quais se conclui que o alerta sonoro pode prover informações espaciais em situações sem clareza nas informações visuais.

Adicionalmente, esse trabalho provê uma metodologia para avaliação de IHC no ambiente automotivo, usando testes com usuários para avaliação do uso conjugado de alertas auditivos e háptico.

As avaliações qualitativas permitem inferir que alguns aspectos técnicos do sistema devem ser mais estudados, como o som utilizado para gerar o alerta auditivo, que apresenta características de timbre, freqüência, volume e cadência muito emergenciais, causando desconforto e susto nos usuários.

Por falta de medidas específicas, não se pôde concluir nada a respeito dos questionamentos feitos pelos trabalhos de Suzuki e Jansson (2003) e de Rossmeier, Grabsch e Döring (2005), nos quais se discute se os alertas sonoros somente chamam o motorista à atenção, delegando ao sentido visual o reconhecimento da ação mais apropriada a ser tomada ou se a percepção auditiva, por si só, conduz a uma ação.

Pode-se perceber também que a eficácia do sistema de alertas está diretamente relacionada ao correto funcionamento do sistema de identificação da situação de risco, não discutido profundamente neste trabalho. 
Alguns aspectos não puderam ser analisados com precisão devido a limitações no ambiente de teste, que não reproduz fielmente o ambiente real da direção. A forma como o ambiente foi montado desistimula o uso do pedal de freio e, portanto, as reações nesse controle foram raras.

O cenário montado no ambiente de teste considera um algoritmo de perseguição em que um carro sempre tenta colidir lateralmente com outro, aproximando-se rapidamente pela traseira. Por conta desse algoritmo, a coleta e a tabulação dos dados referentes a tempo de reação tiveram de ser realizadas manualmente e estão, portanto, sujeita à interpretação daquele que as realiza. A tabulação dos dados no caso sem alertas e no caso com alertas seguiu o mesmo método. Uma vez que a discussão dos resultados é primordialmente comparativa e que os resultados foram estatisticamente significantes, acredita-se que 0 viés decorrente do método escolhido possa ser relevado. Acredita-se também que a escolha dos parâmetros do ambiente de simulação insere menos viés do que os trabalhos semelhantes já realizados como Fitch et al. (2007), discutido na seção 5.1.

Essa pesquisa contribui para a área de fatores humanos com informações sobre como o usuário reage quando submetido a estímulos auditivos e hápticos como forma de alerta. As limitações dos resultados obtidos por conta do ambiente de teste e do método de tabulação dos dados também são contribuições relevantes, pois podem evitar que as mesmas falhas sejam cometidas em experimentos futuros.

\subsection{Artigos publicados}

No decorrer dessa dissertação foram publicados os seguintes artigos:

\section{Artigo completo}

BERTOLDI, E.; FILGUEIRAS, L.V.L. Multimodal advanced driver assistance systems: an overview. In: 2nd IUI workshop on multimodal interfaces for automotive applications, 2010, Hong Kong. Proceedings of MIAA 2010.

\section{Artigo resumido}

BERTOLDI, E.; FILGUEIRAS, L.V.L. Collision-avoidance system using auditory and haptic feedback. In: AutomotiveUI 2009 - First International Conference on 
Automotive User Interfaces and Interactive Vehicular Applications, 2009, Essen. Adjunct Proceedings of the First International Conference on Automotive User Interfaces and Interactive Vehicular Applications, 2009.

\subsection{Trabalhos futuros}

Algumas questões surgiram durante o desenvolvimento dessa dissertação e, por fugirem ao escopo desse trabalho não foram resolvidas nessa pesquisa. Essas questões podem ser tratadas em trabalhos futuros.

É necessário se estudar mais os parâmetros do som usado para o estímulo auditivo. Variações nesses parâmetros podem levar a níveis de aceitação melhores do que os obtidos com os experimentos realizados. $\mathrm{O}$ uso de som tridimensional também pode ser abordado em outro ambiente de teste, para se verificar se a indicação de aproximação leva a comportamentos diferenciados.

Quanto ao alerta háptico, podem ser exploradas outras formas de estímulos, variando-se seu posicionamento e suas características.

O ambiente de teste pode ser melhorado, a resolução da tela de projeção e o posionamento dos controles podem representar um ambiente mais imersivo. Testes em veículos também podem trazer mais informações sobre o desempenho do sistema de alertas e sobre as interferências causadas pelo sistema na direção do motorista.

O próprio cenário pode ser modificado para incluir situações mais realistas, em que 0 participante é ocupado com outras tarefas, além de manter o carro centralizado na faixa. Ele poderia desviar de obstáculos, receber instruções de navegação, enfrentar congestionamentos, dar passagem para motocicletas, dentre outras tarefas.

Esse trabalho não abordou como a situação de quase colisão pode ser identificada por um sistema de deteç̧ão, pois esta seria uma diferente linha de pesquisa, mais voltada para sensores do que para interface homem veículo. A pesquisa sobre esse sistema pode ser material de estudo para futuros trabalhos. 


\subsection{Considerações finais}

Nesta dissertação foi apresentado, avaliado e discutido o uso de alertas auditivos e hápticos em um sistema anti-colisão que intenciona auxiliar o motorista em uma das situações mais comumente enfrentadas no ato da direção, a zona-cega. Os resultados discutidos aqui permitem concluir que o uso de alertas auditivos e hápticos contribui para a redução no número de acidentes. São necessários, entretanto, refinamentos na forma como os alertas são utilizados.

Acredita-se que esse trabalho contribui para a comunidade científica com seus resultados, com sua metodologia, com as idéias aqui apresentadas e com o próprio ambiente de teste. Espera-se que essa pesquisa inspire novos trabalhos na área de fatores humanos voltada para o ambiente automotivo. Os números de acidentes e mortes certamente justificam investimentos e pesquisas maiores que as atuais. 


\section{REFERÊNCIAS}

ADELL E. et al. Developing human-machine interaction components for a driver assistance system for safe speed and safe distance. IEEE Intelligent Systems, v. 2, n. 1, p. 1-14, 2008.

BAINBRIDGE, L. Ironies of automation. Automatica, v. 19, n. 6, p. 775-779, 1983.

BALDWIN, C.L. Acoustic and semantic warning parameters impact vehicle crash rates. In: International Conference on Auditory Display, 13., 2007, Montreal, Canada. Proceedings... Schulich School of Music, McGill University, p. 143-145, 2007.

BEAR, M.F.; CONNORS, B.W.; PARADISO, M.A. Neuroscience: exploring the brain. Baltimore: Williaws \& Wilkins, 2001.

BEGAULT, D.R. et al. Blind flight: do auditory lane departure warnings attract attention or actually guide action? In: International Conference on Auditory Display, 13., 2007, Montreal, Canada. Proceedings... Schulich School of Music, McGill University, p. 131-138, 2007.

BELLOTTI, F. et al. Using 3D sound to improve the effectiveness of the advanced driver assistance systems. Personal and Ubiquitous Computing, v. 6, n. 3, p. 155-163, 2002.

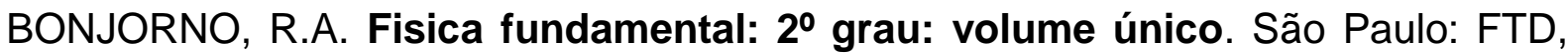
1993.

CHARISSIS, V.; NAEF, M. Evaluation of prototype automotive head-up display interface: testing driver's focusing ability through a VR simulation. In: Intelligent Vehicles Symposium, 2007, Istanbul. Proceedings... p. 560-565, 2007.

MINISTÉRIO DAS CIDADES. CONSELHO NACIONAL DE TRÂNSITO. Resolução no 225: requisitos de localização, identificação e iluminação dos controles, indicadores e lâmpadas piloto. 2007.

CUTNELL, J.D.; JOHNSON, K.W. Physics. New York: Wiley, 1998. 
DENATRAN/CGIE: COORDENAÇÃO GERAL DE INFORMAÇÃO E ESTATÍSTICA. Anuário Estatístico do Denatran. 2006. Disponível em: <http://www.denatran.gov.br>. Acesso em: 26 jun 2009.

DEPARTAMENTO NACIONAL DE TRÂNSITO. Código de Trânsito Brasileiro. Brasília, 1997.

DEPARTAMENTO NACIONAL DE INFRAESTRUTURA DE TRANSPORTES. Número de acidentes por tipo e gravidade. 2008. Disponível em: http://www.dnit.gov.br/menu/rodovias/estat_acid/. Acesso em: 25 ago 2009.

DOERR, K.U. et al. Evaluation of a low-cost 3D sound system for immersive virtual reality training systems. IEEE Transactions on Visualization and Computer Graphics, v. 13, n. 2, p. 204-212, 2007.

DOWNING, D.; CLARK, J. Estatística aplicada. São Paulo: Saraiva, 2003.

Driver distraction: trend and issues. Computing \& Control Engineering Journal, v. 8, n. 1, p. 28-30, 2005.

FEDERAL AVIATION ADMINISTRATION. Human factors design standard, Washington DC, 2003.

FITCH, G.M. et al. Toward developing an approach for alerting drivers to the direction of a crash threat. Human factors: the journal of the human factors and ergonomics society, v. 49, n. 4, p. 710-720, 2007.

FLETCHER, L. Vision in and out of vehicles. IEEE Intelligent Systems, v. 18, n. 3 , p. 12-17, 2003.

HAAS, E.C. Integrating auditory warnings with tactile cues in multimodal displays for challenging environments. In: International Conference on Auditory Display, 13., 2007, Montreal, Canada. Proceedings... Schulich School of Music, McGill University, p. 126-130, 2007.

JONES, C.M.; JONSSON I.M. Automatic recognition of affective cues in the speech of car drivers to allow appropriate responses. In: Australia conference on ComputerHuman Interaction, 17., 2005, Canberra, Australia. Proceedings... p. 1-10, 2005. 
JUNIOR, C.S.; SASSON, S. Biologia. São Paulo: Saraiva, 1998.

KEYROUZ, F.; DIEPOLD, K.; KEYROUZ, S. High performance 3D sound localization for surveillance applications. In: IEEE Conference on Advanced Video and Signal Based Surveillance, 2007. Proceedings... p. 563-566, 2007.

KOMATA, S. et al. Interactive interface of realtime 3D sound movement for embedded applications. In: International Symposium on Circuits and Systems, 2003. Proceedings... p. II-520-523, v. 2, 2003.

KRUM, D.M. et al. All roads lead to CHI: interaction in the automobile. In: Conference on Human Factors in Computing Systems, 2008, Florence, Italy. Proceedings... p. 2387-2390, 2008.

KUAJA, T. Efficiency of visual time-sharing behavior: the effects of menu structure on POI search tasks while driving. In: 1st International Conference on Automotive User Interfaces and Interactive Vehicular Applications, 2009, Essen, Germany. Proceedings... p. 63-70, 2009.

KUMAR, M.; KIM, T. Dynamic speedometer: dashboard redesign to discourage drivers from speeding. In: Conference on Human Factors in Computing Systems, 2005, Portland, USA. Proceedings... p. 1573-1576, 2005.

NAVARRO, J.; FRANCK, M.; HOC, J.M. Lateral control support for car drivers: a human-machine cooperation approach. In: European Conference on Cognitive Ergonomics, 14., 2007, London. Proceedings... p. 249-252, 2007.

NORMAN, D. There's an automobile in HCl's future: an update. Interactions, v. 4, n. 6 , p. 50-51, 2007.

NORMAN, D.A. The design of everyday things. New York: Basic Books, 1988.

PETTITT, M. Visual demand evalution methods for in-vehicle interfaces. 2008. Tese (Doutorado) - University of Nottingham, Nottingham, 2008.

REASON, J. Human error. Cambridge: Cambridge University Press, 1990.

RIENER, A. Sensor-actuator supported implicit interaction in driver assistance systems. Dissertação (Doutorado) - Johannes Kepler Universität, Linz, 2009. 
RIENER, A.; FERSCHA, A. Simulation driven experiment control in driver assistance assessment. In: IEEE/ACM International Symposium on Distributed Simulation and Real-Time Applications, 12., 2008. Proceedings... Washington, DC: IEEE Computer Society, 2008, p. 217-226.

ROSSMEIER, M.; GRABSCH, H.; RIMINI-DOERING, M. Blind flight: do auditory lane departure warnings attract attention or actually guide action? In: International Conference on Auditory Display, 11., 2005, Limerick, Ireland. Proceedings... p. 43-48, 2005.

SARTER, N.B.; AMALBERTI, R. Cognitive engineering in the aviation domain. Mahwah, New Jersey: Lawrence Erlbaum Associates, 2000.

SHERMAN, W.R.; CRAIG, A.B. Understanding virtual reality. San Francisco: Morgan Kaufmann Publishers, 2003.

SIMONDS, C. Software for the next-generation automobile. IT Professional. v. 5, n. 6, p. 7-11, 2003.

SODNIK, J. et al. A user study of auditory versus visual interfaces for use while driving. In: International Journal of Human-Computer Studies, 2008, Duluth, USA. Proceedings... v. 66, n. 5, p. 318-332, 2008.

SUIED, C. et al. Toward a sound design methodology: application to electronic automotive sound. In: International Conference on Auditory Display, 11., 2005, Limerick, Ireland. Proceedings... p. 146-153, 2005.

SUZUKI, K.; JANSSON, H. An analysis of driver's steering behaviour during auditory or haptic warnings for the designing of lane departure warning system. Jap. Soc. Automotive Eng, v. 24, p. 65-70, 2003.

TODORIKI, T. Application of head-up displays for in-vehicle navigation/routeguidance. In: Vehicle Navigation and Information Systems Conference, 1994, Yokohama, Japan. Proceedings... p. 479-484, 1994.

ULFVENGREN, P. Design of natural warning sounds. In: International Conference on Auditory Display, 13., 2007, Montreal, Canada. Proceedings... Schulich School of Music, McGill University, p. 146-153, 2007. 
U.S. DEPARTMENT OF TRANSPORTATION. Traffic safety facts. 2006. Disponível em: < http://www-nrd.nhtsa.dot.gov/Pubs/TSF2006FE.PDF>. Acesso em: 26 jun 2009.

U.S. DEPARTMENT OF TRANSPORTATION. Traffic safety facts. 2007. Disponível em: < http://www-nrd.nhtsa.dot.gov/Pubs/TSF2007FE.PDF>. Acesso em: 26 jun 2009.

VALIN, J.M; MICHAUD, F.; ROUAT, J. Robust 3D localization and tracking of sound sources using beamforming and particle filtering. In: IEEE International Conference on Acoustics, Speech and Signal Processing, 2006, Toulouse. Proceedings... v. 4, p. 841-844, 2006.

VERBIST, K. Car lane-keeping using auditory feedback. Dissertação (Mestrado) Delft University of Technology, Delft, 2009.

WAGNER, R.W.; HOWE, R.D.; STYLOPOULOS N. The role of force feedback in surgery: analysis of blunt dissection. In: $10^{\text {th }}$ Symposium on Haptic Interfaces for Virtual Environment and Teleoperator Systems, 2008. Proceedings... Washington, DC: IEEE Computer Society, 2008, p. 73.

WICKENS, C.D.; HOLLANDS, J.G. Engineering psychology and human performance. New Jersey: Prentice-Hall, 2000.

WIESE, E.E.; LEE, J.D. Auditory alerts for in-vehicle information systems: the effects of temporal conflict and sound parameters on driver attitudes and performance. Ergonomics, v. 47, p. 965-986, 2004.

WIKMAN, A.S.; NIEMINEN, T.; SUMMALA, H. Driving experience and time-sharing during in-car tasks on roads of different width. Ergonomics, v. 41, p. 358-372, 1998.

WILLIAMS, E. Airbone collision avoidance system. In: $9^{\text {th }}$ Australian Workshop on Safety Critical Systems and Software, 2004, Darlinghurst, Australia. Proceedings... v. 47, p. 97-110, 2004.

WU, W. Detection of text on road signs from video. IEEE Intelligent Systems, v. 6 , n. 5, p. 378-390, 2005. 
YOUNG, M.S.; STANON, N.A. Automotive automation: investigating the impact on drivers' mental workload. Int J. Cognitive Ergonomics, v. 1, n. 4, p. 325-336, 1997.

ZHENG, N.N. et al. Toward intelligent driver-assistance and safety warning systems. IEEE Intelligent Systems, v. 19, n. 2, p. 8-11, 2004. 